



\title{
Lysine requirement of growing-finishing pigs: a dose-response study
}

\author{
C.M.C. van der Peet-Schwering ${ }^{1}$, E. Bruininx ${ }^{2}$, R. Gerritsen ${ }^{3}$, G.P. Binnendijk ${ }^{1}$, P.Bikker ${ }^{1}$ \\ ${ }^{1}$ Wageningen Livestock Research; ${ }^{2}$ Agrifirm Innovation Center; ${ }^{3}$ ForFarmers
}

This research was conducted by Wageningen Livestock Research as part of the Public Private Partnership "Feed4Foodure" (TKI-AF-16123), and funded by Vereniging Diervoederonderzoek Nederland (VDN) and the Ministry of Agriculture, Nature and Food Quality (LNV) . 
C.M.C. van der Peet-Schwering, E. Bruininx, R. Gerritsen, G.P. Binnendijk, P. Bikker, 2020. Lysine requirement of growing-finishing pigs: a dose-response study. Wageningen Livestock Research, Report 1249.

This report can be downloaded for free at https://doi.org/10.18174/520737 or at www.wur.nl/livestock-research (under Wageningen Livestock Research publications).

(C) 2020 Wageningen Livestock Research

P.O. Box 338, 6700 AH Wageningen, The Netherlands, T +31 (0)317 483953 ,

E info.livestockresearch@wur.nl,www.wur.nl/livestock-research. Wageningen Livestock Research is part of Wageningen University \& Research.

All rights reserved. No part of this publication may be reproduced and/or made public, whether by print, photocopy, microfilm or any other means, without the prior permission of the publisher or author.

Wageningen Livestock Research is NEN-EN-ISO 9001:2015 certified.

All our research commissions are in line with the Terms and Conditions of the Animal Sciences Group. These are filed with the District Court of Zwolle.

Wageningen Livestock Research Report 1249. 


\section{Table of contents}

$\begin{array}{ll}\text { Foreword } & 5\end{array}$

$\begin{array}{ll}\text { Summary } & 7\end{array}$

1

$\begin{array}{ll}\text { Introduction } & 9\end{array}$

2

$\begin{array}{lr}\text { Material and methods } & 10\end{array}$

$\begin{array}{lll}2.1 & \text { Animals } & 10\end{array}$

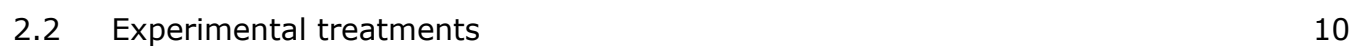

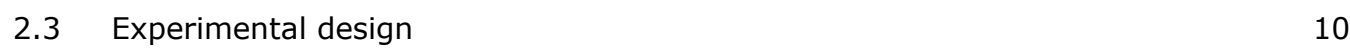

2.4 Housing and climate 11

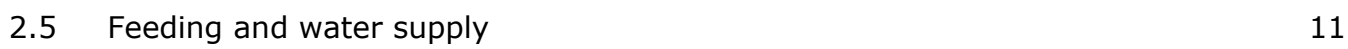

$\begin{array}{lll}2.6 & \text { Measurements } & 12\end{array}$

$\begin{array}{lll}2.7 & \text { Statistical analysis } & 13\end{array}$

2.7.1 Analysis of variance 13

$\begin{array}{ll}\text { 2.7.2 Estimate of lysine requirements } & 13\end{array}$

3

$\begin{array}{ll}\text { Results } & 15\end{array}$

3.1 Diets $\quad 15$

3.2 Performance $\quad 15$

$\begin{array}{lll}3.3 & \text { Slaughter results } & 27\end{array}$

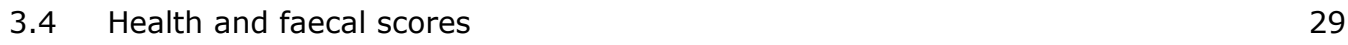

3.5 Estimate of lysine requirements $\quad 31$

$\begin{array}{llr}4 & \text { Discussion } & 37\end{array}$

$\begin{array}{llr}5 & \text { Conclusions } & 40\end{array}$

$\begin{array}{ll}\text { References } & 41\end{array}$

Appendix 1 Composition of the diets (\%) 42

Appendix 2 Analysed nutrients with NIR (g/ kg) 44

Appendix 3 Analysed nutrient composition ( $/ \mathrm{g} / \mathrm{kg}) \quad 45$

Appendix 4 SID lysine requirements on Farm A and B predicted with InraPorc 47 


\section{Foreword}

The research "Lysine requirement of growing-finishing pigs: a dose-response study" was conducted by Wageningen Livestock Research and private partners Agrifirm and ForFarmers as part of the Public Private Partnership "Feed4Foodure", and was funded by Vereniging Diervoederonderzoek Nederland (VDN) and the Ministry of Agriculture, Nature and Food Quality (LNV). The authors thank VDN and LNV for their support, and the members of the Cluster "Swine" of VDN for their valuable and inspiring contribution to the research. The skilful and devoted contribution of staff of the two facilities at which the research was conducted, and of colleagues involved at Agrifirm and ForFarmers is highly appreciated!

Carola van der Peet-Schwering and Paul Bikker 


\section{Summary}

Recently, Van der Peet-Schwering and Bikker (2018) updated the recommendations for standardized ileal digestible (SID) essential amino acids (AA) in starter, grower and finisher diets for current and future growing and finishing (GF) boars, gilts and barrows. The SID lysine requirement was determined using the pig model InraPorc (Van Milgen et al., 2008). The updated SID lysine requirements for current pigs were validated in a dose-response study described in the present report. The study was performed on two farms (Farm A and Farm B) both with GF gilts and boars. The pigs of each sex were assigned to one of four SID lysine levels: $80,95,110$ or $125 \%$ of the recommended level for current boars and gilts in the starter, grower and finisher phase (Van der Peet-Schwering and Bikker, 2018). These levels were fed during the whole GF period. The SID lysine (in $\mathrm{g} / \mathrm{EW}_{2015}$ ) at the $100 \%$ level was sex specific and hence differed between boars and gilts. Recommended SID levels $(100 \%)$ in starter, grower and finisher diets for current GF boars were 8.7, 7.6 and $6.8 \mathrm{~g} / \mathrm{EW}_{2015}$, respectively. Recommended SID levels (100\%) in starter, grower and finisher diets for current GF gilts were 8.3, 7.1 and $6.1 \mathrm{~g} / \mathrm{EW}_{2015}$, respectively. The GF boars and gilts pigs were fed a starter diet during the first five weeks, a grower diet for the subsequent four weeks and a finisher diet until delivery to the slaughterhouse. At Farm A, feed was supplied ad libitum in a dry feed hopper with one feeding place and one drinking nipple per pen. At Farm B, feed was supplied ad libitum in a dry feed hopper with two feeding places and two drinking nipples per pen. On both farms, the feed was provided as pellets via a computerized automatic system, which registered the amount of feed (in $\mathrm{kg}$ ) supplied per pen per day. In each of the three phases, regression analyses with a broken line model with average daily gain (ADG) and feed conversion ratio (FCR) as response variables and SID lysine (g//EW2015) as independent variable was used to determine the required dietary SID lysine content for maximum ADG and minimum FCR.

The study was conducted without major problems. The mean growth performance was at a high level. Mean results on high lysine diets on Farm A was for feed intake 2.2/2.3 kg/d, ADG 1080/990 g/d and FCR 2.1/2.3 for boars and gilts, respectively. For Farm B, mean results were for feed intake 2.1/2.2 $\mathrm{kg} / \mathrm{d}$, ADG 900/840 $\mathrm{g} / \mathrm{d}$ and FCR 2.3/2.6 for boars and gilts, respectively.

Based on the results of this study, the following conclusions were drawn:

- In general, the approach adopted by Van der Peet-Schwering and Bikker (2018) to define the growth performance based on ADG and FCR and derive the SID lysine requirements using InraPorc was confirmed by the present study. Adequate farm specific typing of growth performance of the pigs is crucial. The growth curve on a farm may deviate from that used for the current GF pigs in Van der Peet-Schwering and Bikker (2018).

- $\quad$ The recommended SID levels in starter diets of 8.7 and $8.3 \mathrm{~g} / \mathrm{EW}_{2015}$ for current boars and gilts, respectively, were too low for the farms in this study. For maximizing ADG and minimizing FCR, the recommended SID levels in starter diets for boars and gilts were 10.6 and $9.5 \mathrm{~g} / \mathrm{EW}_{2015}$, respectively, on Farm $A$ and 9.8 and 9.0 g/EW2015, respectively, on Farm B.

- $\quad$ The recommended SID levels in grower diets of 7.6 and $7.1 \mathrm{~g} / E W_{2015}$ for current boars and gilts, respectively, are in accordance with the SID lysine requirement of boars and gilts during the grower phase on Farm A and Farm B.

- $\quad$ The recommended SID level in finisher diets of $6.8 \mathrm{~g} / \mathrm{EW}_{2015}$ for current boars might be too low for boars on Farm A (for minimizing FCR, not for maximizing ADG) but too high for boars on Farm $B$. The recommended SID level in finisher diets of $6.1 \mathrm{~g} / \mathrm{EW}_{2015}$ for current gilts might be too low for gilts on Farm A (for minimizing FCR, not for maximizing ADG) but is in accordance with the SID lysine requirement of gilts during the finisher phase on Farm B. For maximizing ADG and minimizing FCR, the recommended SID levels in finisher diets for boars and gilts were 8.0 and 6.5 $\mathrm{g} / \mathrm{EW}_{2015}$, respectively, on Farm $\mathrm{A}$ and 6.0 and $6.0 \mathrm{~g} / \mathrm{EW}_{2015}$, respectively, on Farm $\mathrm{B}$.

- The difference in estimated requirements on Farm A and Farm B compared to recommendations for current pigs was largely explained by FCR realised in each phase on the two farms, relative to the FCR of current pigs. 


\section{Introduction}

Recently, Van der Peet-Schwering and Bikker (2018) updated the recommendations for standardized ileal digestible (SID) essential amino acids (AA) in starter, grower and finisher diets for current and future growing and finishing (GF) boars, gilts and barrows. The SID lysine requirement was predicted with help of the pig model InraPorc (Van Milgen et al., 2008). The SID requirements of the other essential $A A$, relative to lysine, were estimated based on literature data of the last 10 years. The performance of the current GF pigs was based on the performance of GF boars, gilts and barrows in the control group as published by Van der Peet-Schwering et al. (2012). These performance data were about $5 \%$ better than the mean performance of the GF pigs in the Netherlands as published in the Kengetallenspiegel 2016 (Agrovision, 2017). The daily gain of the future GF pigs was assumed to be $10 \%$ higher than the daily gain of the current GF pigs and was realized by a $10 \%$ higher feed intake or a $10 \%$ improved feed conversion ratio. In Table 1, the performance and the updated recommendations for SID lysine (in $\mathrm{g}$ per $\mathrm{EW}_{2015}$ ) in starter, grower and finisher pig diets for the average current and future GF boar, gilt and barrow (Van der Peet-Schwering and Bikker, 2018) as predicted with InraPorc (Van Milgen et al., 2008) are presented.

Table 1 Performance and updated recommendations for standardized ileal digestible (SID) lysine in starter, grower and finisher pig diets (in $g$ per EW 2015) for the average current and future ${ }^{1}$ growing and finishing pig (Van der Peet-Schwering and Bikker, 2018) as predicted with InraPorc (Van Milgen et al., 2008).

\begin{tabular}{|c|c|c|c|c|c|c|c|c|c|}
\hline & \multicolumn{3}{|c|}{$\begin{array}{l}\text { Current growing and } \\
\text { Finishing pigs }\end{array}$} & \multicolumn{3}{|c|}{$\begin{array}{l}\text { Future growing and } \\
\text { finishing pigs: } 10 \% \text { higher } \\
\text { feed intake }\end{array}$} & \multicolumn{3}{|c|}{$\begin{array}{l}\text { Future growing and finishing } \\
\text { pigs: } 10 \% \text { improved feed } \\
\text { conversion ratio }\end{array}$} \\
\hline & Boar & Gilt & Barrow & Boar & Gilt & Barrow & Boar & Gilt & Barrow \\
\hline \multicolumn{10}{|c|}{ Performance $(25-120 \mathrm{~kg})$ : } \\
\hline $\mathrm{ADG}^{2}(\mathrm{~g} / \mathrm{d})$ & 869 & 841 & 826 & 957 & 929 & 906 & 956 & 929 & 905 \\
\hline $\mathrm{ADFI}^{2}(\mathrm{~kg} / \mathrm{d})$ & 1.99 & 2.08 & 2.11 & 2.19 & 2.29 & 2.32 & 1.99 & 2.09 & 2.11 \\
\hline $\mathrm{FCR}^{2}$ & 2.29 & 2.47 & 2.56 & 2.29 & 2.46 & 2.57 & 2.09 & 2.25 & 2.33 \\
\hline Mean $\mathrm{PD}^{2}(\mathrm{~g} / \mathrm{d})$ & 145 & 136 & 132 & 157 & 148 & 142 & 163 & 156 & 149 \\
\hline
\end{tabular}

SID lysine $\left(\mathrm{g} / \mathrm{EW}_{2015}\right)$ :

\begin{tabular}{llllllllll}
\hline Starter diet $(25-50 \mathrm{~kg})$ & 8.7 & 8.3 & 8.3 & 9.1 & 8.7 & 8.7 & 9.6 & 8.7 & 8.9 \\
\hline Grower diet $(50-80 \mathrm{~kg})$ & 7.6 & 7.1 & 7.1 & 7.8 & 7.3 & 7.1 & 8.5 & 8.0 & 7.8 \\
\hline Finisher diet $(80-120 \mathrm{~kg})$ & 6.8 & 6.1 & 5.8 & 6.8 & 6.1 & 5.8 & 7.6 & 7.2 & 6.8
\end{tabular}

${ }^{1}$ The daily gain of the future growing and finishing pigs is $10 \%$ higher than the daily gain of the current growing and finishing pigs and is realized by a $10 \%$ higher feed intake or a $10 \%$ improved feed conversion ratio; ${ }^{2}$ ADG = average daily gain; $A D F I=$ average daily feed intake; $F C R=$ feed conversion ratio; PD = protein deposition.

The goal of this experiment was to validate the updated SID lysine recommendations for current growing and finishing pigs (Van der Peet-Schwering and Bikker, 2018) in a dose-response study. The study was performed on two farms both with GF gilts and boars. 


\section{$2 \quad$ Material and methods}

\section{$2.1 \quad$ Animals}

The trial was conducted at two farms:

- Farm A: pig research facility Laverdonk of Agrifirm;

- Farm B: pig farm of ForFarmers.

On Farm A, the trial was conducted with in total 520 GF pigs (Tempo boar x T20 sow and Tempo boar $x$ TN70 sow). At an age of nine weeks, 260 GF boars and 260 GF gilts were assigned to the experiment in four batches with each three weeks in between. On Farm B, the trial was conducted with in total 1408 GF pigs (Triton boar x TN70 sow). At an age of nine weeks, 704 GF boars and 704 GF gilts were assigned to the experiment in four batches with each one week in between. On both farms, pigs were followed till delivery to the slaughterhouse. Pigs in all pens were delivered to the slaughterhouse in two or three deliveries with about two weeks in between. The heaviest pigs in a pen were first delivered to the slaughterhouse and then the remainder of the pigs. The trial was conducted from January till July 2019.

\section{$2.2 \quad$ Experimental treatments}

The GF boars and gilts were assigned to one of four SID lysine levels: $80,95,110$ or $125 \%$ of the recommended level for current boars and gilts (Van der Peet-Schwering and Bikker, 2018). These levels were fed during the whole GF period. The content of SID lysine (in $\mathrm{g} / \mathrm{kg}$ ) at the $100 \%$ level differed between boars and gilts. The content of SID lysine (in $\mathrm{g} / \mathrm{kg}$ ) in the starter, grower and finisher diet at the four SID lysine levels is presented in Table 2 (see chapter 2.5) for both the GF boars and gilts. Boars and gilts were housed separately.

\subsection{Experimental design}

\section{Farm A}

On Farm A, pigs were blocked for BW. Each block contained four pens (the four dietary treatments) with boars or four pens with gilts. Two blocks (one block with boars and one block with gilts) with a similar BW were assigned to rooms with eight pens each. The four pens in each block were randomly allotted to the four dietary treatments. In total 64 pens (4 dietary treatments $\times 2$ sexes $\times 8$ replicates) were assigned to the experiment.

\section{Farm B}

On Farm B, pigs were not blocked for BW. In every batch, three rooms (one room with only boars, one room with only gilts and one room with boars and gilts (separately housed)) with each 12 pens were assigned to the experiment. Two pens of each 11 pigs were fed by one feed valve. Therefore, the feed intake was not available per pen but per two pens. Six feeding valves (12 pens) per room were randomly assigned to the dietary treatments. In the room with only boars, four feeding valves ( 8 pens) were assigned to the four dietary treatments. In total 128 pens ( 64 feeding valves) (4 dietary treatments $\times 2$ sexes $\times 8$ replicates) were assigned to the experiment. 


\section{$2.4 \quad$ Housing and climate}

\section{Farm A}

The GF pigs were housed in eight rooms (three rooms in batch 1 , two rooms in batch 2 , two rooms in batch 3 and one room in batch 4) with eight pens each. The number of pigs per pen was 7 in three rooms, 8 in two rooms, 9 in two rooms and 10 in one room. The pens with 7 pigs per pen were $1.75 \times$ $3.30 \mathrm{~m}$ and had $40 \%$ concrete solid floor and $60 \%$ slats. The pens with 8,9 or 10 pigs were $2.65 \times$ $3.20 \mathrm{~m}$ and had $40 \%$ concrete solid floor and $60 \%$ slats. In all rooms, the climate was controlled by computer and an automatic curve (room temperature: $25^{\circ} \mathrm{C}$ at day 1 and gradually decreasing to $21^{\circ} \mathrm{C}$ at day 100). From 7.30 till $16.30 \mathrm{~h}$ artificial light was on in the rooms (automatically by a timer). A control lamp was on from 7.00 till $20.00 \mathrm{~h}$ (automatically by a timer). A chain with a toy was supplied in every pen as pen enrichment. Boars and gilts were housed separately.

\section{Farm B}

The GF pigs were housed in 12 rooms (three rooms per batch) with 12 pens each. In every pen, 11 pigs were housed. All pens were $2.20 \times 4.00 \mathrm{~m}$ and had $40 \%$ concrete solid floor and $60 \%$ slats. Two pens of 11 pigs were fed by one feed valve. In all rooms, the climate was controlled by computer and an automatic curve (room temperature: $25^{\circ} \mathrm{C}$ at day 1 and gradually decreasing to $21^{\circ} \mathrm{C}$ at day 100 ). From 7.30 till $16.30 \mathrm{~h}$ artificial light was on in the rooms (manually operated). A control lamp was on from 7.00 till $20.00 \mathrm{~h}$ (automatically by a timer). A chain with a toy was supplied in every pen as pen enrichment. Boars and gilts were housed separately.

\subsection{Feeding and water supply}

The GF boars and gilts pigs were fed a starter diet during the first five weeks, then a grower diet for four weeks and then a finisher diet till delivery to the slaughterhouse. At Farm A, feed was supplied ad libitum in a dry feed hopper with one feeding place and one drinking nipple per pen. At Farm $B$, feed was supplied ad libitum in a dry feed hopper with two feeding places and two drinking nipples per pen. At Farm B, two pens of each 11 pigs were fed by one feed valve. On both farms, the feed was provided as pellets via a computerized automatic system, which registered the amount of feed (in $\mathrm{kg}$ ) supplied per pen per day. Water was supplied ad libitum.

From the starter, grower and finisher diet only the diets with the highest SID lysine level ( $125 \%$ for the GF boars) and the lowest SID lysine level ( $80 \%$ for the GF gilts) were produced. The other diets were obtained by mixing the diets with the highest and lowest SID level on pen level with the computerized feeding system on the farms. The SID lysine content (in $\mathrm{g} / \mathrm{kg}$ and in $\mathrm{g} / \mathrm{EW}_{2015}$ ) in the starter, grower and finisher diet supplied to the GF boars and gilts at the four SID lysine levels and the ratio between the diets with the highest and the lowest SID lysine level is presented in Table 2 . The SID lysine levels in the starter diet $125 \%$ for boars and $80 \%$ for gilts were 12.00 and $7.28 \mathrm{~g} / \mathrm{kg}$, respectively. The SID lysine levels in the grower diet $125 \%$ for boars and $80 \%$ for gilts were 10.50 and $6.24 \mathrm{~g} / \mathrm{kg}$, respectively. The SID lysine levels in the finisher diet $125 \%$ for boars and $80 \%$ for gilts were 9.38 and $5.36 \mathrm{~g} / \mathrm{kg}$, respectively. All diets had an $\mathrm{EW}=1.10$ (=9.68 MJ NE). The levels of SID methionine + cysteine, threonine, tryptophan, isoleucine and valine were at least $5 \%$ higher than the updated recommendations in Van der Peet-Schwering and Bikker (2018) to be sure that there was no shortage of these amino acids. The ingredient and nutrient composition of the diets is shown in Appendix 1. 
Table 2 Standardized ileal digestible (SID) lysine content (in $\mathrm{g} / \mathrm{kg}$ and $\mathrm{g} / E W_{2015}$ ) in the starter, grower and finisher diet supplied to the growing and finishing (GF) boars and gilts at the four SID lysine levels (80, 95, 110 and 125\%) and the ratio between the diets with the highest (125\% for boars) and the lowest ( $80 \%$ for gilts) SID lysine level

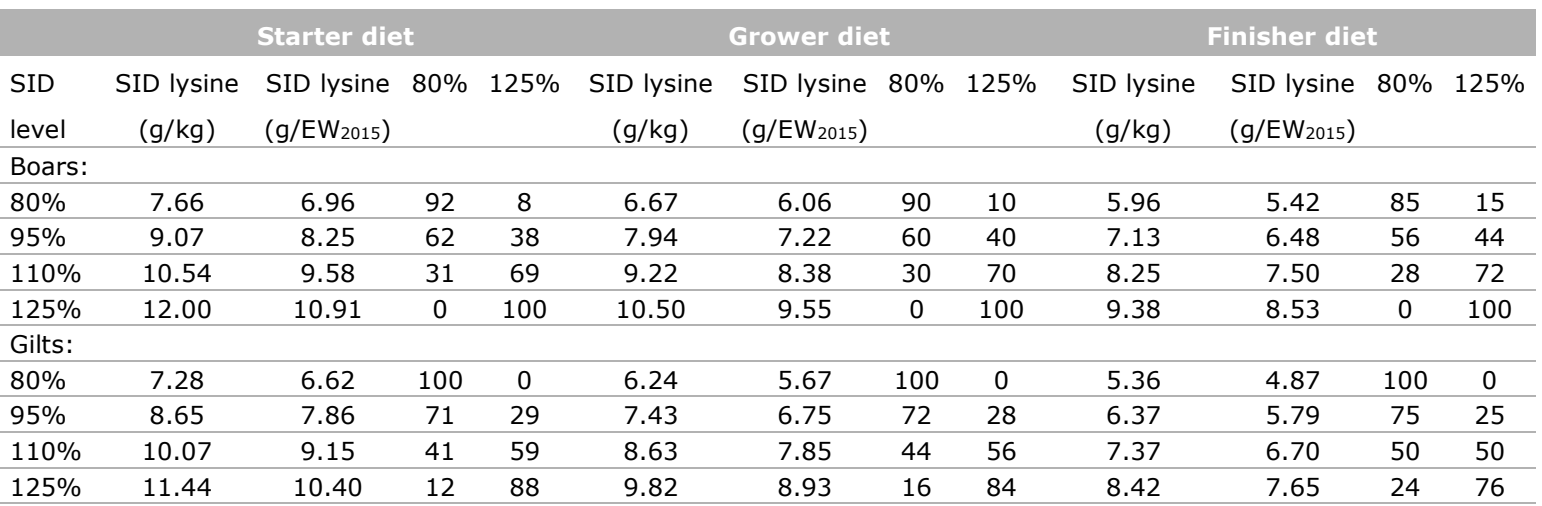

\subsection{Measurements}

Body weight, feed intake and slaughter data

The pigs were weighed individually on Farm A and at pen level on Farm B at the start of the trial, at day 35 (day of transition from starter diet to grower diet), at day 63 (day of transition from grower to finisher diet), one day prior to first delivery to the slaughterhouse, remaining pigs at second or third delivery (only Farm A) and in case of culling. On Farm B, the remaining pigs after first delivery were not weighed when they were delivered to the slaughterhouse. Therefore, the BW at slaughter of all delivered pigs was calculated from the slaughter weight with the following equation

(Uniformeringsafspraken Varkenshouderij, 2012):

- Boars: calculated BW at slaughter $=5+$ (slaughter weight $\times 1.22$ )

- $\quad$ Gilts: calculated BW at slaughter $=5+$ (slaughter weight $\times 1.20)$

Total feed intake per pen (feed supply - remainder of feed) was measured at every weighing of pigs and in case of culling of a pig. At every weighing of pigs, the remainders of the diet per pen were collected and weighed to determine the feed intake per pen. Feed intake included intake of starter diet, grower diet and finisher diet. At slaughter the following data were collected of each individual pig: slaughter weight, lean meat percentage, backfat thickness and muscle thickness.

\section{Culling, veterinary treatments and faecal scores}

The number of culled pigs and the number of pigs treated with antibiotics were recorded including date and reason of culling and veterinary treatment. Feed intake was registered on the day of culling to correct for the feed intake of the lost animal. Faecal scores were performed once a week during the starter phase (week 1-5). On Farm A, in each pen the number of GF pigs with normal faeces (score = 0 ), soft faeces (score $=1$ ) and watery faeces (score $=2$ ) was scored visually by the same person across the treatment groups. On Farm B, the faeces of the pigs was scored on pen level with normal faeces (score $=0$ ), little bit soft faeces (score $=0.5$ ), soft faeces (score $=1$ ) and watery faeces (score $=2$ ) by the same person.

\section{Diets}

For Farm A, the starter, grower and finisher diets were produced in six, six and four (finisher diet $125 \%$ ) or five (finisher diet $80 \%$ ) batches, respectively. For Farm B, the starter, grower and finisher diets were produced in four, five and eleven batches, respectively. Before the diets were delivered to the farms, they were analysed on the contents of crude protein, moisture, ash, crude fibre, crude fat, starch and sugar with Near-Infrared Spectroscopy (NIR). When the difference between calculated and analysed crude protein content was greater than $6 \mathrm{~g} / \mathrm{kg}$, the diet was produced again. The mean results of the NIR analyses per diet per farm are presented in Appendix 2. In all diets, the calculated and analysed nutrients were very similar.

Subsamples from every batch per diet per farm were pooled and analysed for dry matter, ash, nitrogen (N), crude fat, starch, sugar and AA composition. Dry matter was analysed by drying at 103 
${ }^{\circ} \mathrm{C}$ (ISO 6496), ash by combustion to a constant weight at $550{ }^{\circ} \mathrm{C}$ (ISO, 5984), $\mathrm{N}$ by using the Dumas method (ISO 16634-1) and crude fat after hydrolysis (ISO, 6492). Starch was enzymatically determined (ISO 15914). Determination of sugars was based on the method described by Van Vuuren et al. (1993). Amino acid composition was analysed by acid hydrolysis at $110^{\circ} \mathrm{C}$ for $23 \mathrm{~h}$ and ionexchange chromatography with postcolumn derivatisation with ninhydrin (ISO13903; ISO, 2005a) and tryptophan by alkaline hydrolysis at $110^{\circ} \mathrm{C}$ for $20 \mathrm{~h}$ ion-exchange chromatography with fluorescence detection (MOD.0094 version G; ISO 13904; ISO, 2005c). The analysed nutrient composition is presented in Appendix 3.

\subsection{Statistical analysis}

\subsubsection{Analysis of variance}

The data were statistically analysed by means of F-tests using ANOVA (GenStat, 2018) using pen as the experimental unit on Farm $A$ and using feed valve (two pens were fed by one feed valve) as experimental unit on Farm $B$. Results were considered significant at a $\mathrm{P} \leq 0.05$ and considered a trend at $\mathrm{P} \leq 0.10$.

The performance data (daily gain, daily feed intake, daily SID lysine intake and feed conversion ratio) and slaughter data (slaughter weight, lean meat percentage, backfat thickness, muscle thickness and dressing percentage) were analysed with a split-plot model. Sex was tested on block level and SID lysine on pen level. The level of SID lysine was included as a second degree polynomial in the analysis so that linear and quadratic effects of the SID lysine level and the influence of sex on this could be determined.

$Y=\mu+$ Batch + Block(Batch $)+$ Sex + SID lysine linear + SID lysine quadratic + Sex x SID lysine linear + Sex $x$ SID lysine quadratic + residual error

in which:

$\mathrm{Y}=$ dependent variable

Batch $=$ batch effect $(1-4)$

Block $=$ block effect within batch (1-16)

Sex $=$ boar vs gilt

SID lysine $=4$ levels: $80,95,110$ and $125 \%$

This model allows the determination of linear and quadratic effects of SID lysine and determination of sex effects on the overall level of the response parameter, the linear component and the quadratic component of the SID lysine effect. In the analysis of lean meat percentage, backfat thickness, muscle thickness and dressing percentage, slaughter weight was added to the model as a covariate.

The number of culled and veterinary treated piglets were analysed using the Chi-square test.

The percentage of GF pigs within a pen with soft or watery faeces (score 1 and 2) (Farm A) and the mean faecal score on pig level (Farm A) or pen level (Farm B) were analysed with the same model as used for the performance data.

\subsubsection{Estimate of lysine requirements}

In each of the three phases, regression analyses with a broken line model with ADG and FCR as response $(y)$ variables and SID lysine $\left(g / / E W_{2015}\right)$ as independent $(x)$ variables was used to determine the required dietary SID lysine content for maximum ADG and minimum FCR. These analyses were conducted using a broken stick procedure in GenStat (2018) based on the RCYCLE and FIT directive. The model was described by three parameters:

- a plateau, representing the maximum AGD or the minimum FCR at adequate dietary SID lysine;

- a breakpoint, representing the SID lysine level $\left(g / E W_{2015}\right)$ to reach the maximum ADG or the minimum FCR; 
- $\quad$ a slope, representing the increase in ADG or decrease in FCR per $g$ increase of SID lysine/EW 2015 from the lowest inclusion level until the breakpoint was reached.

The minimum model $(0)$ included three common parameters for boars and gilts, indicating that none of these parameters differed between the sexes. The maximum model (7) included six parameters, with each of the three parameters separately estimated for the two sexes. The other models included one or two parameters combined for the two sexes and the other separate for boars and gilts: model (1) separate plateau, model (2) separate breakpoint, model (3) separate slope, model (4) separate plateau and breakpoint, model (5) separate plateau and slope, model (6) separate breakpoint and slope. Starting with the minimum model, stepwise forward and backward selection procedures were used to determine the contribution of the inclusion of a sex effect on the three different parameters, based on the additional sums of squares and to determine the optimal model with the highest explained variance (highest adjusted $\mathrm{R}^{2}$, lowest Root Mean Square Error, RMSE) containing only significant parameters. This implies that separate parameters for boars and gilts for one of the three parameters would only be included in the final model if this significantly improve the model. Secondly, the stepwise approach implied that first sex specific estimates were included for one of the three parameters, based on the highest addition in model sums of squares. Subsequently, it was determined whether an additional sex effect on one of the remaining two parameters gave a significant contribution. In the results, only the final model with significantly different parameters was included. Inclusion of one parameter estimate for boars and gilts combined implies absence of statistical proof of a sex effect on this parameter.

For Farm A, we conducted an additional analyses using the relative ADG and FCR within a room as response parameters. These relative values were calculated by dividing the ADG and FCR of each pen by the mean of all eight pens for boars and gilts within a room. This approach allows accounting for the room effect, largely caused by the body weight block allocated to the rooms. As a result, the residual variation (error) is reduced, allowing for a sharper test of treatment effects. The results of this additional analyses was included in the response table of Farm A (see Table 13). Farm B did not use this blocking on the basis of body weight within rooms. 


\section{Results}

\subsection{Diets}

The analysed nutrient composition (dry matter, ash, crude protein, crude fat, crude fibre, starch and sugar) of the diets and the analysed content of AA and of free AA in the diets are presented in Appendix 3. In all diets, the analysed contents of ash, crude protein, crude fat, crude fibre, sugar, $A A$ and free AA were as expected. The analysed contents of starch were 20 to $30 \mathrm{~g} / \mathrm{kg}$ lower than the calculated contents.

\subsection{Performance}

The performance of the GF pigs from the start till the day of first delivery to the slaughter house and from the start till slaughter is presented in Table 3 (Farm A) and Table 4 (Farm B).

Table 3 Performance ${ }^{1}$ from the start till the day of first delivery to the slaughterhouse and from the start till slaughter of growing-finishing pigs (boars and gilts) (Farm A) that were fed diets differing in standardized ileal digestible (SID) lysine content (80, 95, 110 or $125 \%$ of the recommended level for current boars ${ }^{2}$ and gilts ${ }^{3}$ (Van der Peet-Schwering and Bikker, 2018)).

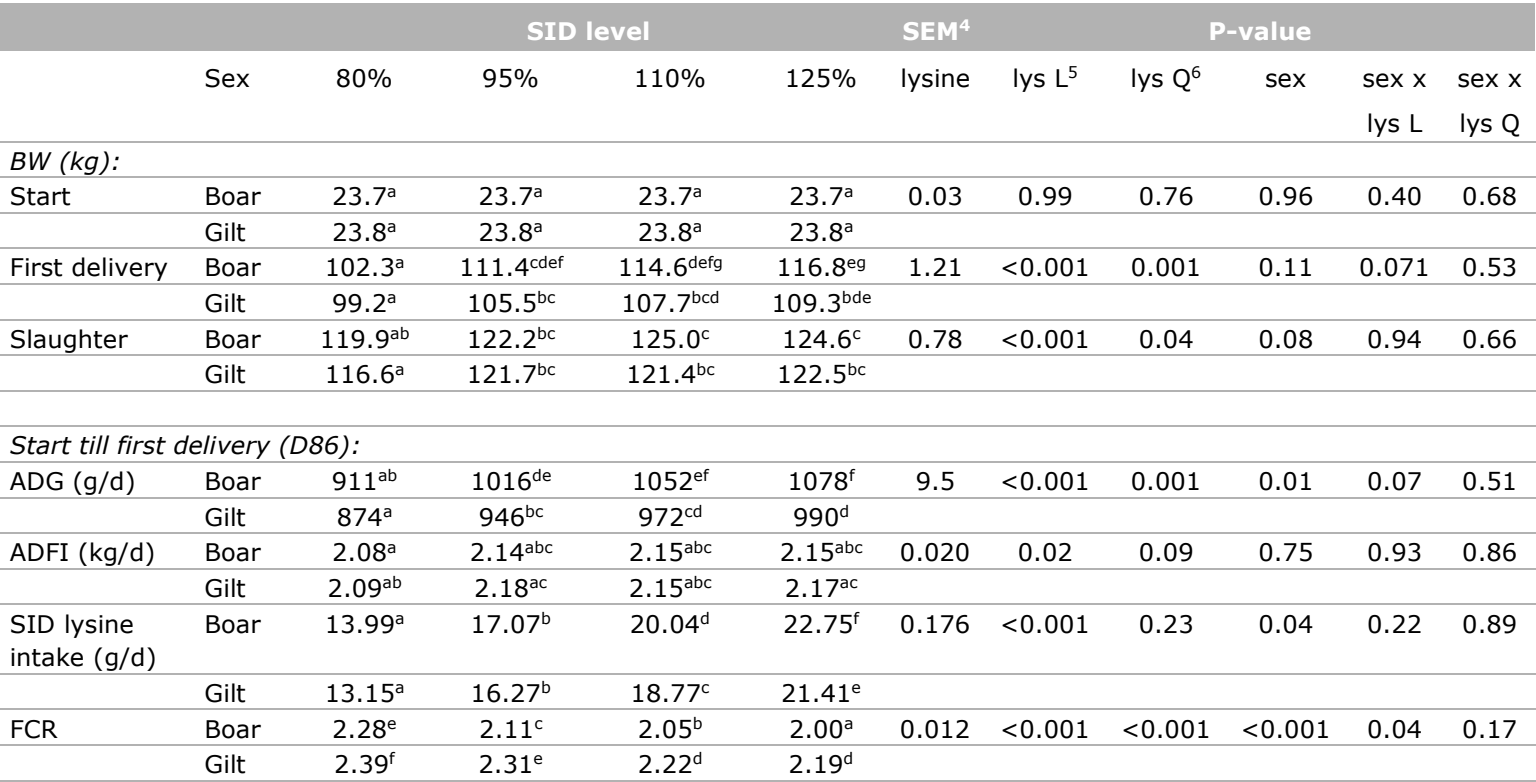

\begin{tabular}{|c|c|c|c|c|c|c|c|c|c|c|c|}
\hline \multicolumn{12}{|c|}{ Start till slaughter: } \\
\hline \multirow[t]{2}{*}{ No of days } & Boar & 103.4 & 96.1 & 96.1 & 93.8 & & & & & & \\
\hline & Gilt & 105.3 & 103.0 & 100.5 & 100.5 & & & & & & \\
\hline ADG $(g / d)$ & Boar & $932^{\mathrm{ab}}$ & $1026^{\mathrm{cd}}$ & $1054^{\text {de }}$ & $1077^{e}$ & 8.5 & $<0.001$ & $<0.001$ & 0.006 & 0.08 & 0.73 \\
\hline \multirow[t]{2}{*}{ ADFI $(\mathrm{kg} / \mathrm{d})$} & Boar & $2.21^{\mathrm{a}}$ & $2.24^{\mathrm{abc}}$ & $2.23^{\mathrm{abc}}$ & $2.22^{a}$ & 0.020 & 0.54 & 0.17 & 0.26 & 0.74 & 0.60 \\
\hline & Gilt & $2.23^{\mathrm{ab}}$ & $2.32^{\mathrm{ac}}$ & $2.27^{\mathrm{abc}}$ & $2.28^{\mathrm{abc}}$ & & & & & & \\
\hline & Gilt & $13.59^{a}$ & $16.80^{\mathrm{b}}$ & $19.23^{c}$ & $21.92^{\mathrm{e}}$ & & & & & & \\
\hline \multirow[t]{2}{*}{ FCR } & Boar & $2.38^{\text {de }}$ & $2.18^{c}$ & $2.12^{b}$ & $2.07^{a}$ & 0.013 & $<0.001$ & $<0.001$ & $<0.001$ & 0.04 & 0.25 \\
\hline & Gilt & $2.53^{f}$ & $2.44^{e}$ & $2.33^{d}$ & $2.32^{d}$ & & & & & & \\
\hline
\end{tabular}

${ }^{1}$ Data are based on 8 pens (65 pigs) per treatment per sex; ${ }^{2}$ Recommended SID levels (100\%) in starter, grower and finisher diets for current growing-finishing boars are $8.7,7.6$ and $6.8 \mathrm{~g} / \mathrm{EW}_{2015}$, respectively; ${ }^{3}$ Recommended SID levels $(100 \%)$ in starter, grower and finisher diets for current growing-finishing gilts are $8.3,7.1$ and $6.1 \mathrm{~g} / \mathrm{EW}_{2015}$, respectively; ${ }^{4}$ $\mathrm{SEM}=$ pooled SEM. Means are presented as least squares means; ${ }^{5}$ Iys $\mathrm{L}=$ linear effect of SID lysine level; ${ }^{6}$ lys $\mathrm{Q}=$ quadratic effect of SID lysine level. 
Table 3 shows that from start till first delivery and from start till slaughter, boars grew faster and had a higher SID lysine intake and a lower FCR than gilts. ADFI was similar in boars and gilts. In both boars and gilts, ADG was highest at the 125\% SID lysine level and lowest at the $80 \%$ SID lysine level. ADG at the $125 \%$ SID lysine level did not differ significantly from ADG at the $110 \%$ SID lysine level. FCR was lowest at the $125 \%$ SID lysine level and highest at the $80 \%$ SID lysine level in both boars and gilts. In gilts, FCR was similar at the 110 and 125\% SID lysine level. SID lysine intake (g/d) increased with increasing SID lysine level in the diet.

Table 4 Performance ${ }^{1}$ from the start till the day of first delivery to the slaughterhouse and from the start till slaughter of growing-finishing pigs (boars and gilts) (Farm B) that were fed diets differing in standardized ileal digestible (SID) lysine content (80, 95, 110 or $125 \%$ of the recommended level for current boars ${ }^{2}$ and gilts ${ }^{3}$ (Van der Peet-Schwering and Bikker, 2018)).

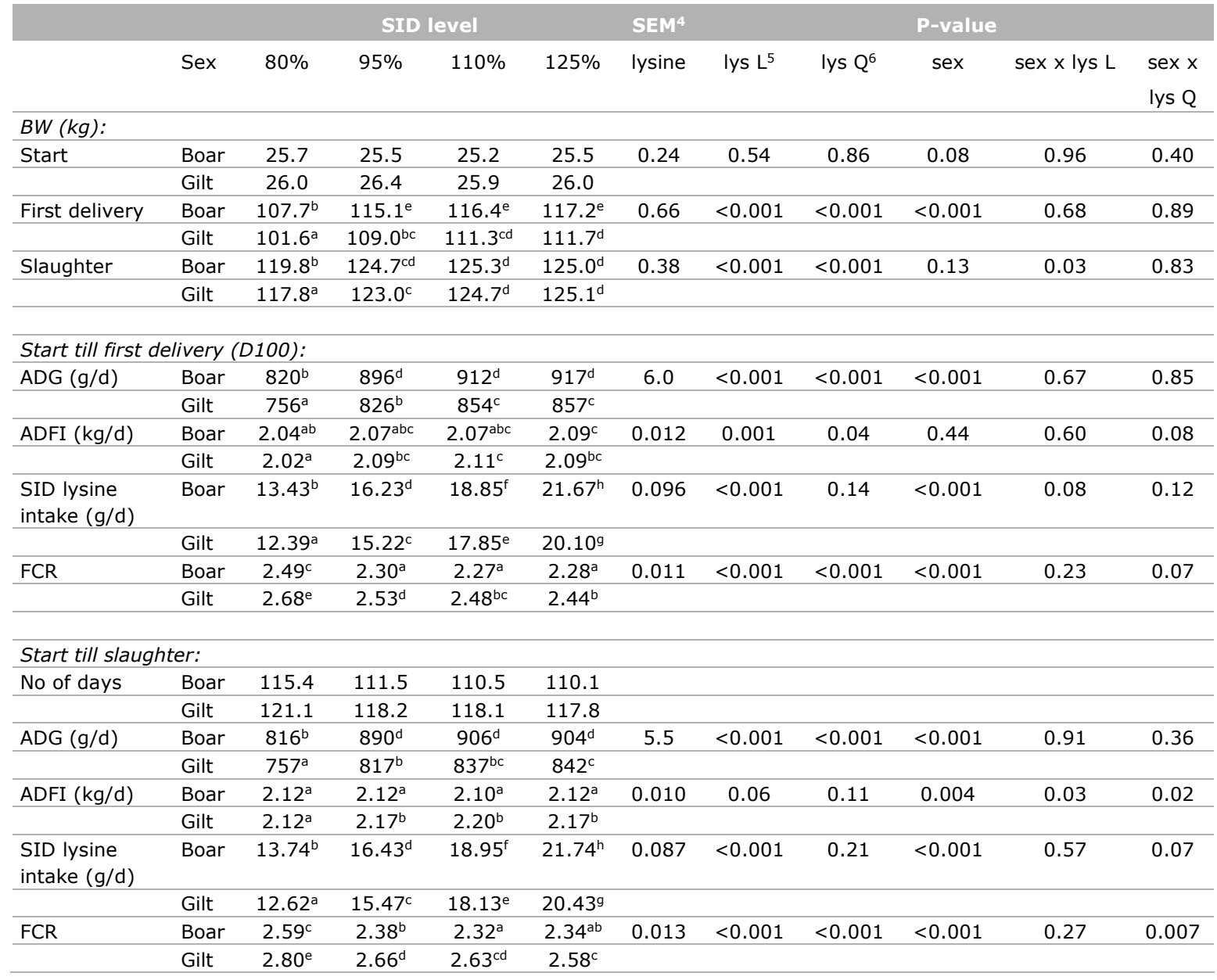

${ }^{1}$ Data are based on 8 pens (176 pigs) per treatment per sex; ${ }^{2}$ Recommended SID levels (100\%) in starter, grower and finisher diets for current growing-finishing boars are $8.7,7.6$ and $6.8 \mathrm{~g} / \mathrm{EW}_{2015}$, respectively; ${ }^{3}$ Recommended SID levels $(100 \%)$ in starter, grower and finisher diets for current growing-finishing gilts are $8.3,7.1$ and $6.1 \mathrm{~g} / \mathrm{EW}_{2015}$, respectively; ${ }^{4}$ $\mathrm{SEM}=$ pooled SEM. Means are presented as least squares means; ${ }^{5}$ lys $\mathrm{L}=$ linear effect of SID lysine level; ${ }^{6}$ lys $\mathrm{Q}=$ quadratic effect of SID lysine level.

Table 4 shows that from start till first delivery and from start till slaughter, boars grew faster and had a higher SID lysine intake and a lower FCR than gilts. From start till first delivery, ADFI was similar in boars and gilts whereas from start till slaughter, ADFI was higher in gilts than in boars. In both boars and gilts, ADG was highest at the 125\% SID lysine level and lowest at the $80 \%$ SID lysine level. ADG was similar at the 110 and $125 \%$ SID lysine level. FCR was lowest at the $125 \%$ SID lysine level in gilts and at the $110 \%$ SID lysine level in boars and highest at the $80 \%$ SID lysine level. FCR was similar at the 110 and $125 \%$ SID lysine level in both boars and gilts. SID lysine intake $(\mathrm{g} / \mathrm{d})$ increased with increasing SID lysine level in the diet. 
The performance of the GF pigs from the start till day 35, day 35-63, day 63 till first delivery to the slaughterhouse and day 63 till slaughter is presented in Table 5 (Farm A) and Table 6 (Farm B). The average daily gain and feed conversion ratio from the start till day 35, day 35-63, day 63 till first delivery to the slaughterhouse and day 63 till slaughter are also presented in Figures 1-8 (Farm A) and Figures 9-16 (Farm B).

Table 5 and Figures 1 and 2 show that from start till day 35 (the starter phase), ADG, ADFI and SID lysine intake were similar in boars and gilts. FCR was lower in boars. In boars, ADG was highest and FCR was lowest at the $125 \%$ SID lysine level. In gilts, ADG was highest at the $110 \%$ SID lysine level and FCR was lowest at the $125 \%$ SID lysine level. FCR, however, was similar at the 110 and $125 \%$ SID lysine level. SID lysine intake $(\mathrm{g} / \mathrm{d})$ increased with increasing SID lysine level in the diet.

Table 5 and Figures 3 and 4 show that from day 35-63 (the grower phase), boars grew faster and had a higher SID lysine intake and a lower FCR than gilts. ADFI was similar in boars and gilts. In boars, ADG was highest and FCR was lowest at the $110 \%$ SID lysine level. ADG and FCR, however, were similar in boars at the 95, 110 and $125 \%$ SID lysine level. In gilts, ADG was highest and FCR was lowest at the $125 \%$ SID lysine level. ADG and FCR, however, were similar in gilts at the 95,110 and $125 \%$ SID lysine level. SID lysine intake $(\mathrm{g} / \mathrm{d})$ increased with increasing SID lysine level in the diet.

Table 5 and Figures 5 and 6 show that from day 63 till first delivery at day 86, boars grew faster and had a higher ADFI, a higher SID lysine intake and a lower FCR than gilts. In boars, ADG was highest and FCR was lowest at the 125\% SID lysine level. ADG and FCR, however, were similar at the 110 and $125 \%$ SID lysine level. In gilts, ADG was highest and FCR was lowest at the $125 \%$ SID lysine level. ADG and FCR, however, were similar at the 95, 110 and 125\% SID lysine level. SID lysine intake $(\mathrm{g} / \mathrm{d})$ increased with increasing SID lysine level in the diet.

Table 5 and Figures 7 and 8 show that from day 63 till slaughter, boars grew faster and had a higher SID lysine intake and a lower FCR than gilts. ADFI was similar in boars and gilts. In boars, ADG was highest and FCR was lowest at the 125\% SID lysine level. ADG, however, was similar at the 95, 110 and $125 \%$ whereas FCR was similar at the 110 and $125 \%$ SID lysine level. In gilts, ADG was highest at the $125 \%$ SID lysine level and FCR was lowest at the $110 \%$ SID lysine level. ADG and FCR, however, were similar at the 95, 110 and 125\% SID lysine level. SID lysine intake ( $\mathrm{g} / \mathrm{d})$ increased with increasing SID lysine level in the diet.

Table 6 and Figures 9 and 10 show that from start till day 35 (the starter phase), ADG and SID lysine intake were similar in boars and gilts. ADFI and FCR were lower in boars. In both boars and gilts, ADG was highest and FCR was lowest at the 125\% SID lysine level. ADG and FCR, however, were similar at the 110 and $125 \%$ SID lysine level. SID lysine intake $(\mathrm{g} / \mathrm{d})$ increased with increasing SID lysine level in the diet.

Table 6 and Figures 11 and 12 show that from day 35-63 (the grower phase), boars grew faster and had a higher SID lysine intake and a lower FCR than gilts. ADFI was similar in boars and gilts. In boars, ADG was highest at the $125 \%$ SID lysine level and FCR was lowest at the $110 \%$ SID lysine level. ADG and FCR, however, were similar in boars at the 95, 110 and 125\% SID lysine level. In gilts, ADG was highest at the $110 \%$ SID lysine level and FCR was lowest at the $125 \%$ SID lysine level. ADG, however, was similar at the 110 and $125 \%$ SID lysine level. FCR was similar at the 95,110 and $125 \%$ SID lysine level. SID lysine intake $(\mathrm{g} / \mathrm{d})$ increased with increasing SID lysine level in the diet.

Table 6 and Figures 13-16 show that from day 63 till first delivery at day 100 and from day 63 till slaughter, boars grew faster and had a higher SID lysine intake and a lower FCR than gilts. ADFI was similar in boars and gilts. In boars, ADG was highest and FCR was lowest at the 95\% SID lysine level. ADG and FCR at the 80 and $125 \%$ SID lysine level were worse than ADG and FCR at the $95 \%$ SID lysine level. In gilts, ADG was highest at the $125 \%$ SID lysine level. ADG, however, was similar at the 95, 110 and $125 \%$ SID lysine level. FCR was not affected by SID lysine level in the diet and was similar at the $80,95,110$ and $125 \%$ SID lysine level. SID lysine intake $(\mathrm{g} / \mathrm{d})$ increased with increasing SID lysine level in the diet. 
Table 5 Performance ${ }^{1}$ from the start till day 35, day 35-63, day 63 till first delivery to the slaughterhouse and day 63 till slaughter of growing-finishing pigs (boars and gilts) (Farm A) that were fed diets differing in standardized ileal digestible (SID) lysine content (80, 95, 110 or $125 \%$ of the recommended level for current boars ${ }^{2}$ and gilts ${ }^{3}$ (Van der PeetSchwering and Bikker, 2018)).

\begin{tabular}{|c|c|c|c|c|c|c|c|c|c|c|c|}
\hline & & \multicolumn{4}{|c|}{ SID level } & \multicolumn{2}{|l|}{ SEM ${ }^{4}$} & \multicolumn{3}{|c|}{ P-value } & \multirow{2}{*}{$\begin{array}{l}\operatorname{sex} x \\
\text { lys } Q\end{array}$} \\
\hline & & & & & & & & & & lys L & \\
\hline \multirow[t]{2}{*}{ Start } & Boar & $23.7^{a}$ & $23.7^{a}$ & $23.7^{a}$ & $23.7^{a}$ & 0.03 & 0.99 & 0.76 & 0.96 & 0.40 & 0.68 \\
\hline & Gilt & $23.8^{a}$ & $23.8^{a}$ & $23.8^{a}$ & $23.8^{a}$ & & & & & & \\
\hline \multirow[t]{2}{*}{ Day 63} & Boar & $78.9^{\mathrm{ab}}$ & $85.1^{\text {acd }}$ & $87.6^{\text {cde }}$ & $89.2^{\mathrm{ce}}$ & 0.73 & 0.005 & 0.77 & 0.52 & 0.19 & 0.85 \\
\hline & Gilt & $78.3^{a}$ & $82.6^{\mathrm{bc}}$ & $85.3^{\text {bcde }}$ & $85.6^{\text {bde }}$ & & & & & & \\
\hline \multirow[t]{2}{*}{ First delivery } & Boar & $102.3^{a}$ & $111.4^{\text {cdef }}$ & $114.6^{\text {defg }}$ & $116.8^{\mathrm{eg}}$ & 1.21 & $<0.001$ & 0.001 & 0.11 & 0.071 & 0.53 \\
\hline & Gilt & $99.2^{\mathrm{a}}$ & $105.5^{b c}$ & $107.7^{\mathrm{bcd}}$ & $109.3^{\text {bde }}$ & & & & & & \\
\hline Slaughter & Boar & $119.9^{\mathrm{ab}}$ & $122.2^{\mathrm{bc}}$ & $125.0^{c}$ & $124.6^{c}$ & 0.78 & $<0.001$ & 0.04 & 0.08 & 0.94 & 0.66 \\
\hline ADG $(g / d)$ & Gilt & $808^{\mathrm{ab}}$ & $853^{\mathrm{bc}}$ & $926^{\text {de }}$ & $919^{\text {de }}$ & & & & & & \\
\hline \multirow[t]{2}{*}{ ADFI $(\mathrm{kg} / \mathrm{d})$} & Boar & $1.55^{\mathrm{a}}$ & $1.58^{\mathrm{a}}$ & $1.61^{a}$ & $1.61^{a}$ & 0.019 & 0.15 & 0.18 & 0.22 & 0.43 & 0.56 \\
\hline & Gilt & $1.66^{a}$ & $1.68^{\mathrm{a}}$ & $1.71^{a}$ & $1.66^{\mathrm{a}}$ & & & & & & \\
\hline \multirow{2}{*}{$\begin{array}{l}\text { SID lysine } \\
\text { intake }(g / d)\end{array}$} & Boar & $11.92^{a}$ & $14.32^{\mathrm{b}}$ & $17.01^{\mathrm{c}}$ & $19.30^{d}$ & 0.205 & $<0.001$ & 0.33 & 0.89 & 0.50 & 0.48 \\
\hline & Gilt & $12.08^{a}$ & $14.54^{b}$ & $17.27^{c}$ & $19.03^{d}$ & & & & & & \\
\hline \multirow[t]{2}{*}{ FCR } & Boar & $2.01^{\text {de }}$ & $1.85^{c}$ & $1.76^{\mathrm{b}}$ & $1.67^{a}$ & 0.012 & $<0.001$ & 0.04 & $<0.001$ & 0.01 & 0.46 \\
\hline & Gilt & $2.05^{e}$ & $1.97^{d}$ & $1.85^{c}$ & $1.81^{b c}$ & & & & & & \\
\hline \multicolumn{12}{|l|}{ Day 35-63: } \\
\hline \multirow[t]{2}{*}{$\operatorname{ADG}(\mathrm{g} / \mathrm{d})$} & Boar & $1007^{a b}$ & $1127^{\mathrm{cd}}$ & $1136^{d}$ & $1136^{d}$ & 16.8 & $<0.001$ & 0.005 & 0.02 & 0.90 & 0.53 \\
\hline & Gilt & $936^{a}$ & $1033^{b}$ & $1041^{b c}$ & $1060^{\mathrm{bcd}}$ & & & & & & \\
\hline Day 63 till firs & ery $(D$ & 6): & & & & & & & & & \\
\hline ADG $(g / d)$ & Boar & $1002^{\mathrm{bc}}$ & $1127^{d}$ & $1155^{d}$ & $1183^{d}$ & 14.6 & $<0.001$ & 0.04 & $<0.001$ & 0.09 & 0.23 \\
\hline & Gilt & $895^{a}$ & $982^{\mathrm{bc}}$ & $959^{b}$ & $1018^{c}$ & & & & & & \\
\hline ADFI $(\mathrm{kg} / \mathrm{d})$ & Boar & $2.60^{\mathrm{abc}}$ & $2.69^{c}$ & $2.71^{c}$ & $2.68^{c}$ & 0.028 & 0.03 & 0.24 & 0.072 & 0.85 & 0.28 \\
\hline & Gilt & $2.50^{\mathrm{a}}$ & $2.62^{b c}$ & $2.52^{\mathrm{ab}}$ & $2.64^{c}$ & & & & & & \\
\hline SID lysine & Boar & $15.47^{b}$ & $19.16^{d}$ & $22.38^{\mathrm{e}}$ & $25.13^{f}$ & 0.215 & $<0.001$ & 0.47 & $<0.001$ & 0.05 & 0.15 \\
\hline & Gilt & $13.42^{a}$ & $16.68^{c}$ & $18.64^{d}$ & $22.22^{\mathrm{e}}$ & & & & & & \\
\hline FCR & Boar & $2.60^{c}$ & $2.41^{b}$ & $2.35^{\mathrm{ab}}$ & $2.27^{a}$ & 0.029 & $<0.001$ & 0.10 & $<0.001$ & 0.11 & 0.81 \\
\hline & Gilt & $2.80^{d}$ & $2.68^{c}$ & $2.64^{c}$ & $2.60^{c}$ & & & & & & \\
\hline Day 63 till sla & & & & & & & & & & & \\
\hline No of days & Boar & 40.4 & 33.1 & 33.1 & 30.8 & & & & & & \\
\hline & Gilt & 42.3 & 40.0 & 37.5 & 37.5 & & & & & & \\
\hline ADG (g/d) & Boar & $1013^{b}$ & $1117^{c}$ & $1125^{c}$ & $1154^{c}$ & 12.0 & $<0.001$ & 0.01 & $<0.001$ & 0.07 & 0.58 \\
\hline & Gilt & $904^{a}$ & $979^{b}$ & $959^{b}$ & $986^{b}$ & & & & & & \\
\hline ADFI $(\mathrm{kg} / \mathrm{d})$ & Boar & $2.72^{\mathrm{ab}}$ & $2.81^{\mathrm{ab}}$ & $2.77^{\mathrm{ab}}$ & $2.77^{a b}$ & 0.029 & 0.38 & 0.19 & 0.39 & 0.99 & 0.79 \\
\hline & Gilt & $2.66^{a}$ & $2.80^{\mathrm{b}}$ & $2.67^{a}$ & $2.74^{\mathrm{ab}}$ & & & & & & \\
\hline SID lysine & Boar & $16.19^{b}$ & $19.97^{d}$ & $22.88^{e}$ & $25.97^{f}$ & 0.211 & $<0.001$ & 0.33 & $<0.001$ & 0.05 & 0.52 \\
\hline & Gilt & $14.28^{a}$ & $17.77^{c}$ & $19.73^{d}$ & $23.09^{e}$ & & & & & & \\
\hline
\end{tabular}

${ }^{1}$ Data are based on 8 pens (65 pigs) per treatment per sex; ${ }^{2}$ Recommended SID levels (100\%) in starter, grower and finisher diets for current growing-finishing boars are 8.7, 7.6 and $6.8 \mathrm{~g} / \mathrm{EW}_{2015}$, respectively; ${ }^{3}$ Recommended SID levels $(100 \%)$ in starter, grower and finisher diets for current growing-finishing gilts are $8.3,7.1$ and $6.1 \mathrm{~g} / \mathrm{EW} 2015$, respectively; ${ }^{4}$ $\mathrm{SEM}=$ pooled SEM. Means are presented as least squares means; ${ }^{5}$ lys $\mathrm{L}=$ linear effect of SID lysine level; ${ }^{6}$ lys $\mathrm{Q}=$ quadratic effect of SID lysine level. 


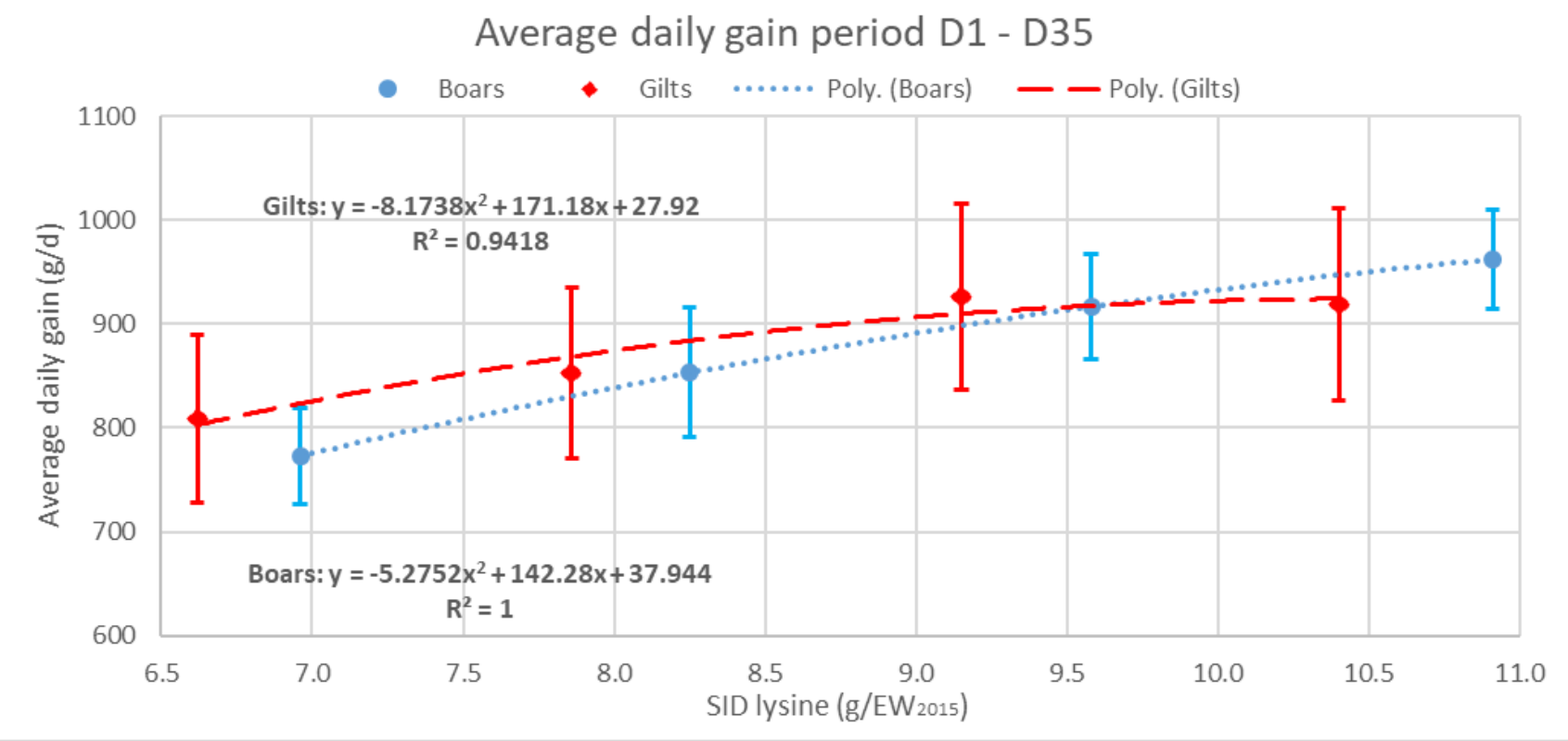

Figure 1 Average daily gain from the start till day 35 of growing-finishing pigs (boars and gilts) (Farm A) that were fed diets differing in standardized ileal digestible (SID) lysine content $(80,95,110$ or $125 \%$ of the recommended level for current boars and gilts (Van der Peet-Schwering and Bikker, 2018)). Recommended SID levels (100\%) in starter diets for current growing-finishing boars and gilts are 8.7 and $8.3 \mathrm{~g} / \mathrm{EW}_{2015}$, respectively.

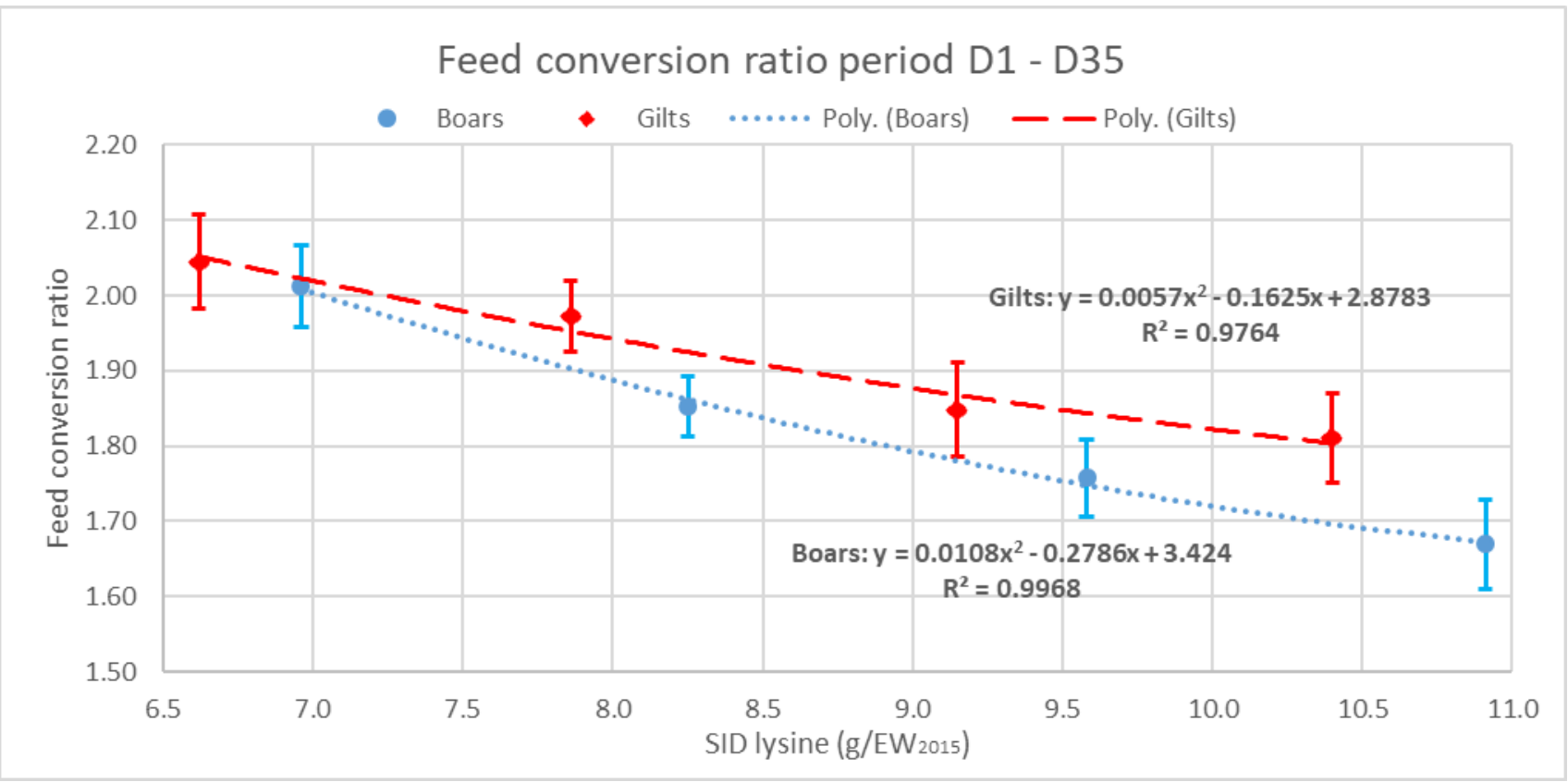

Figure 2 Feed conversion ratio from the start till day 35 of growing-finishing pigs (boars and gilts) (Farm A) that were fed diets differing in standardized ileal digestible (SID) lysine content $(80,95,110$ or $125 \%$ of the recommended level for current boars and gilts (Van der Peet-Schwering and Bikker, 2018)). Recommended SID levels (100\%) in starter diets for current growing-finishing boars and gilts are 8.7 and $8.3 \mathrm{~g} / \mathrm{EW}_{2015}$, respectively. 


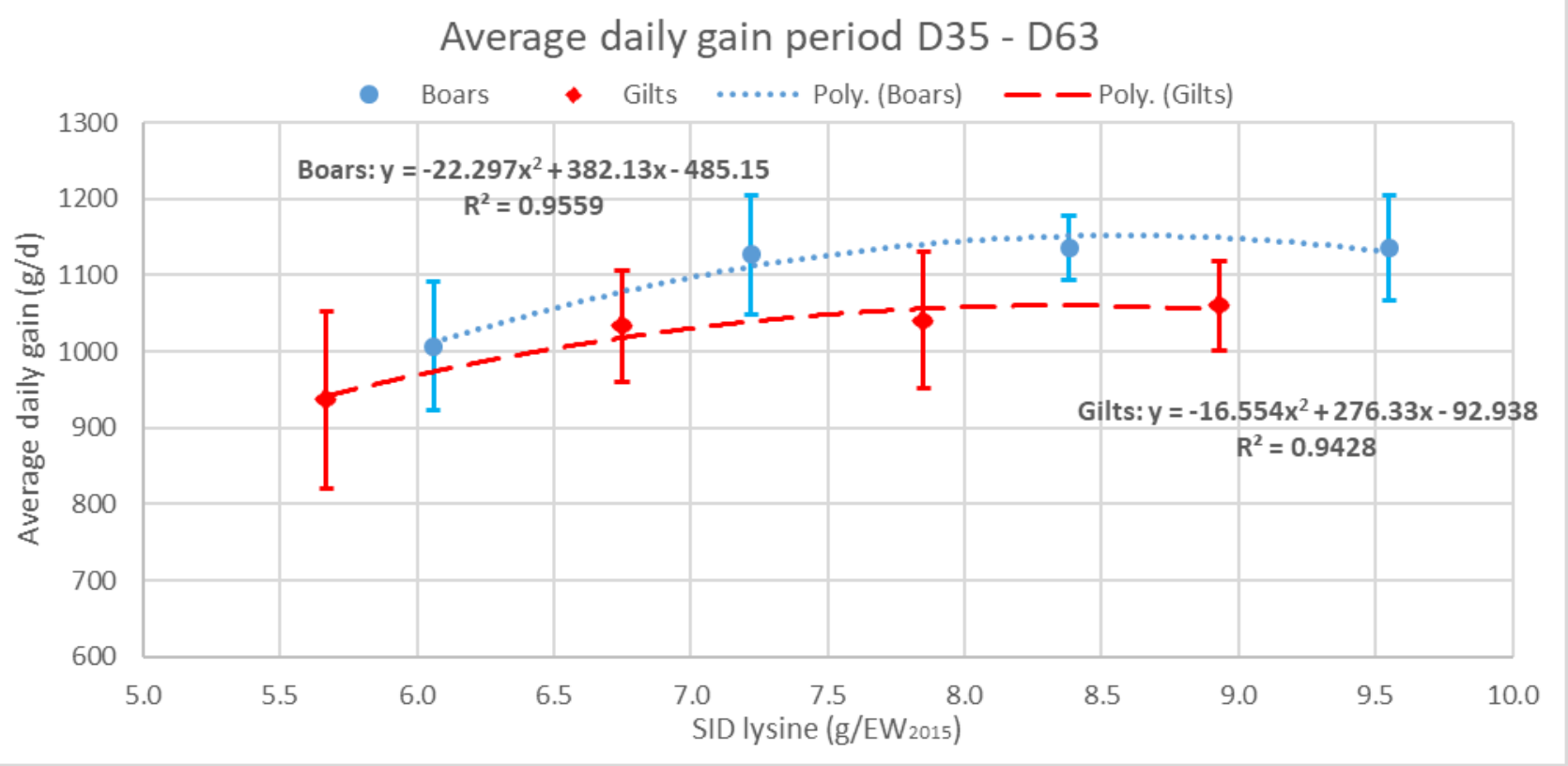

Figure 3 Average daily gain from day 35 till day 63 of growing-finishing pigs (boars and gilts) (Farm A) that were fed diets differing in standardized ileal digestible (SID) lysine content $(80,95,110$ or $125 \%$ of the recommended level for current boars and gilts (Van der Peet-Schwering and Bikker, 2018)). Recommended SID levels (100\%) in grower diets for current growing-finishing boars and gilts are 7.6 and $7.1 \mathrm{~g} / \mathrm{EW}_{2015}$, respectively.

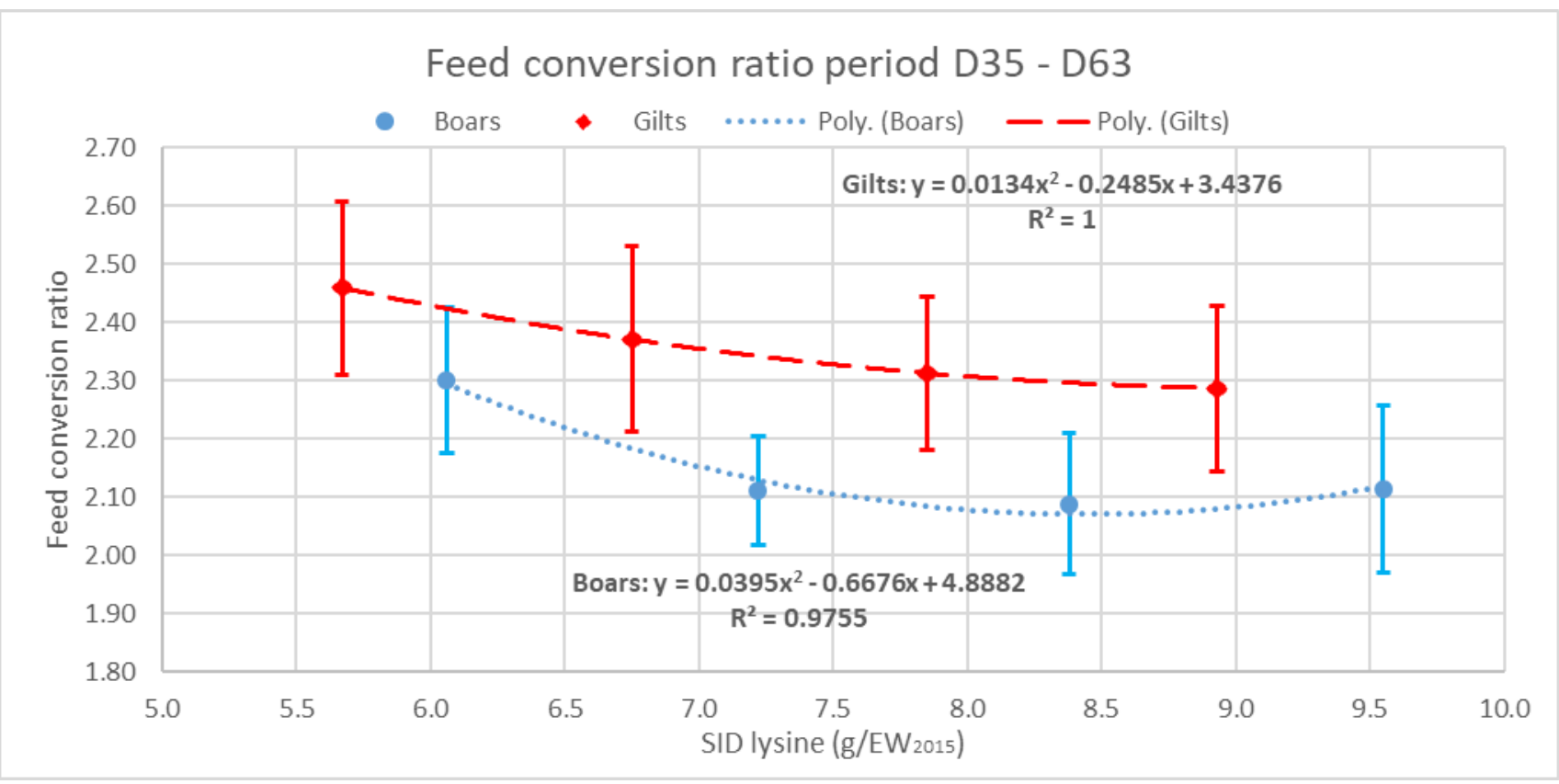

Figure 4 Feed conversion ratio from day 35 till day 63 of growing-finishing pigs (boars and gilts) (Farm A) that were fed diets differing in standardized ileal digestible (SID) lysine content $(80,95,110$ or $125 \%$ of the recommended level for current boars and gilts (Van der Peet-Schwering and Bikker, 2018)). Recommended SID levels (100\%) in grower diets for current growing-finishing boars and gilts are 7.6 and $7.1 \mathrm{~g} / \mathrm{EW}_{2015}$, respectively. 


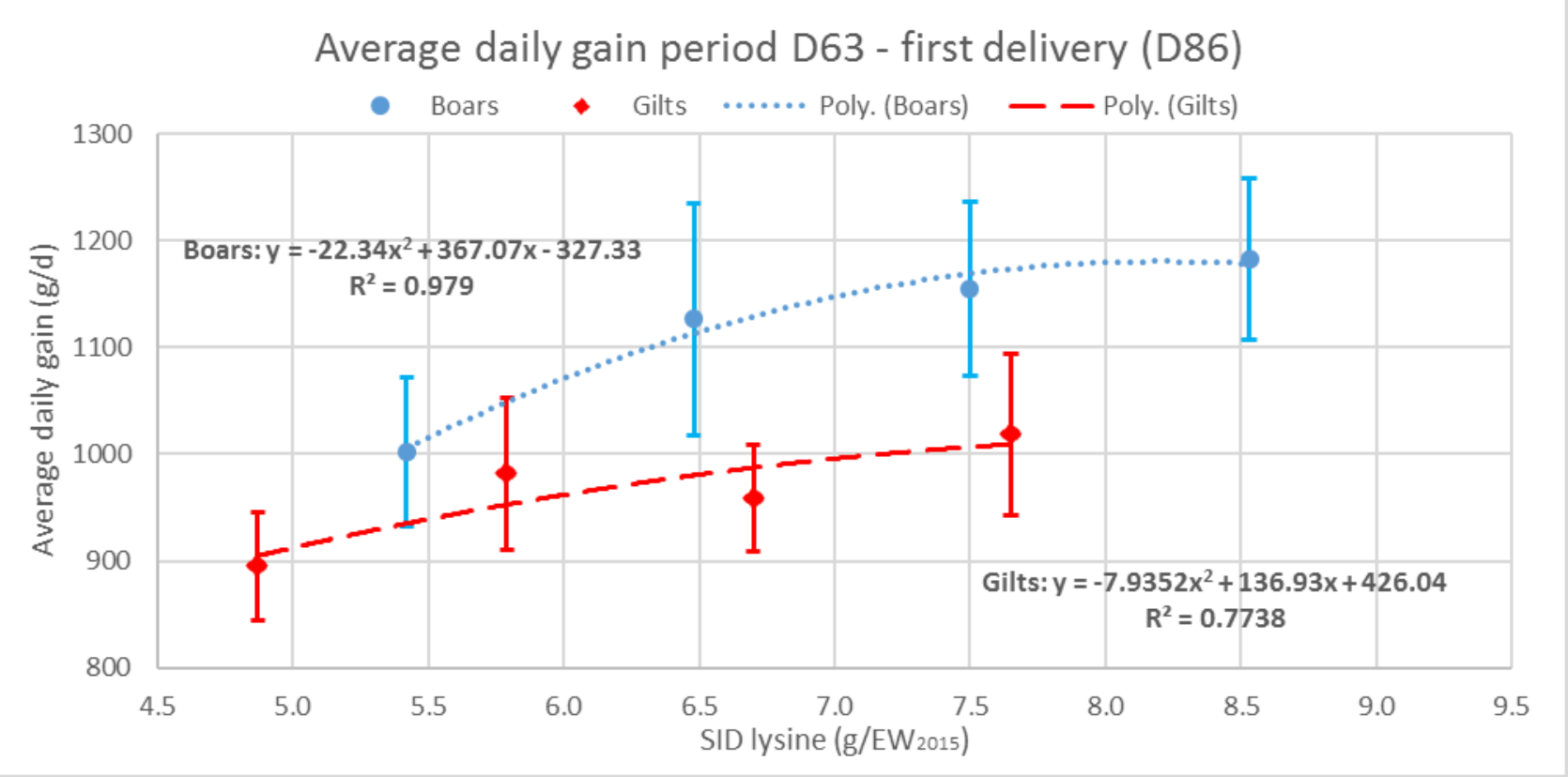

Figure 5 Average daily gain from day 63 till first delivery of growing-finishing pigs (boars and gilts) (Farm A) that were fed diets differing in standardized ileal digestible (SID) lysine content $(80,95,110$ or $125 \%$ of the recommended level for current boars and gilts (Van der Peet-Schwering and Bikker, 2018)). Recommended SID levels (100\%) in finisher diets for current growing-finishing boars and gilts are 6.8 and $6.1 \mathrm{~g} / \mathrm{EW}_{2015}$, respectively.

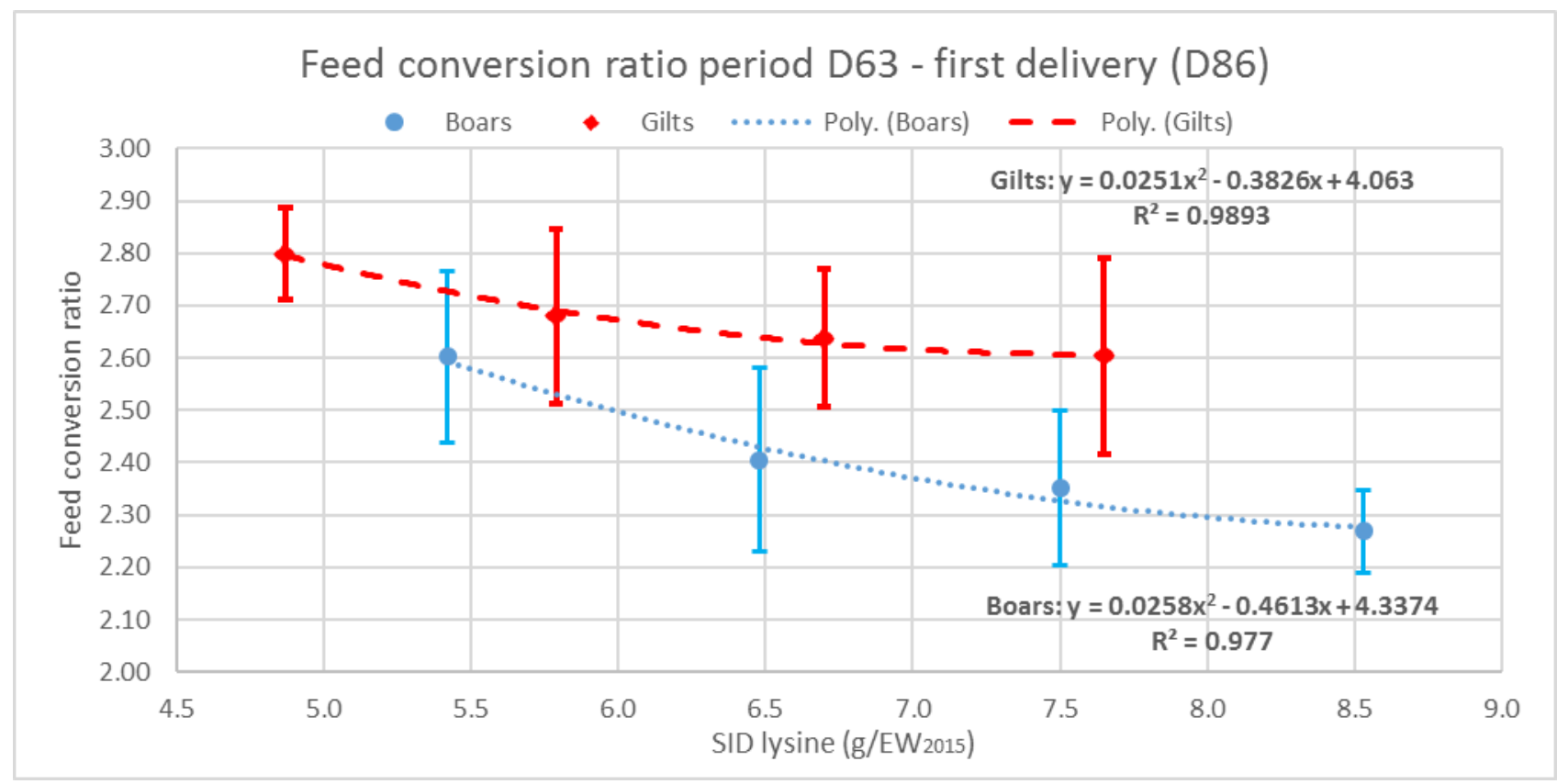

Figure 6 Feed conversion ratio from day 63 till first delivery of growing-finishing pigs (boars and gilts) (Farm A) that were fed diets differing in standardized ileal digestible (SID) lysine content $(80,95,110$ or $125 \%$ of the recommended level for current boars and gilts (Van der Peet-Schwering and Bikker, 2018)). Recommended SID levels (100\%) in finisher diets for current growing-finishing boars and gilts are 6.8 and $6.1 \mathrm{~g} / \mathrm{EW}_{2015}$, respectively. 


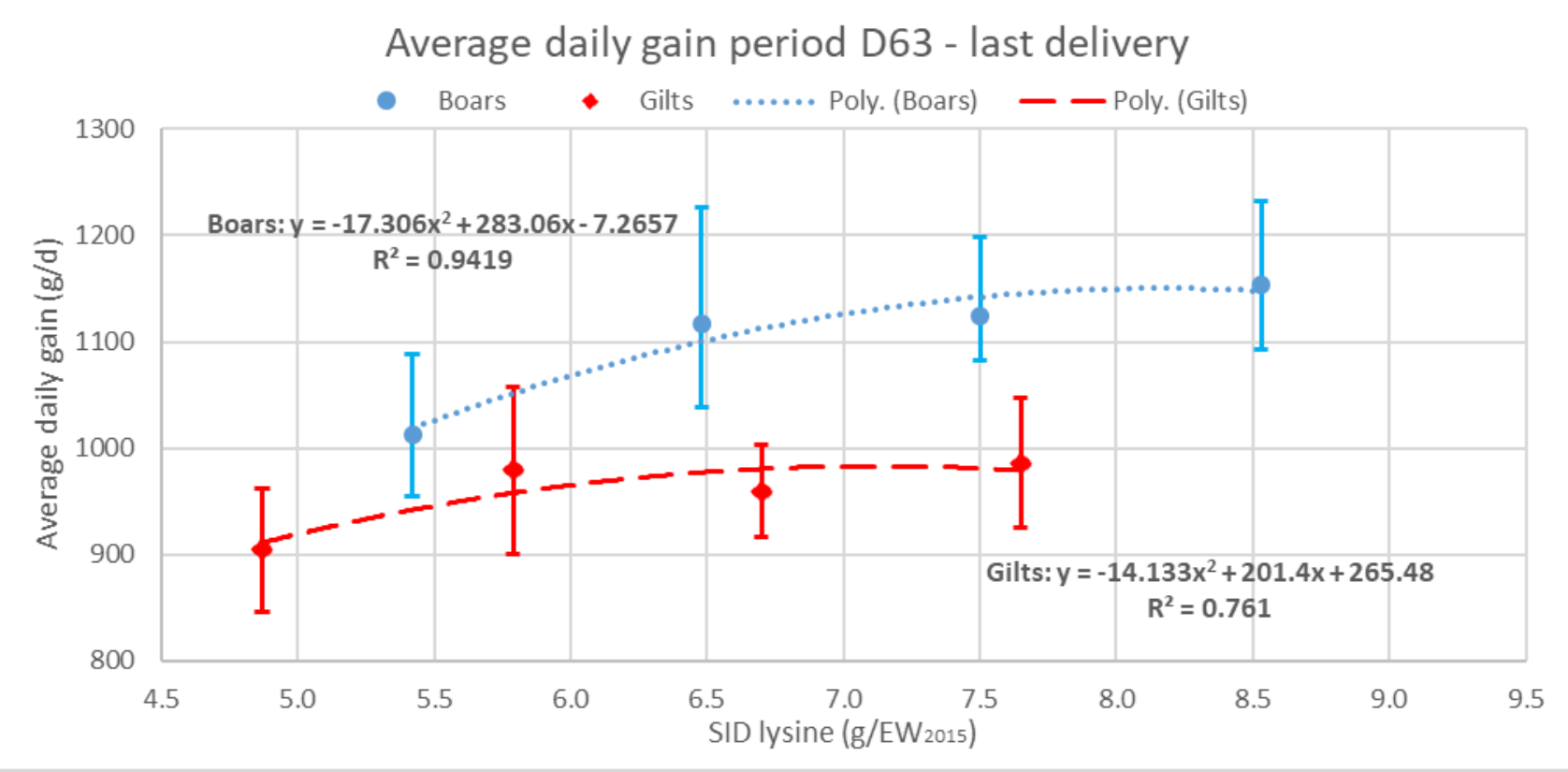

Figure $7 \quad$ Average daily gain from day 63 till last delivery of growing-finishing pigs (boars and gilts) (Farm A) that were fed diets differing in standardized ileal digestible (SID) lysine content $\left(80,95,110\right.$ or $125 \%$ of the recommended level for current boars ${ }^{2}$ and gilts ${ }^{3}$ (Van der Peet-Schwering and Bikker, 2018)). Recommended SID levels (100\%) in finisher diets for current growing-finishing boars and gilts are 6.8 and $6.1 \mathrm{~g} / E W_{2015}$, respectively.

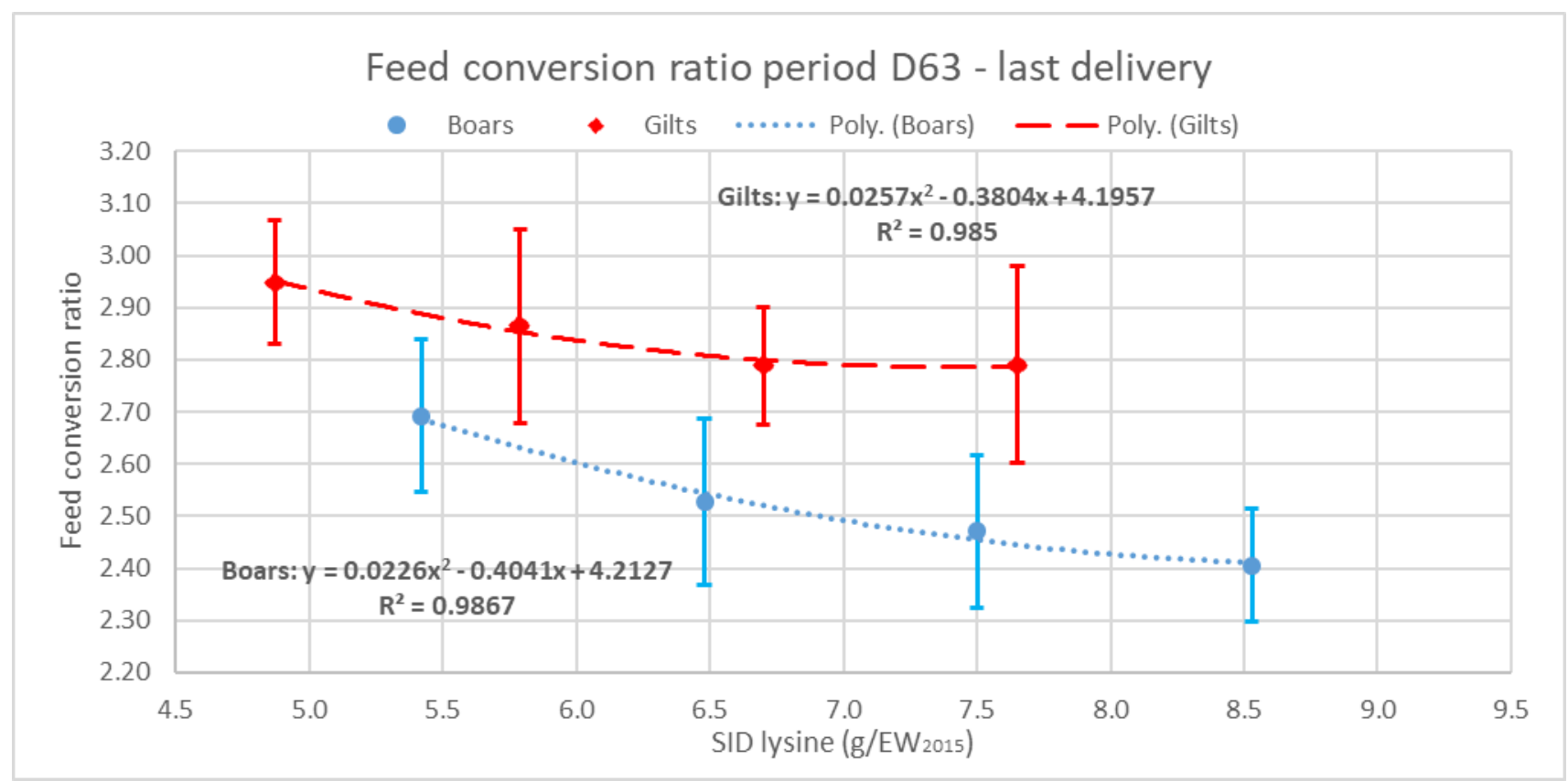

Figure 8 Feed conversion ratio from day 63 till last delivery of growing-finishing pigs (boars and gilts) (Farm A) that were fed diets differing in standardized ileal digestible (SID) lysine content $(80,95,110$ or $125 \%$ of the recommended level for current boars and gilts (Van der Peet-Schwering and Bikker, 2018)). Recommended SID levels (100\%) in finisher diets for current growing-finishing boars and gilts are 6.8 and $6.1 \mathrm{~g} / \mathrm{EW}_{2015}$, respectively. 
Table 6 Performance ${ }^{1}$ from the start till day 35, day 35-63, day 63 till first delivery to the slaughterhouse and day 63 till slaughter of growing-finishing pigs (boars and gilts) (Farm $B$ ) that were fed diets differing in standardized ileal digestible (SID) lysine content (80, 95, 110 or $125 \%$ of the recommended level for current boars ${ }^{2}$ and gilts ${ }^{3}$ (Van der PeetSchwering and Bikker, 2018)).

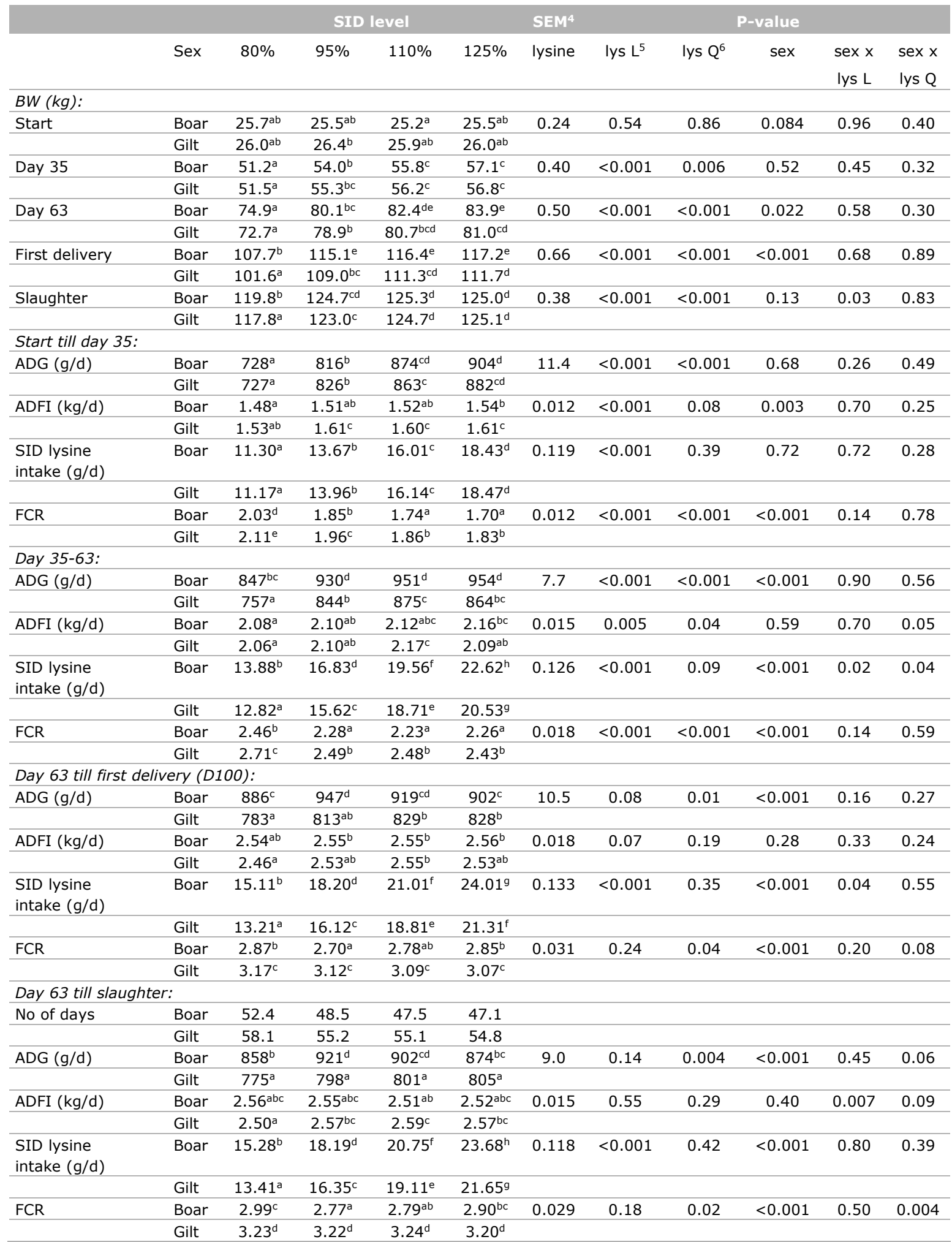

${ }^{1}$ Data are based on 8 pens (176 pigs) per treatment per sex; ${ }^{2}$ Recommended SID levels (100\%) in starter, grower and finisher diets for current growing-finishing boars are 8.7, 7.6 and $6.8 \mathrm{~g} / \mathrm{EW}_{2015}$, respectively; ${ }^{3}$ Recommended SID levels $(100 \%)$ in starter, grower and finisher diets for current growing-finishing gilts are $8.3,7.1$ and $6.1 \mathrm{~g} / \mathrm{EW} 2015$, respectively; ${ }^{4}$ $\mathrm{SEM}=$ pooled SEM. Means are presented as least squares means; ${ }^{5}$ Iys $\mathrm{L}=$ linear effect of SID lysine level; ${ }^{6}$ lys $\mathrm{Q}=$ quadratic effect of SID lysine level. 


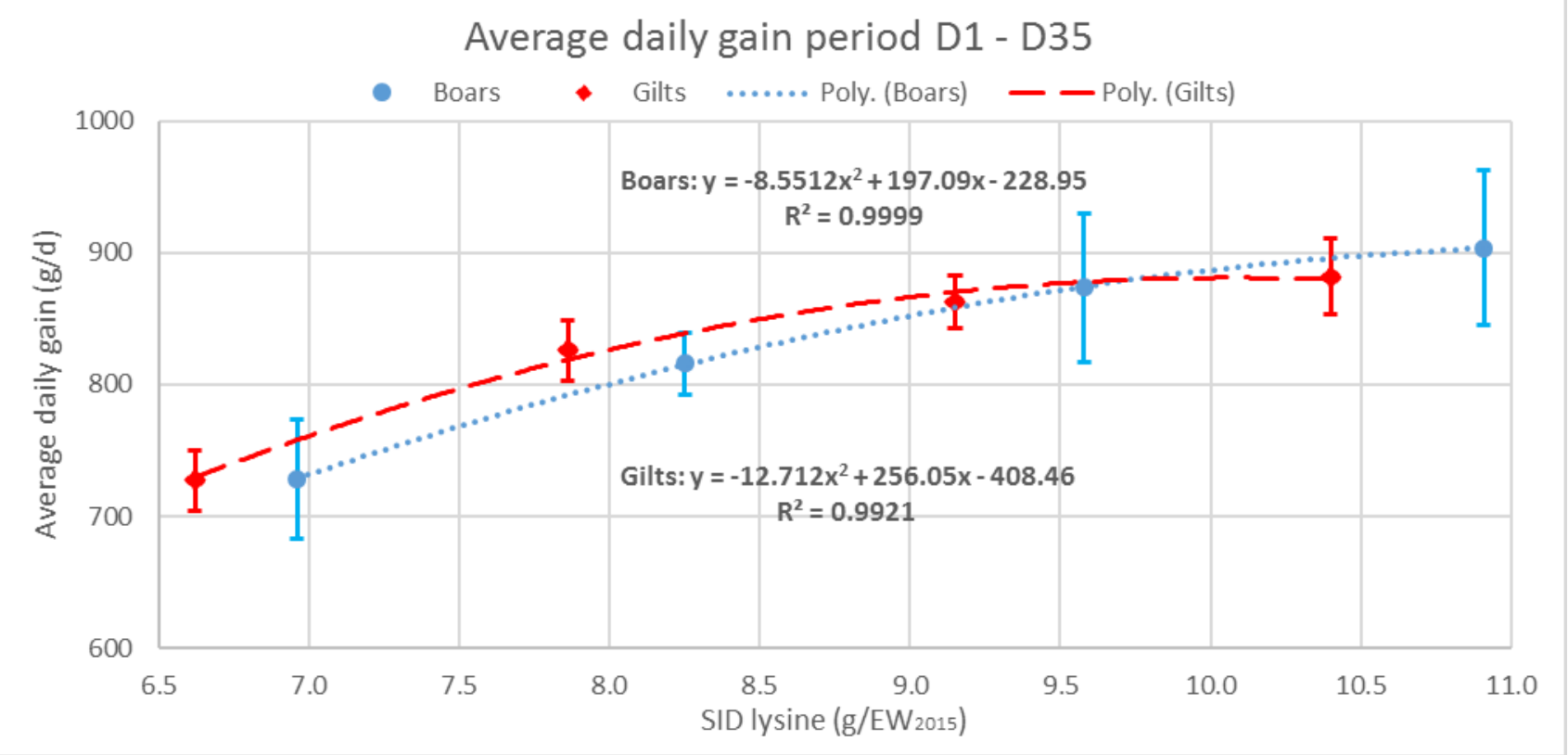

Figure 9 Average daily gain from the start till day 35 of growing-finishing pigs (boars and gilts) (Farm B) that were fed diets differing in standardized ileal digestible (SID) lysine content $(80,95,110$ or $125 \%$ of the recommended level for current boars and gilts (Van der Peet-Schwering and Bikker, 2018)). Recommended SID levels (100\%) in starter diets for current growing-finishing boars and gilts are 8.7 and $8.3 \mathrm{~g} / \mathrm{EW}_{2015}$, respectively.

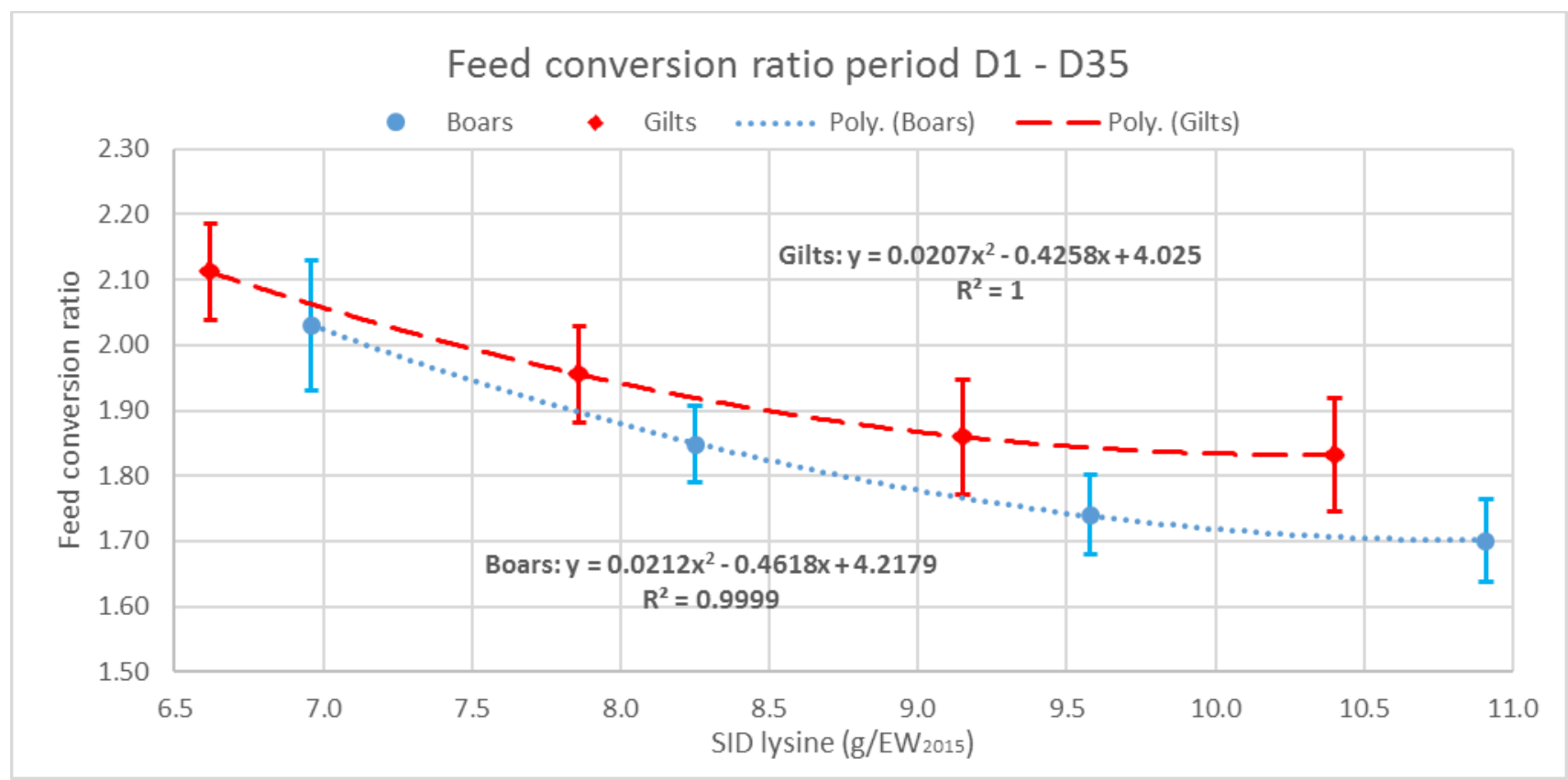

Figure 10 Feed conversion ratio from the start till day 35 of growing-finishing pigs (boars and gilts) (Farm B) that were fed diets differing in standardized ileal digestible (SID) lysine content $(80,95,110$ or $125 \%$ of the recommended level for current boars and gilts (Van der Peet-Schwering and Bikker, 2018)). Recommended SID levels (100\%) in starter diets for current growing-finishing boars and gilts are 8.7 and $8.3 \mathrm{~g} / E W_{2015}$, respectively. 


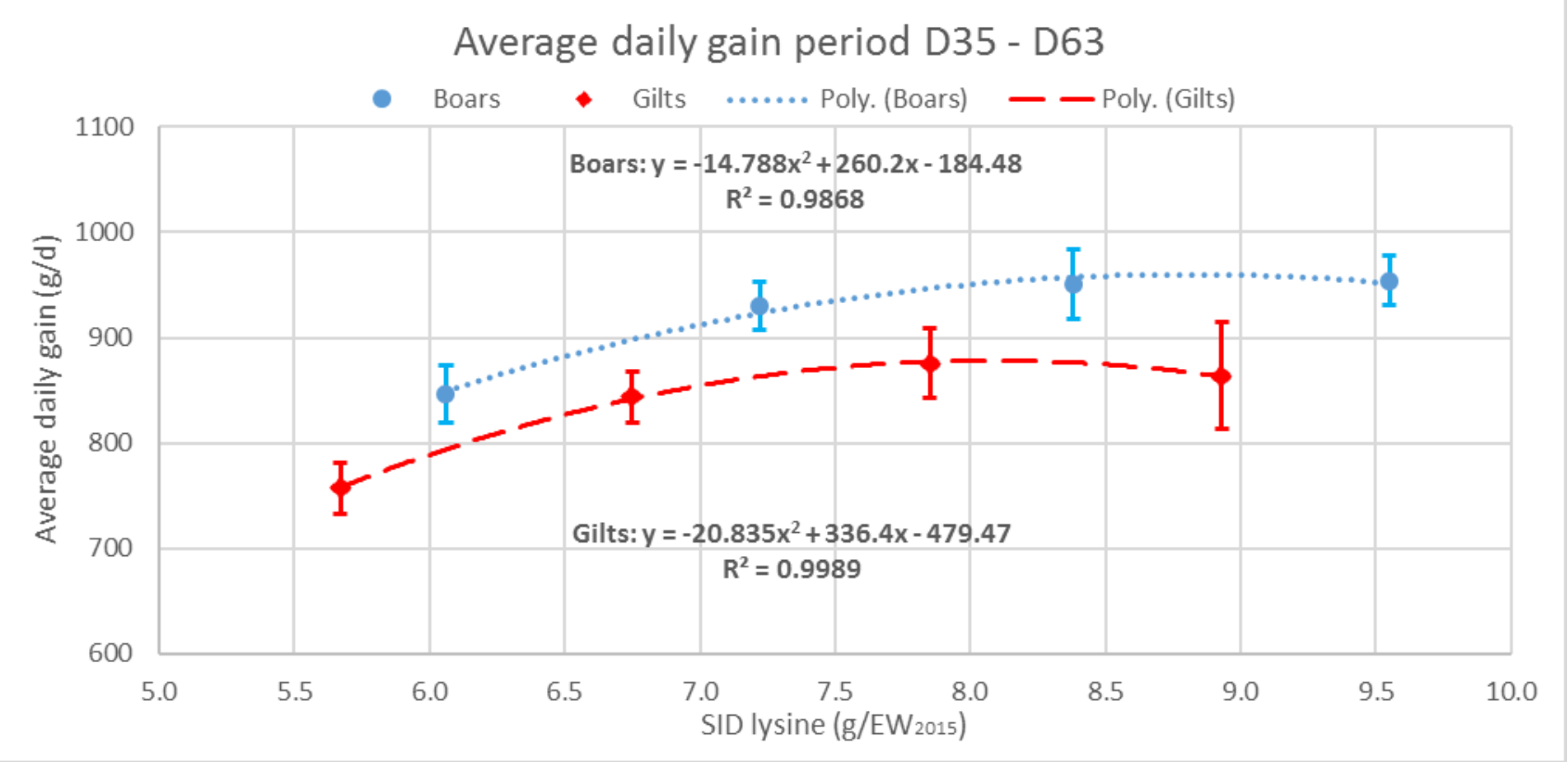

Figure 11 Average daily gain from day 35 till day 63 of growing-finishing pigs (boars and gilts) (Farm B) that were fed diets differing in standardized ileal digestible (SID) lysine content $(80,95,110$ or $125 \%$ of the recommended level for current boars and gilts (Van der Peet-Schwering and Bikker, 2018)). Recommended SID levels (100\%) in grower diets for current growing-finishing boars and gilts are 7.6 and $7.1 \mathrm{~g} / \mathrm{EW}_{2015}$, respectively.

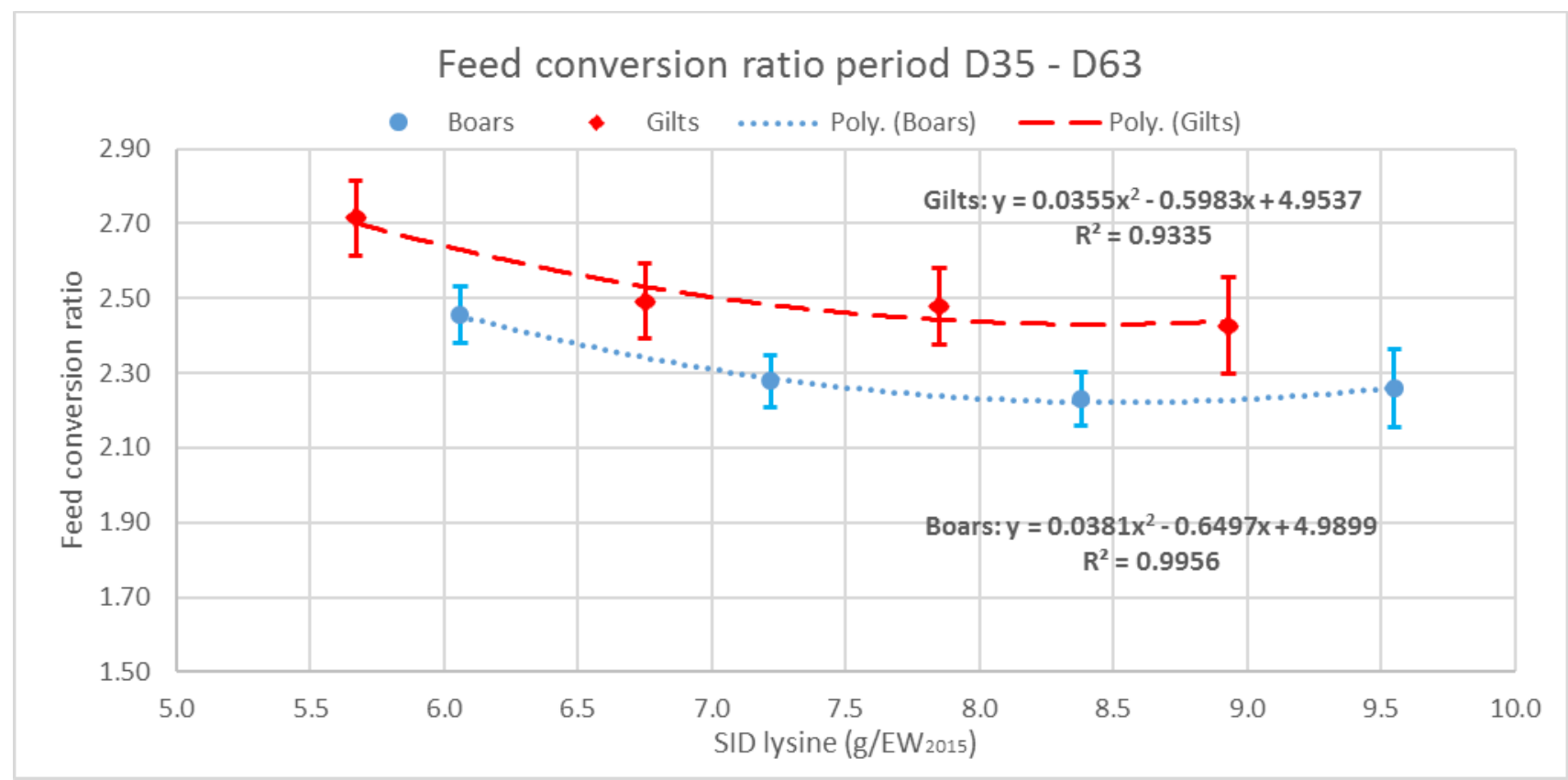

Figure 12 Feed conversion ratio from day 35 till day 63 of growing-finishing pigs (boars and gilts) (Farm B) that were fed diets differing in standardized ileal digestible (SID) lysine content $(80,95,110$ or $125 \%$ of the recommended level for current boars and gilts (Van der Peet-Schwering and Bikker, 2018)). Recommended SID levels (100\%) in grower diets for current growing-finishing boars and gilts are 7.6 and $7.1 \mathrm{~g} / \mathrm{EW}_{2015}$, respectively. 


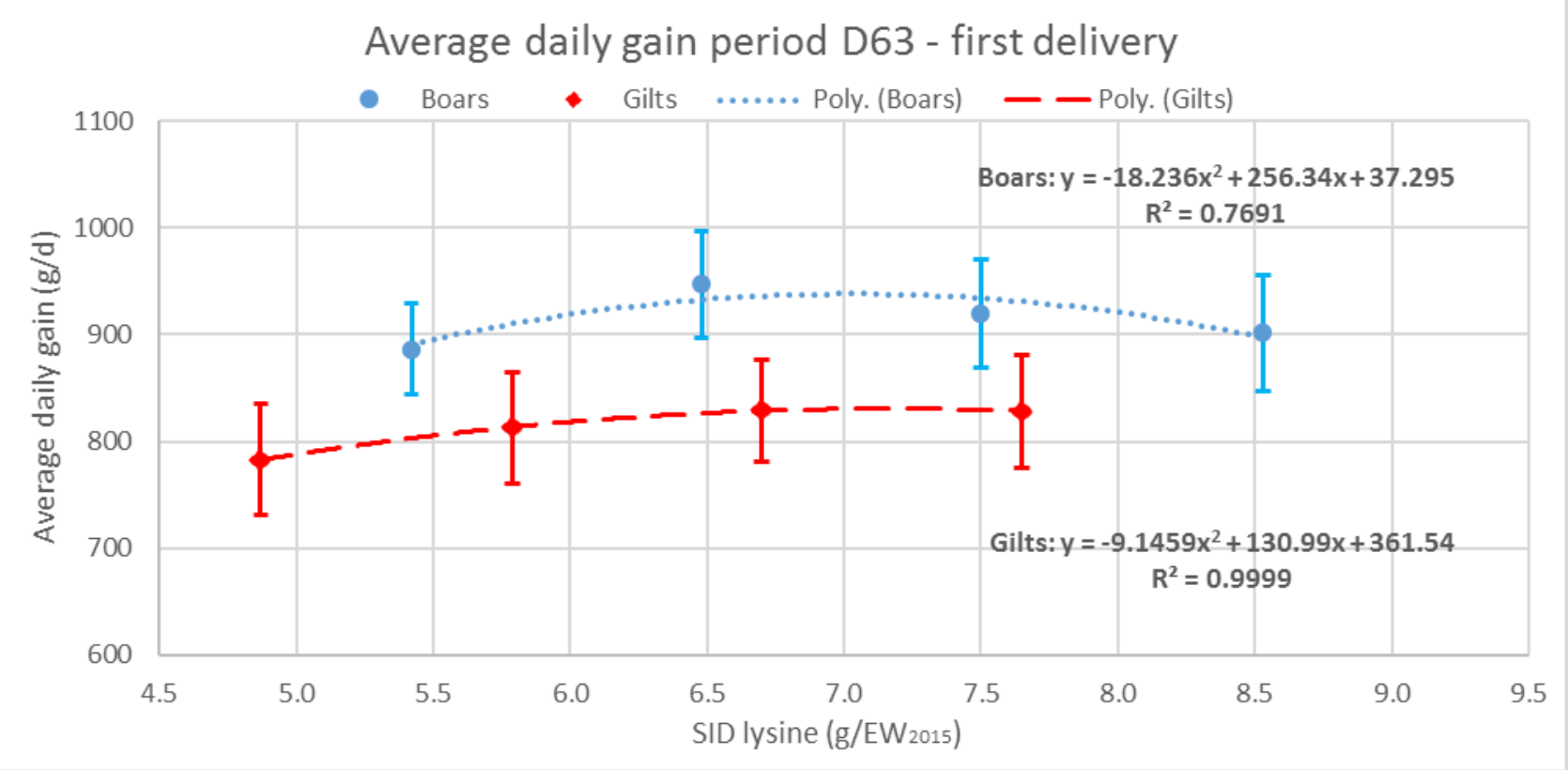

Figure 13 Average daily gain from day 63 till first delivery of growing-finishing pigs (boars and gilts) (Farm B) that were fed diets differing in standardized ileal digestible (SID) lysine content $(80,95,110$ or $125 \%$ of the recommended level for current boars and gilts (Van der Peet-Schwering and Bikker, 2018)). Recommended SID levels (100\%) in finisher diets for current growing-finishing boars and gilts are 6.8 and $6.1 \mathrm{~g} / \mathrm{EW}_{2015}$, respectively.

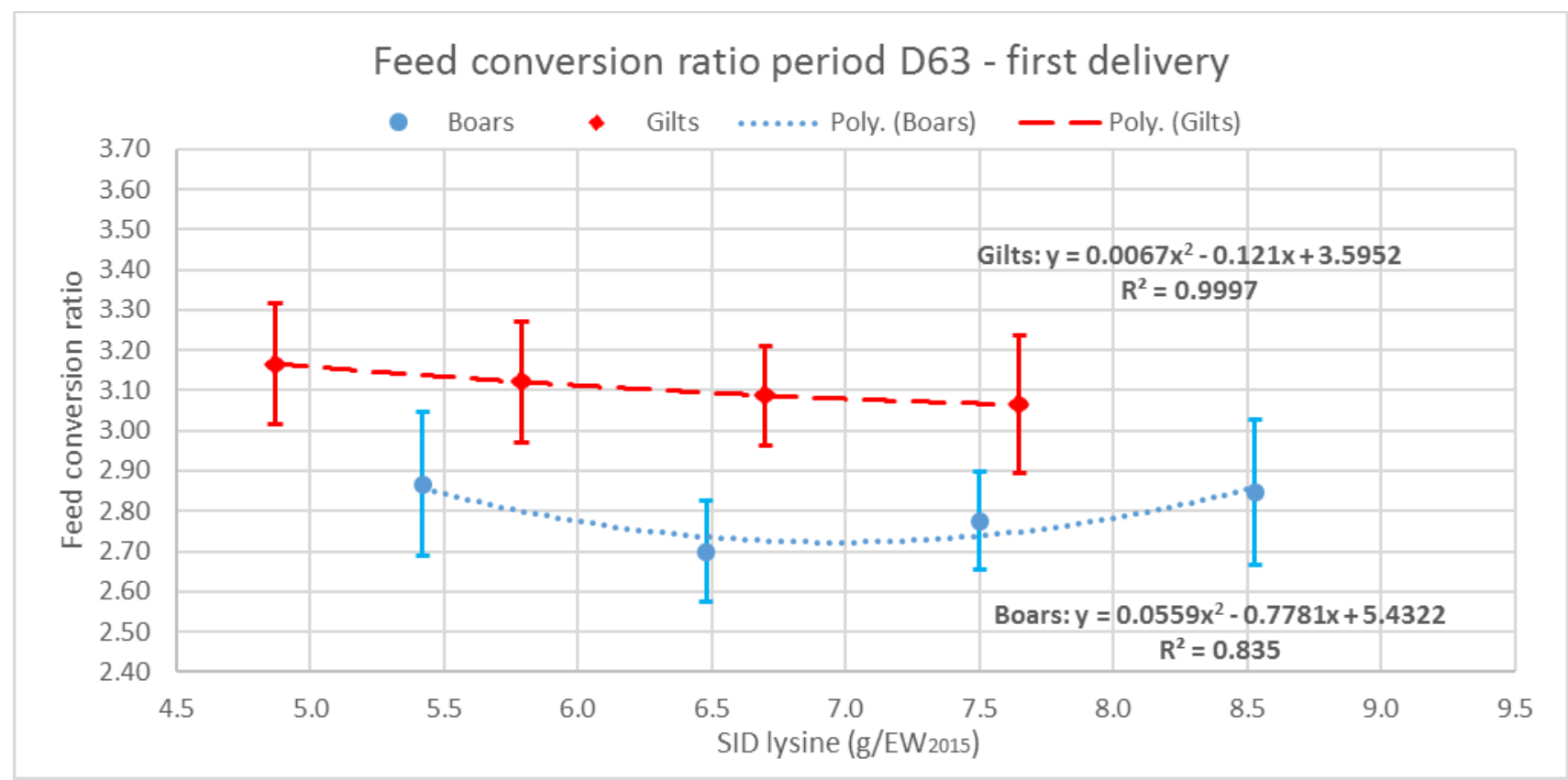

Figure 14 Feed conversion ratio from day 63 till first delivery of growing-finishing pigs (boars and gilts) (Farm B) that were fed diets differing in standardized ileal digestible (SID) lysine content (80, 95, 110 or $125 \%$ of the recommended level for current boars and gilts (Van der Peet-Schwering and Bikker, 2018)). Recommended SID levels (100\%) in finisher diets for current growing-finishing boars and gilts are 6.8 and $6.1 \mathrm{~g} / \mathrm{EW}_{2015}$, respectively. 


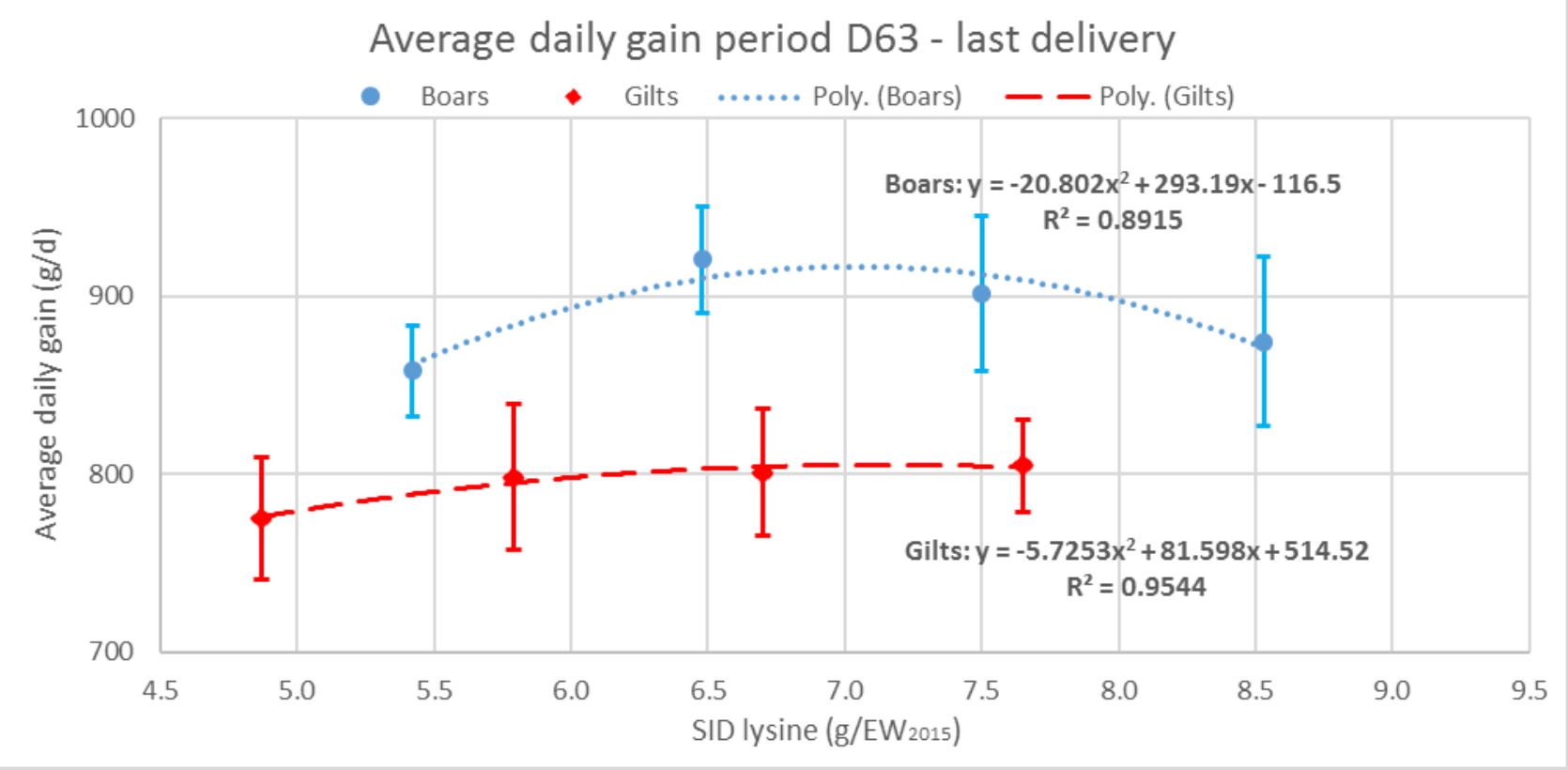

Figure 15 Average daily gain from day 63 till last delivery of growing-finishing pigs (boars and gilts) (Farm B) that were fed diets differing in standardized ileal digestible (SID) lysine content $(80,95,110$ or $125 \%$ of the recommended level for current boars and gilts (Van der Peet-Schwering and Bikker, 2018)). Recommended SID levels (100\%) in finisher diets for current growing-finishing boars and gilts are 6.8 and $6.1 \mathrm{~g} / E W_{2015}$, respectively.

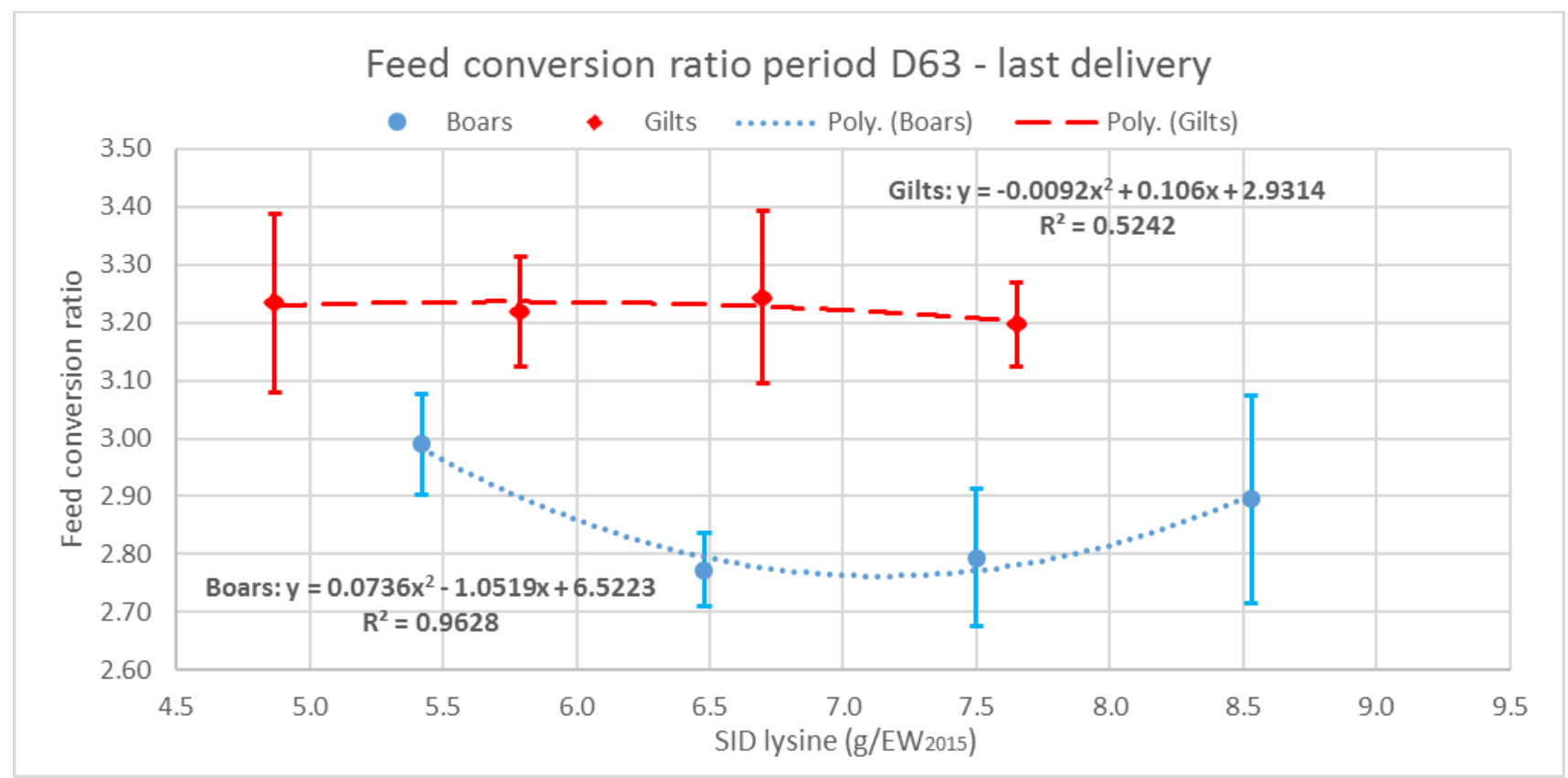

Figure 16 Feed conversion ratio from day 63 till last delivery of growing-finishing pigs (boars and gilts) (Farm B) that were fed diets differing in standardized ileal digestible (SID) lysine content (80, 95, 110 or $125 \%$ of the recommended level for current boar ${ }^{2}$ and gilts (Van der Peet-Schwering and Bikker, 2018)). Recommended SID levels (100\%) in finisher diets for current growing-finishing boars and gilts are 6.8 and $6.1 \mathrm{~g} / E W_{2015}$, respectively.

\subsection{Slaughter results}

The slaughter results of the GF pigs are presented in Table 7 (Farm A) and Table 8 (Farm B). 
Table $7 \quad$ Slaughter results of growing-finishing pigs (boars and gilts) (Farm A) that were fed diets differing in standardized ileal digestible (SID) lysine content (80, 95, 110 or $125 \%$ of the recommended level for current boars ${ }^{1}$ and gilts ${ }^{2}$ (Van der Peet-Schwering and Bikker, 2018)).

\begin{tabular}{|c|c|c|c|c|c|c|c|c|c|c|c|}
\hline & \multicolumn{5}{|c|}{ SID level } & \multicolumn{3}{|l|}{ SEM $^{3}$} & \multicolumn{3}{|c|}{ P-value } \\
\hline & & & & & & & & & & & Iys Q \\
\hline No of pigs & Gilt & 61 & 59 & 65 & 61 & & & & & & \\
\hline Slaughter weight (kg) & Boar & $90.6^{a}$ & $93.5^{b}$ & $95.1^{b}$ & $95.0^{\mathrm{b}}$ & 0.64 & $<0.001$ & 0.04 & 0.79 & 0.73 & 0.82 \\
\hline Meat \% & Gilt & $59.9^{\mathrm{ab}}$ & $60.3^{\mathrm{bcd}}$ & $60.5^{\text {cde }}$ & $60.6^{\text {de }}$ & & & & & & \\
\hline \multirow[t]{2}{*}{ Muscle thickness (mm) } & Boar & $64.4^{\mathrm{a}}$ & $67.2^{\mathrm{b}}$ & $68.6^{\mathrm{bc}}$ & $68.9^{\mathrm{bc}}$ & 0.61 & $<0.001$ & 0.34 & 0.03 & 0.30 & 0.34 \\
\hline & Gilt & $67.6^{b}$ & $69.4^{\mathrm{bc}}$ & $69.2^{\mathrm{bc}}$ & $70.8^{c}$ & & & & & & \\
\hline \multirow[t]{2}{*}{ Backfat (mm) } & Boar & $13.0^{d}$ & $12.7^{\mathrm{cd}}$ & $11.4^{\mathrm{a}}$ & $11.7^{\mathrm{ab}}$ & 0.20 & $<0.001$ & 0.28 & 0.95 & 0.27 & 0.72 \\
\hline & Gilt & $12.8^{\mathrm{cd}}$ & $12.3^{\mathrm{bcd}}$ & $12.0^{\mathrm{abc}}$ & $11.8^{\mathrm{ab}}$ & & & & & & \\
\hline
\end{tabular}

${ }^{1}$ Recommended SID levels (100\%) in starter, grower and finisher diets for current growing-finishing boars are 8.7, 7.6 and $6.8 \mathrm{~g} / \mathrm{EW}_{2015}$, respectively; ${ }^{2}$ Recommended SID levels (100\%) in starter, grower and finisher diets for current growingfinishing gilts are 8.3, 7.1 and $6.1 \mathrm{~g} / \mathrm{EW}_{2015}$, respectively; ${ }^{3} \mathrm{SEM}=$ pooled SEM. Means are presented as least squares means; ${ }^{4}$ lys $\mathrm{L}=$ linear effect of SID lysine level; ${ }^{5}$ lys $\mathrm{Q}=$ quadratic effect of SID lysine level.

Table 7 shows that meat\% and backfat thickness were similar in boars and gilts. Muscle thickness and dressing\% were higher in gilts. In boars, meat\% was highest and backfat thickness was lowest at the $110 \%$ SID lysine level. Meat\% and backfat thickness, however, were similar at the 110 and $125 \%$ SID lysine level. Muscle thickness was highest at the $125 \%$ SID lysine level, but did not differ from the muscle thickness at the 95 and $110 \%$ SID lysine level. In gilts, meat\% and muscle thickness were highest and backfat thickness was lowest at the 125\% SID lysine level. Meat\%, muscle thickness and backfat thickness, however, were similar art the 95, 110 and 125\% SID lysine level.

Table $8 \quad$ Slaughter results of growing-finishing pigs (boars and gilts) (Farm B) that were fed diets differing in standardized ileal digestible (SID) lysine content (80, 95, 110 or $125 \%$ of the recommended level for current boars ${ }^{1}$ and gilts ${ }^{2}$ (Van der Peet-Schwering and Bikker, 2018)).

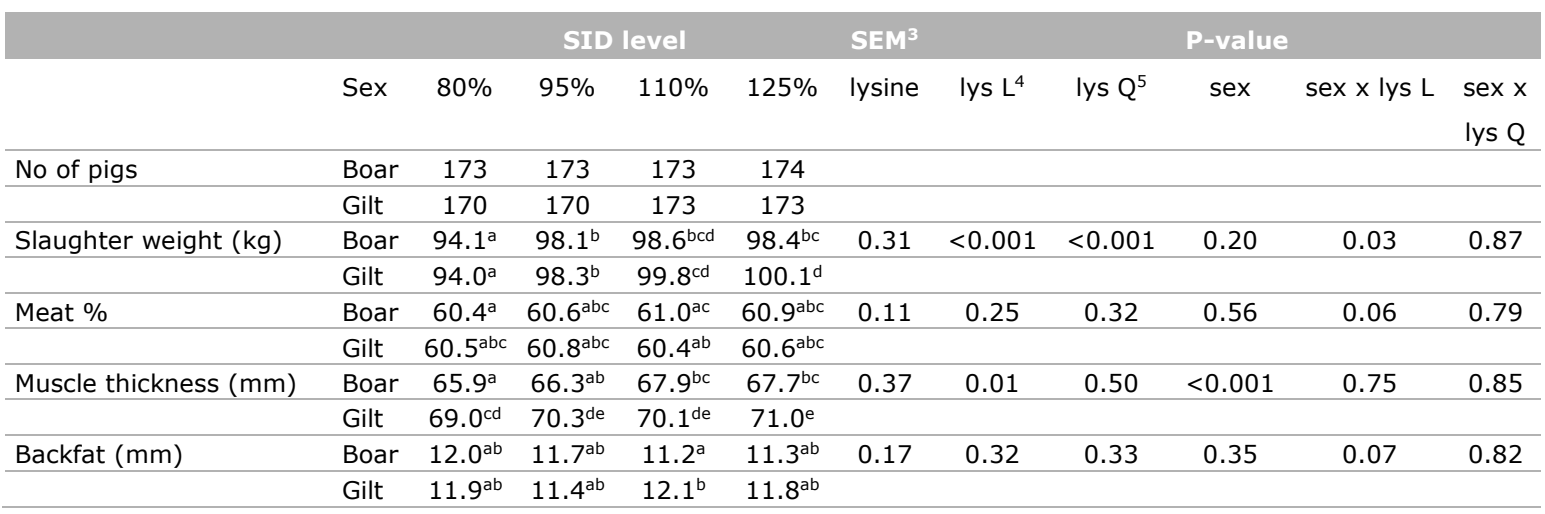

${ }^{1}$ Recommended SID levels (100\%) in starter, grower and finisher diets for current growing-finishing boars are $8.7,7.6$ and $6.8 \mathrm{~g} / \mathrm{EW}_{2015}$, respectively; ${ }^{2}$ Recommended SID levels (100\%) in starter, grower and finisher diets for current growingfinishing gilts are 8.3, 7.1 and $6.1 \mathrm{~g} / \mathrm{EW}_{2015}$, respectively; ${ }^{3} \mathrm{SEM}=$ pooled SEM. Means are presented as least squares means; ${ }^{4}$ lys $L=$ linear effect of SID Iysine level; ${ }^{5}$ lys $Q=$ quadratic effect of SID lysine level.

Table 8 shows that meat\% and backfat thickness were similar in boars and gilts. Muscle thickness was higher in gilts. In both boars and gilts, meat\% and backfat thickness were not affected by SID lysine level. In boars, muscle thickness was highest at the $110 \%$ SID lysine level but did not differ from the muscle thickness at the 95 and $125 \%$ SID lysine level. In gilts, muscle thickness was highest at the $125 \%$ SID lysine level, but did not differ from the muscle thickness at the 95 and 110\% SID lysine level. 


\subsection{Health and faecal scores}

The number of culled and veterinary treated GF pigs are presented in Table 9 (Farm A) and Table 10 (Farm B). Also the reasons of culling and veterinary treatment are presented.

Table 9 Number of culled and veterinary treated growing-finishing pigs (boars and gilts) (Farm A) that were fed diets differing in standardized ileal digestible (SID) lysine content (80, 95,110 or $125 \%$ of the recommended level for current boars ${ }^{1}$ and gilts ${ }^{2}$ (Van der PeetSchwering and Bikker, 2018)).

\begin{tabular}{|c|c|c|c|c|c|c|c|c|c|c|}
\hline & \multicolumn{4}{|c|}{ Boars } & \multicolumn{4}{|c|}{ Gilts } & \multicolumn{2}{|c|}{ P-value } \\
\hline No of pigs at start & 65 & 65 & 65 & 65 & 65 & 65 & 65 & 65 & & \\
\hline \multicolumn{11}{|l|}{ Reason of culling: } \\
\hline - GIT $^{3}$ disorder & 0 & 0 & 1 & 2 & 0 & 1 & 0 & 1 & 4 & 4 \\
\hline - lung problems & 0 & 0 & 0 & 0 & 2 & 3 & 0 & 0 & 4 & 4 \\
\hline - leg problems & 1 & 1 & 1 & 0 & 0 & 1 & 0 & 0 & 4 & 4 \\
\hline - miscellaneous & 1 & 0 & 0 & 0 & 1 & 1 & 0 & 0 & 4 & 4 \\
\hline - unknown & 0 & 1 & 0 & 0 & 1 & 0 & 0 & 2 & 4 & 4 \\
\hline No of veterinary treated pigs & 1 & 2 & 1 & 0 & 0 & 2 & 2 & 1 & 0.74 & 0.38 \\
\hline
\end{tabular}

${ }^{1}$ Recommended SID levels (100\%) in starter, grower and finisher diets for current growing-finishing boars are 8.7, 7.6 and $6.8 \mathrm{~g} / \mathrm{EW}_{2015}$, respectively; ${ }^{2}$ Recommended SID levels (100\%) in starter, grower and finisher diets for current growingfinishing gilts are 8.3, 7.1 and $6.1 \mathrm{~g} / \mathrm{EW}_{2015}$, respectively; ${ }^{3} \mathrm{GIT}=$ gastrointestinal; ${ }^{4}$ Number too low for analysis.

Table 9 shows that the number of culled and veterinary treated pigs was not affected by sex or SID lysine level.

Table 10 Number of culled and veterinary treated growing-finishing pigs (boars and gilts) (Farm $B$ ) that were fed diets differing in standardized ileal digestible (SID) lysine content (80, 95, 110 or $125 \%$ of the recommended level for current boars ${ }^{1}$ and gilts ${ }^{2}$ (Van der PeetSchwering and Bikker, 2018)).

\begin{tabular}{|c|c|c|c|c|c|c|c|c|c|c|}
\hline & \multicolumn{4}{|c|}{ Boars } & \multicolumn{4}{|c|}{ Gilts } & \multicolumn{2}{|c|}{ P-value } \\
\hline No of pigs at start & 176 & 176 & 176 & 176 & 176 & 176 & 176 & 176 & & \\
\hline \multicolumn{11}{|l|}{ Reason of culling: } \\
\hline - $\mathrm{GIT}^{3}$ disorder & 0 & 1 & 0 & 0 & 1 & 0 & 1 & 1 & 4 & 4 \\
\hline - lung problems & 1 & 0 & 0 & 0 & 2 & 0 & 1 & 0 & 4 & 4 \\
\hline - leg problems & 1 & 1 & 2 & 0 & 0 & 2 & 0 & 1 & 4 & 4 \\
\hline - unknown & 0 & 1 & 1 & 2 & 2 & 4 & 1 & 1 & 4 & 4 \\
\hline No of veterinary treated pigs & 7 & 5 & 5 & 10 & 8 & 5 & 2 & 3 & 0.17 & 0.34 \\
\hline \multicolumn{11}{|l|}{ Reason of treatment: } \\
\hline
\end{tabular}

${ }^{1}$ Recommended SID levels (100\%) in starter, grower and finisher diets for current growing-finishing boars are 8.7, 7.6 and $6.8 \mathrm{~g} / \mathrm{EW}_{2015}$, respectively; ${ }^{2}$ Recommended SID levels (100\%) in starter, grower and finisher diets for current growingfinishing gilts are 8.3, 7.1 and $6.1 \mathrm{~g} / \mathrm{EW}_{2015}$, respectively; ${ }^{3} \mathrm{GIT}=$ gastrointestinal; ${ }^{4}$ Number too low for analysis.

Table 10 shows that the number of culled and veterinary treated pigs was not affected by sex or SID lysine level. 
On Farm A, in each pen the number of GF pigs with normal faeces (score $=0$ ), soft faeces (score $=1$ ) and watery faeces (score $=2$ ) was scored. On Farm B, the faeces of the pigs was scored on pen level. The percentage of GF pigs with soft or watery faeces (score 1 and 2) within a pen in week 1-5 after the start is presented in Table 11 (Farm A). The mean faecal score in week 1-5 after the start is presented in Tables 11a (Farm A) and Table 12 (Farm B).

Table 11 Percentage of growing-finishing pigs (boars and gilts) with soft or watery faeces (score 1 and 2$)^{1}$ within a pen (Farm A) that were fed diets differing in standardized ileal digestible (SID) lysine content $\left(80,95,110\right.$ or $125 \%$ of the recommended level for current boars ${ }^{2}$ and gilts ${ }^{3}$ (Van der Peet-Schwering and Bikker, 2018)).

\begin{tabular}{lccccccccccc}
\multicolumn{1}{c}{ Boars } & \multicolumn{9}{c}{ Gilts } \\
Week & $80 \%$ & $95 \%$ & $110 \%$ & $125 \%$ & $80 \%$ & $95 \%$ & $110 \%$ & $125 \%$ & sex & lysine & sex x lysine \\
\hline 1 & $3.8^{\mathrm{ab}}$ & $1.8^{\mathrm{ab}}$ & $8.0^{\mathrm{ab}}$ & $3.0^{\mathrm{ab}}$ & $9.7^{\mathrm{b}}$ & $8.0^{\mathrm{ab}}$ & $4.3^{\mathrm{ab}}$ & $1.6^{\mathrm{a}}$ & 0.67 & 0.41 & 0.19 \\
\hline 2 & $1.4^{\mathrm{a}}$ & $0.0^{\mathrm{a}}$ & $4.5^{\mathrm{a}}$ & $1.6^{\mathrm{a}}$ & $3.3^{\mathrm{a}}$ & $2.5^{\mathrm{a}}$ & $0.0^{\mathrm{a}}$ & $0.0^{\mathrm{a}}$ & 0.79 & 0.76 & 0.17 \\
\hline 3 & $1.8^{\mathrm{ab}}$ & $0.0^{\mathrm{a}}$ & $0.4^{\mathrm{ab}}$ & $4.1^{\mathrm{b}}$ & $0.0^{\mathrm{a}}$ & $3.0^{\mathrm{ab}}$ & $0.0^{\mathrm{a}}$ & $0.0^{\mathrm{a}}$ & 0.33 & 0.60 & 0.09 \\
\hline 4 & $0.0^{\mathrm{a}}$ & $0.0^{\mathrm{a}}$ & $0.0^{\mathrm{a}}$ & $4.2^{\mathrm{b}}$ & $0.0^{\mathrm{a}}$ & $1.6^{\mathrm{a}}$ & $0.0^{\mathrm{a}}$ & $0.0^{\mathrm{a}}$ & 0.34 & 0.09 & 0.02 \\
\hline 5 & $0.0^{\mathrm{a}}$ & $4.5^{\mathrm{ac}}$ & $1.6^{\mathrm{abc}}$ & $0.0^{\mathrm{a}}$ & $0.0^{\mathrm{ab}}$ & $3.0^{\mathrm{abc}}$ & $1.6^{\mathrm{abc}}$ & $0.0^{\mathrm{ab}}$ & 0.62 & 0.08 & 0.95 \\
\hline
\end{tabular}

${ }^{1}$ Faecal score was recorded weekly during the starter phase $(5$ weeks $)$ : normal faeces $($ score $=0)$, pasty faeces $($ score $=1)$, watery faeces (score $=2$ ); ${ }^{2}$ Recommended SID levels $(100 \%$ ) in starter, grower and finisher diets for current growingfinishing boars are 8.7, 7.6 and $6.8 \mathrm{~g} / \mathrm{EW}_{2015}$, respectively; ${ }^{3}$ Recommended SID levels (100\%) in starter, grower and finisher diets for current growing-finishing gilts are 8.3, 7.1 and $6.1 \mathrm{~g} / \mathrm{EW} 2015$, respectively.

Table 11a Average faecal score of growing-finishing pigs (boars and gilts) within a pen (Farm A) that were fed diets differing in standardized ileal digestible (SID) lysine content (80, 95, 110 or $125 \%$ of the recommended level for current boars ${ }^{2}$ and gilts ${ }^{3}$ (Van der PeetSchwering and Bikker, 2018)).

\begin{tabular}{|c|c|c|c|c|c|c|c|c|c|c|c|}
\hline \multirow[b]{2}{*}{ Week } & \multicolumn{4}{|c|}{ Boars } & \multicolumn{4}{|c|}{ Gilts } & \multicolumn{3}{|c|}{ P-value } \\
\hline & $80 \%$ & $95 \%$ & $110 \%$ & $125 \%$ & $80 \%$ & $95 \%$ & $110 \%$ & $125 \%$ & sex & lysine & sex $x$ lysine \\
\hline 1 & $0.38^{\mathrm{abc}}$ & $0.13^{a}$ & $0.75^{a b c}$ & $0.25^{\mathrm{abc}}$ & $0.88^{\mathrm{ac}}$ & $0.75^{\mathrm{abc}}$ & $0.38^{\mathrm{abc}}$ & $0.13^{\mathrm{ab}}$ & 0.69 & 0.35 & 0.17 \\
\hline 3 & $0.13^{\mathrm{ab}}$ & $0.00^{a}$ & $0.02^{a}$ & $0.38^{b}$ & $0.00^{a}$ & $0.25^{\mathrm{ab}}$ & $0.00^{a}$ & $0.00^{a}$ & 0.38 & 0.51 & 0.09 \\
\hline 4 & $0.00^{\mathrm{a}}$ & $0.00^{a}$ & $0.00^{a}$ & $0.38^{b}$ & $0.00^{a}$ & $0.13^{a}$ & $0.00^{a}$ & $0.00^{a}$ & 0.30 & 0.07 & 0.02 \\
\hline 5 & $0.00^{a}$ & $0.38^{b}$ & $0.13^{\mathrm{ab}}$ & $0.00^{a}$ & $0.00^{a}$ & $0.25^{\mathrm{ab}}$ & $0.13^{a b}$ & $0.00^{a}$ & 0.62 & 0.07 & 0.95 \\
\hline
\end{tabular}

${ }^{1}$ Faecal score was recorded weekly during the starter phase $(5$ weeks $)$ : normal faeces $($ score $=0)$, pasty faeces $($ score $=1)$, watery faeces (score $=2$ ); ${ }^{2}$ Recommended SID levels $(100 \%$ ) in starter, grower and finisher diets for current growingfinishing boars are 8.7, 7.6 and $6.8 \mathrm{~g} / \mathrm{EW}_{2015}$, respectively; ${ }^{3}$ Recommended SID levels (100\%) in starter, grower and finisher diets for current growing-finishing gilts are $8.3,7.1$ and $6.1 \mathrm{~g} / \mathrm{EW}_{2015}$, respectively.

Table 11 and 11 a shows that the percentage of GF with soft or watery faeces and the average faecal score were low and were not affected by sex or SID lysine level.

Table 12 Average faecal score of pens (boars and gilts) (Farm B) that were fed diets differing in standardized ileal digestible (SID) lysine content $(80,95,110$ or $125 \%$ of the recommended level for current boars ${ }^{2}$ and gilts ${ }^{3}$ (Van der Peet-Schwering and Bikker, 2018)).

\begin{tabular}{|c|c|c|c|c|c|c|c|c|c|c|c|}
\hline Week & \multicolumn{4}{|c|}{ Boars } & \multicolumn{4}{|c|}{ Gilts } & \multicolumn{3}{|c|}{ P-value } \\
\hline 1 & $0.13^{a}$ & $0.00^{a}$ & $0.19^{a}$ & $0.00^{a}$ & $0.00^{a}$ & $0.00^{a}$ & $0.19^{a}$ & $0.13^{a}$ & 0.99 & 0.13 & 0.48 \\
\hline 3 & $0.13^{a}$ & $0.06^{a}$ & $0.00^{a}$ & $0.13^{a}$ & $0.00^{a}$ & $0.00^{a}$ & $0.06^{a}$ & $0.06^{a}$ & 0.36 & 0.60 & 0.36 \\
\hline 4 & $0.06^{\mathrm{ab}}$ & $0.00^{a}$ & $0.00^{a}$ & $0.00^{a}$ & $0.06^{a b}$ & $0.13^{a b}$ & $0.06^{\mathrm{ab}}$ & $0.19^{b}$ & 0.03 & 0.77 & 0.42 \\
\hline 5 & 0.00 & 0.00 & 0.00 & 0.00 & 0.00 & 0.00 & 0.00 & 0.00 & & & \\
\hline
\end{tabular}

${ }^{1}$ Faecal score was recorded weekly during the starter phase $(5$ weeks $)$ : normal faeces $($ score $=0)$, pasty faeces $($ score $=1)$, watery faeces (score $=2$ ); ${ }^{2}$ Recommended SID levels (100\%) in starter, grower and finisher diets for current growingfinishing boars are 8.7, 7.6 and $6.8 \mathrm{~g} / \mathrm{EW}_{2015}$, respectively; ${ }^{3}$ Recommended SID levels (100\%) in starter, grower and finisher diets for current growing-finishing gilts are 8.3, 7.1 and $6.1 \mathrm{~g} / \mathrm{EW}_{2015}$, respectively.

Table 12 shows that the average faecal score was low and was not affected by SID lysine level. In week 4 , the average faecal score was higher in gilts than in boars. 


\subsection{Estimate of lysine requirements}

The results of the broken-line analysis for the variables ADG and FCR from start till day 35, day 35-63, day 63 till first delivery to the slaughterhouse and day 63 till slaughter are presented in Table 13 and Figures 17-20 for Farm A.

Table 13 Estimated parameters of a broken-line model to describe the response of ADG and FCR of growing-finishing pigs to an increase in dietary standardized ileal digestible (SID) lysine ( $\left.g / E W_{2015}\right)$ from the start until day 35, day 35-63, day 63 until first delivery to the slaughterhouse and day 63 until slaughter of all pigs. The plateau (maximum ADG and minimum FCR), breakpoint (SID lysine in $\mathrm{g} / E W_{2015}$ ) and slope are presented for boars and gilts separately only in case of a significant sex effect $(P<0.05)$ on the respective parameter (Farm A).

\begin{tabular}{|c|c|c|c|c|c|c|c|c|}
\hline & Sex & plateau & $\mathbf{P}^{1}$ & $\begin{array}{l}\text { SID Lys } \\
\left(\mathrm{g} / \mathrm{W}_{2015}\right)\end{array}$ & $\mathbf{P}^{1}$ & slope & $R^{2}$ & RMSE \\
\hline \multicolumn{9}{|c|}{ Start till day 35: } \\
\hline \multirow[t]{2}{*}{ ADG $(g / d)$} & Boar & $963 \pm 26$ & 0.20 & $10.5 \pm 0.60$ & 0.06 & $51 \pm 12.9$ & 37.8 & 74.6 \\
\hline & Gilt & $922 \pm 18$ & 0.03 & $9.0 \pm 0.64$ & 0.004 & & 63.4 & \\
\hline \multirow[t]{2}{*}{ FCR } & Boar & $1.67 \pm 0.022$ & $<0.001$ & $10.6 \pm 0.36$ & 0.008 & $-0.09 \pm 0.008$ & 80.6 & 0.059 \\
\hline & Gilt & $1.81 \pm 0.022$ & & $9.5 \pm 0.33$ & $<0.001$ & & 87.3 & \\
\hline \multicolumn{9}{|l|}{ Day 35-63: } \\
\hline \multirow[t]{2}{*}{$A D G(g / d)$} & Boar & $1126 \pm 16$ & $<0.001$ & $7.1 \pm 0.45$ & $(0.30)$ & $95 \pm 38$ & 36.9 & 82.6 \\
\hline & Gilt & $1060 \pm 18$ & & & $(0.20)$ & & 45.9 & \\
\hline \multirow[t]{2}{*}{ FCR } & Boar & $2.11 \pm 0.031$ & $<0.001$ & $7.4 \pm 0.45$ & $(0.55)$ & $-0.12 \pm 0.043$ & 43.3 & 0.141 \\
\hline & Gilt & $2.29 \pm 0.031$ & & & $(0.32)$ & & 66.5 & \\
\hline \multicolumn{9}{|c|}{ Day 63 till first delivery (D86): } \\
\hline \multirow[t]{2}{*}{ ADG $(g / d)$} & Boar & $1169 \pm 20$ & $<0.001$ & $6.8 \pm 0.37$ & 0.049 & $118 \pm 38$ & 57.8 & 79.8 \\
\hline & Gilt & $986 \pm 16$ & & $5.6 \pm 0.37$ & 0.008 & & 72.8 & \\
\hline \multirow[t]{2}{*}{ FCR } & Boar & $2.27 \pm 0.057$ & $<0.001$ & $8.0 \pm 0.69$ & 0.077 & $-0.12 \pm 0.034$ & 53.3 & 0.155 \\
\hline & Gilt & $2.62 \pm 0.042$ & & $6.3 \pm 0.57$ & 0.017 & & 69.6 & \\
\hline \multicolumn{9}{|c|}{ Day 63 until slaughter: } \\
\hline \multirow[t]{2}{*}{$\operatorname{ADG}(g / d)$} & Boar & $1139 \pm 19$ & $<0.001$ & $6.7 \pm 0.39$ & 0.028 & $98.4 \pm 36.9$ & 52.8 & 78.1 \\
\hline & Gilt & $975 \pm 16$ & & $5.6 \pm 0.41$ & $<0.001$ & & 74.7 & \\
\hline \multirow[t]{2}{*}{ FCR } & Boar & $2.41 \pm 0.06$ & $<0.001$ & $8.0 \pm 0.82$ & 0.118 & $-0.10 \pm 0.034$ & 57.6 & 0.156 \\
\hline & Gilt & $2.79 \pm 0.04$ & & $6.5 \pm 0.71$ & 0.004 & & 83.6 & \\
\hline
\end{tabular}

${ }^{1} \mathrm{P}$-value of the sex effect on respective parameters. The $\mathrm{p}$-values and $\mathrm{R}^{2}$ in gray shading are derived from the broken line analyses of relative ADG and FCR within room, i.e. standardized for the mean performance of the room; ${ }^{2}$ Adjusted $R^{2}$, percentage of variance explained by the model.

Table 13 and Figure 17 show that from start till day 35 (the starter phase), the optimum SID lysine level for ADG and FCR in boars was 10.5 and $10.6 \mathrm{~g} / \mathrm{EW}_{2015}$, respectively. In gilts, the optimum SID lysine level for ADG and FCR was 9.0 and $9.5 \mathrm{~g} / \mathrm{EW}_{2015}$, respectively.

Table 13 and Figure 18 show that from day 35-63 (the grower phase), the optimum SID lysine level for ADG and FCR in boars and gilts combined was 7.1 and $7.4 \mathrm{~g} / \mathrm{EW}_{2015}$, respectively, and not significantly different between the sexes.

Table 13 and Figure 19 show that from day 63 till first delivery, the optimum SID lysine level for ADG and FCR in boars was 6.8 and $8.0 \mathrm{~g} / \mathrm{EW}_{2015}$, respectively. In gilts, the optimum SID lysine level for ADG and FCR was 5.6 and $6.3 \mathrm{~g} / \mathrm{EW}_{2015}$, respectively.

Table 13 and Figure 20 show that from day 63 till slaughter (the finisher phase), the optimum SID lysine level for ADG and FCR in boars was 6.7 and $8.0 \mathrm{~g} / \mathrm{EW}_{2015}$, respectively. In gilts, the optimum SID lysine level for ADG and FCR was 5.6 and $6.5 \mathrm{~g} / \mathrm{EW}_{2015}$, respectively. 

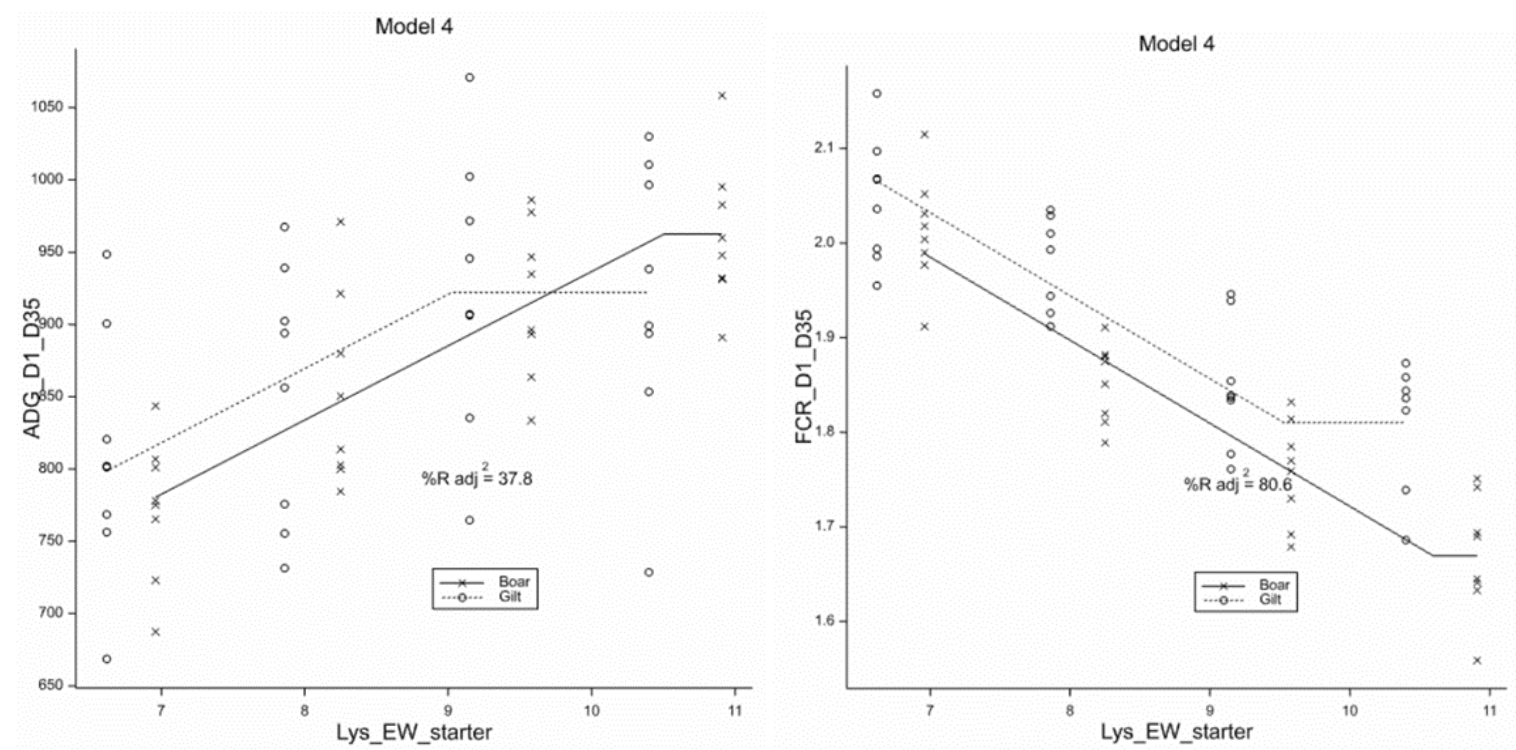

Figure 17 The effect of increasing standardized ileal digestible (SID) lysine (g/EW2015) on ADG and FCR from the start till day 35 of growing-finishing pigs using a broken-line model. The plateau, breakpoint (SID lysine in $\mathrm{g} / E W_{2015}$ ) and slope below the breakpoint are presented for boars and gilts (Farm A). The plateau and breakpoint (model 4) for ADG and FCR differ between boars and gilts.
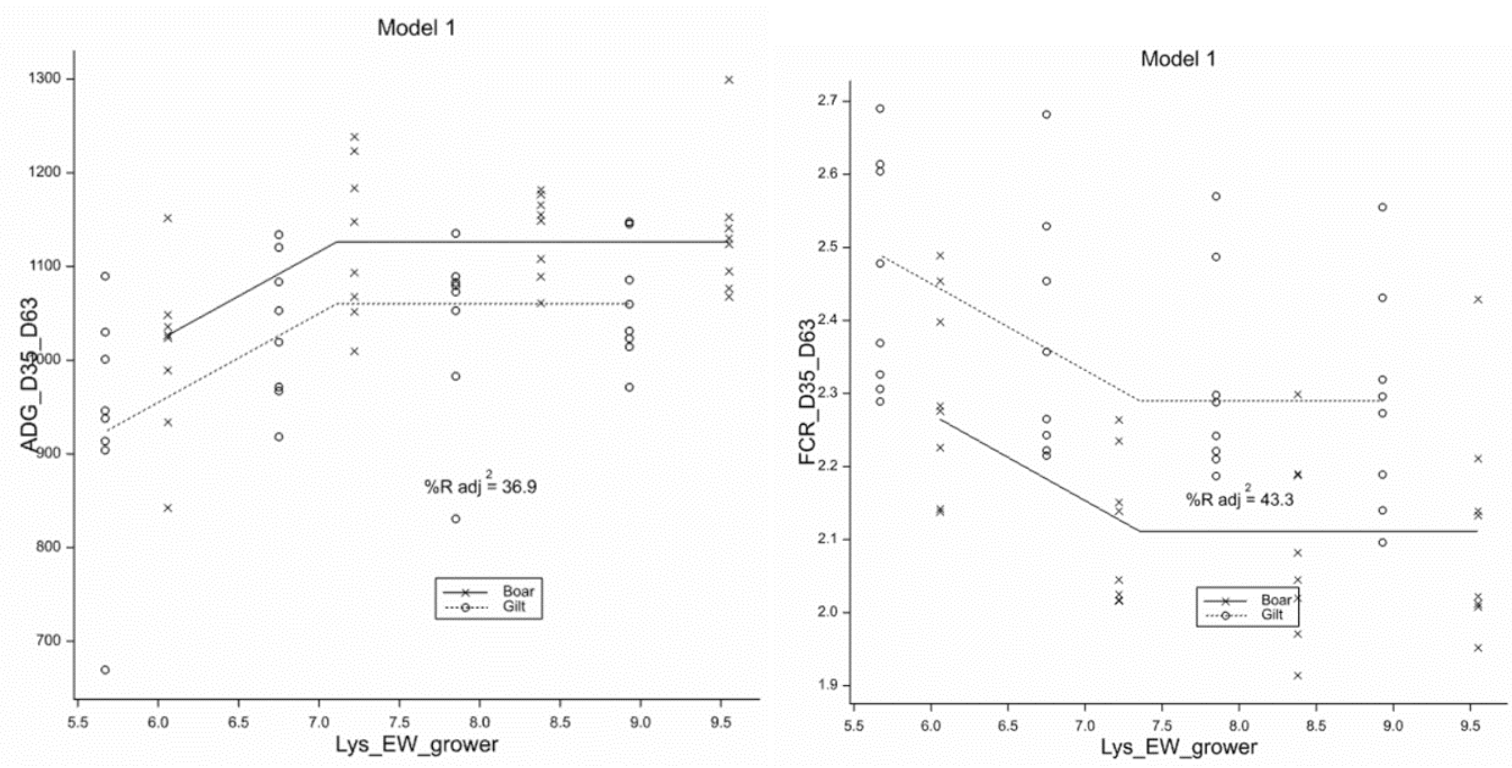

Figure 18 The effect of increasing standardized ileal digestible (SID) lysine (g/EW 2015$)$ on ADG and FCR from day 35 till day 63 of growing-finishing pigs using a broken-line model. The plateau, breakpoint (SID lysine in $g / E W_{2015}$ ) and slope below the breakpoint are presented for boars and gilts (Farm A). The plateau (model 1) for ADG and FCR differs between boars and gilts. 

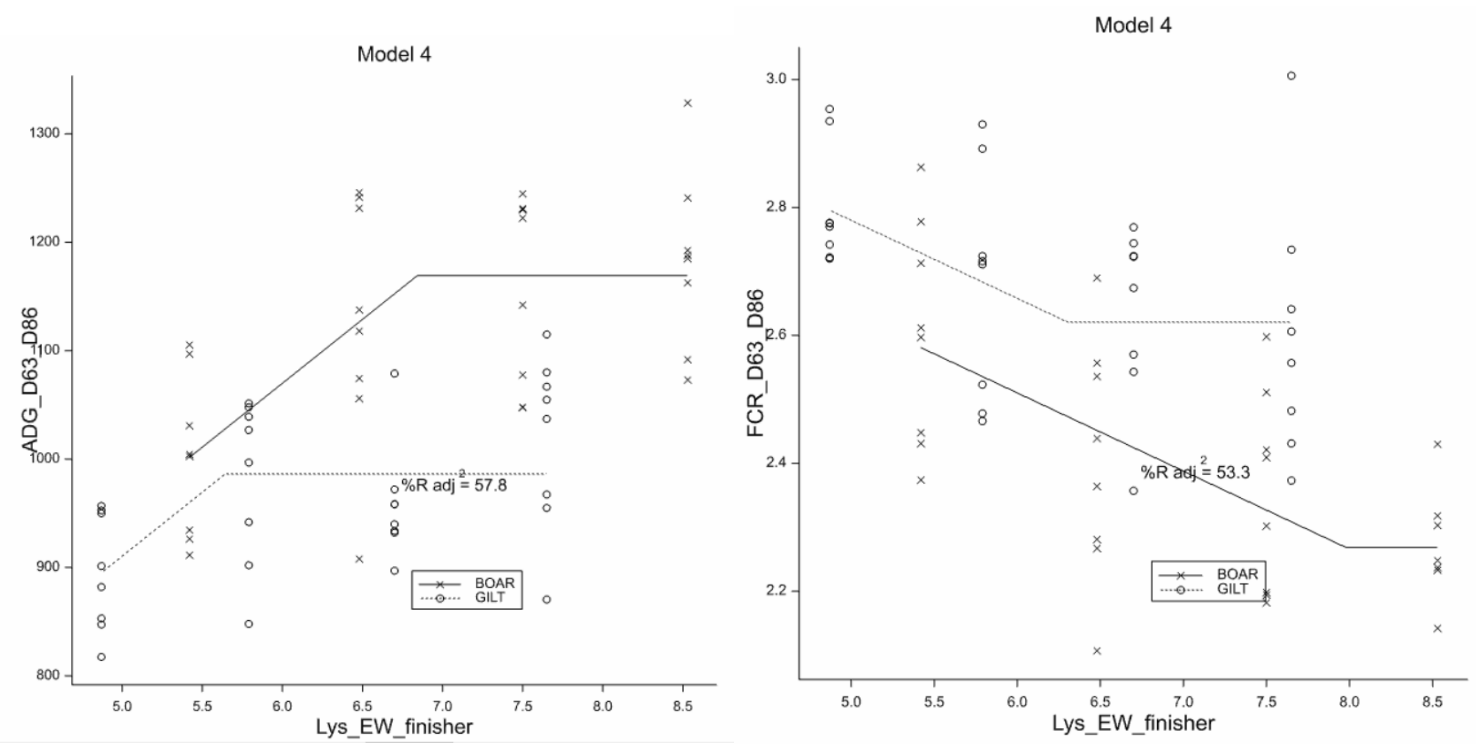

Figure 19 The effect of increasing standardized ileal digestible (SID) lysine ( $\left.\mathrm{g} / E W_{2015}\right)$ on ADG and FCR from day 63 till first delivery of growing-finishing pigs using a broken-line model. The plateau, breakpoint (SID lysine in $\mathrm{g} / \mathrm{EW}_{2015}$ ) and slope below the breakpoint are presented for boars and gilts (Farm A). The plateau and breakpoint (model 4) for ADG and FCR differs between boars and gilts.
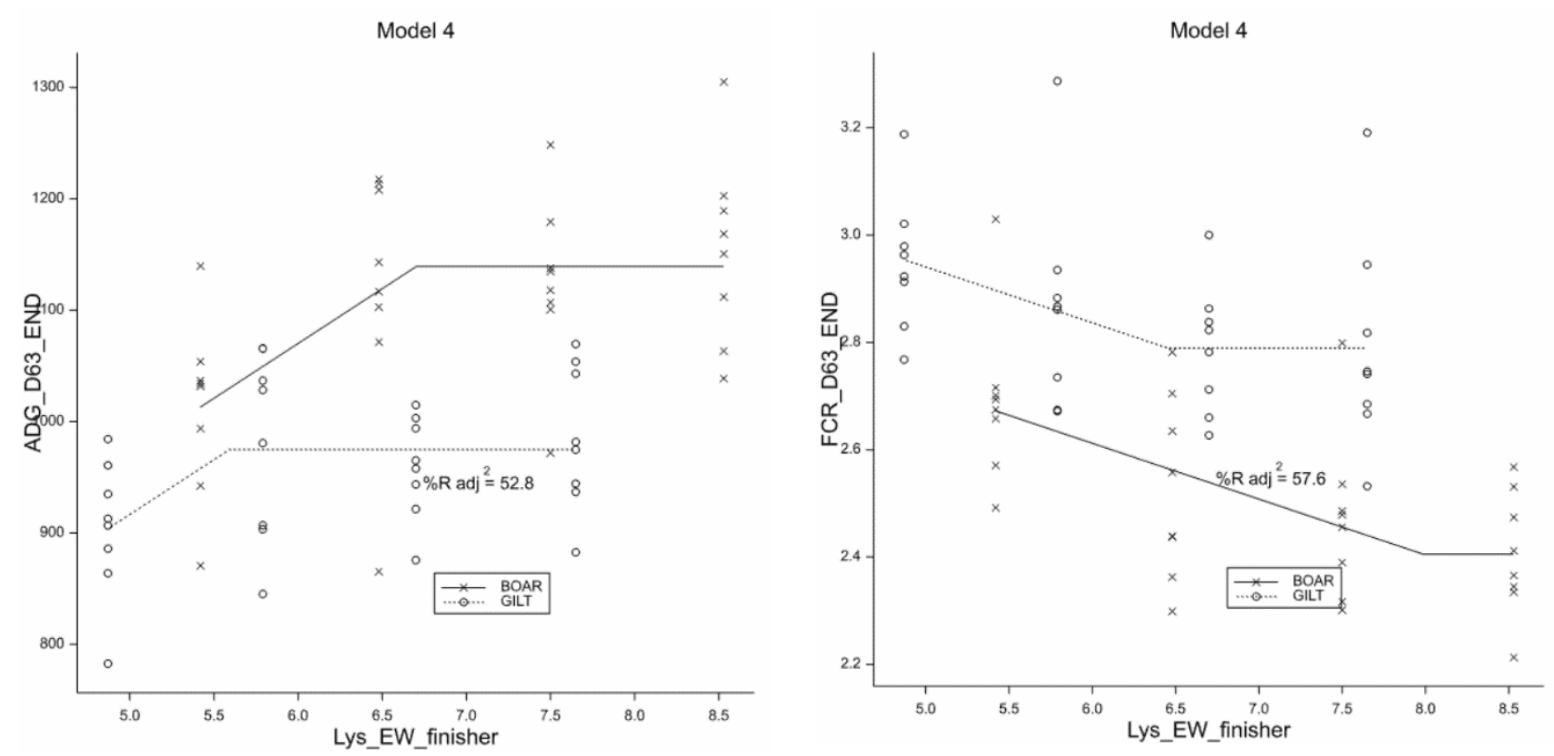

Figure 20 The effect of increasing standardized ileal digestible (SID) lysine ( $\left.\mathrm{g} / E W_{2015}\right)$ on ADG and FCR from day 63 until slaughter of all growing-finishing pigs using a broken-line model. The plateau, breakpoint (SID lysine in $\mathrm{g} / \mathrm{EW}_{2015}$ ) and slope below the breakpoint are presented for boars and gilts (Farm A). The plateau and breakpoint (model 4) for ADG and FCR differs between boars and gilts.

The results of the broken-line analysis for the variables ADG and FCR from start till day 35, day 35-63, day 63 till first delivery to the slaughterhouse and day 63 till slaughter are presented in Table 14 and Figures 21-24 for Farm B. 
Table 14 Estimated parameters of a broken-line model to describe the response of ADG and FCR of growing-finishing pigs to an increase in dietary standardized ileal digestible (SID) lysine ( $\left.g / E W_{2015}\right)$ from the start until day 35, day 35-63, day 63 until first delivery to the slaughterhouse and day 63 until slaughter of all pigs. The plateau (maximum ADG and minimum FCR), breakpoint (SID lysine in $\mathrm{g} / E W_{2015}$ ) and slope are presented for boars and gilts separately only in case of a significant sex effect $(P<0.05)$ on the respective parameter, whereas tendencies for a sex effect on breakpoint were also included (Farm B).

\begin{tabular}{|c|c|c|c|c|c|c|c|c|c|}
\hline & $\operatorname{sex}$ & plateau & $\mathbf{P}^{1}$ & $\begin{array}{l}\text { SID Lys } \\
\left(\mathrm{g} / \mathrm{E}_{2015}\right)\end{array}$ & $\mathbf{P}^{1}$ & slope & $\mathbf{P}^{1}$ & $\mathbf{R}^{2}$ & RMSE \\
\hline \multicolumn{10}{|c|}{ Start till day 35: } \\
\hline \multirow{2}{*}{$\operatorname{ADG}(\mathrm{g} / \mathrm{d})$} & Boar & $881 \pm 7.5$ & $(0.32)$ & $9.1 \pm 0.30$ & 0.074 & $74 \pm 11.8$ & & 66.9 & 43.4 \\
\hline & Gilt & & & $8.7 \pm 0.29$ & & & & & \\
\hline \multirow[t]{2}{*}{ FCR } & Boar & $1.70 \pm 0.030$ & $<0.001$ & $9.8 \pm 0.36$ & 0.12 & $-0.11 \pm 0.014$ & & 71.2 & 0.082 \\
\hline & Gilt & $1.85 \pm 0.021$ & & $8.9 \pm 0.34$ & & & & & \\
\hline \multicolumn{10}{|l|}{ Day 35-63: } \\
\hline \multirow[t]{2}{*}{$\operatorname{ADG}(g / d)$} & Boar & $952 \pm 8.1$ & $<0.001$ & $7.5 \pm 0.19$ & 0.11 & $75 \pm 10.4$ & & 77.8 & 32.9 \\
\hline & Gilt & $870 \pm 8.1$ & & $7.1 \pm 0.19$ & & & & & \\
\hline \multirow[t]{2}{*}{ FCR } & Boar & $2.26 \pm 0.019$ & $<0.001$ & $7.0 \pm 0.22$ & $(0.73)$ & $-0.21 \pm 0.045$ & & 69.5 & 0.098 \\
\hline & Gilt & $2.45 \pm 0.022$ & & & & & & & \\
\hline \multicolumn{10}{|c|}{ Day 63 till first delivery (D100): } \\
\hline \multirow[t]{2}{*}{$\operatorname{ADG}(g / d)$} & Boar & $922 \pm 10.0$ & $<0.001$ & $6.4 \pm 0.43$ & $(0.77)$ & $32 \pm 16.9$ & & 48.5 & 53.8 \\
\hline & Gilt & $831 \pm 11.5$ & & & & & & & \\
\hline \multirow[t]{2}{*}{ FCR } & Boar & $2.78 \pm 0.033$ & $<0.001$ & $6.5 \pm 0.19$ & $(0.84)$ & $-0.067 \pm 0.041$ & & 44.2 & 0.177 \\
\hline & Gilt & $3.07 \pm 0.038$ & & & & & & & \\
\hline \multicolumn{10}{|c|}{ Day 63 until slaughter: } \\
\hline \multirow[t]{2}{*}{ ADG $(g / d)$} & Boar & $899 \pm 7.6$ & $<0.001$ & $6.0 \pm 0.78$ & $(0.99)$ & $75 \pm 109$ & 0.60 & 60.1 & 39.6 \\
\hline & Gilt & $803 \pm 9.6$ & & & & $25 \pm 21$ & & & \\
\hline \multirow[t]{2}{*}{ FCR } & Boar & $2.82 \pm 0.02$ & $<0.001$ & $5.7 \pm 0.53$ & $(0.74)$ & $-0.71 \pm 1.60$ & 0.017 & 66.7 & 0.13 \\
\hline & Gilt & $3.22 \pm 0.02$ & & & & $-0.02 \pm 0.05$ & & & \\
\hline
\end{tabular}

${ }^{1} \mathrm{P}$-value of the sex effect on respective parameters; ${ }^{2}$ Adjusted $\mathrm{R}^{2}$, percentage of variance explained by the model.

Table 14 and Figure 21 show that from start till day 35 (the starter phase), the optimum SID lysine level for ADG in boars and gilts was 9.1 and $8.7 \mathrm{~g} / \mathrm{EW}_{2015}$, respectively. The optimum SID lysine level for FCR in boars and gilts was 9.8 and $8.9 \mathrm{~g} / \mathrm{EW}_{2015}$, respectively.

Table 14 and Figure 22 show that from day 35-63 (the grower phase), the optimum SID lysine level for ADG in boars and gilts was 7.5 and $7.1 \mathrm{~g} / \mathrm{EW}_{2015}$, respectively. The optimum SID lysine level for FCR in boars and gilts was $7.0 \mathrm{~g} / \mathrm{EW}_{2015}$.

Table 14 and Figure 23 show that from day 63 till first delivery, the optimum SID lysine level for ADG and FCR in boars and gilts combined was 6.4 and $6.5 \mathrm{~g} / \mathrm{EW}_{2015}$, respectively.

Table 14 and Figure 24 show that from day 63 till slaughter, the optimum SID lysine level for ADG and FCR in boars and gilts combined was 6.0 and $5.7 \mathrm{~g} / \mathrm{EW}_{2015}$, respectively. 

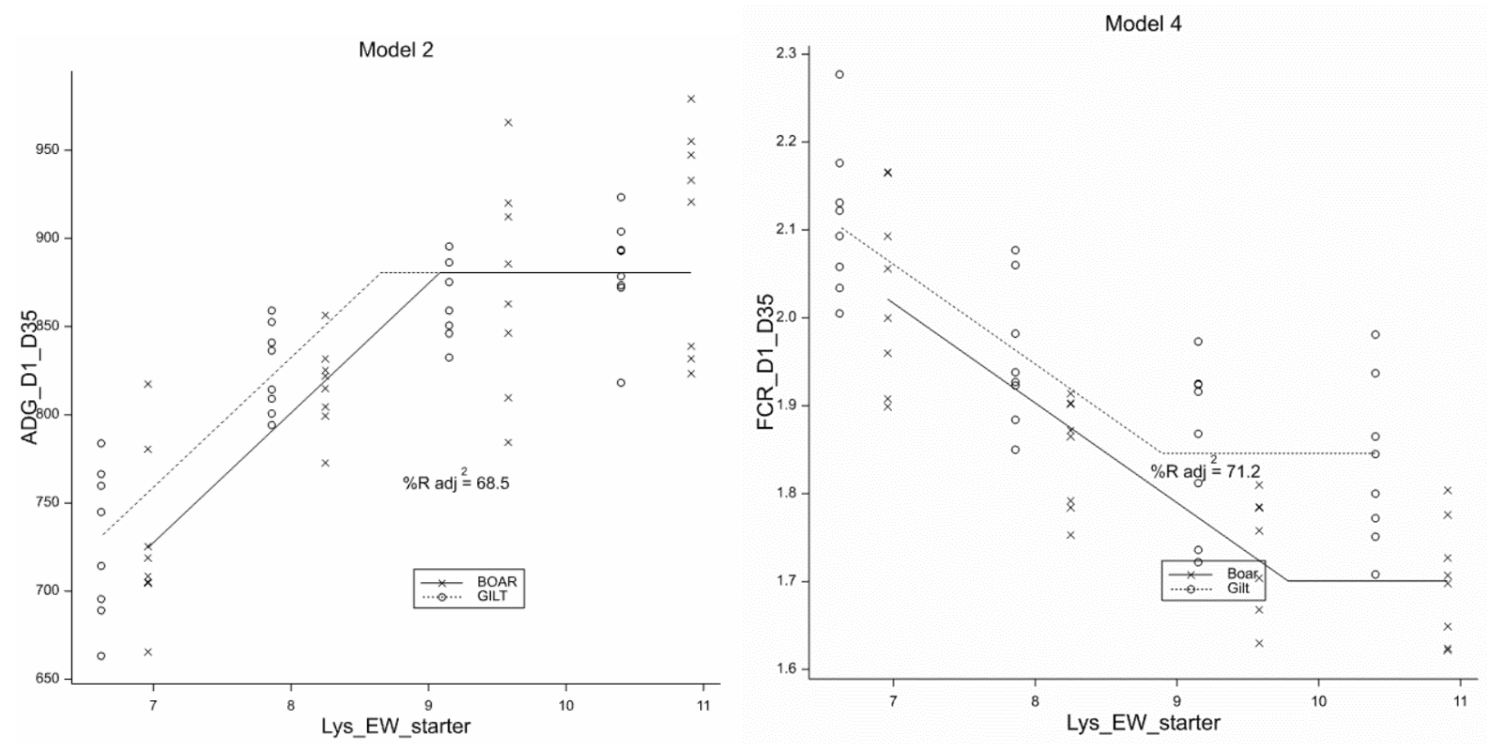

Figure 21 The effect of increasing standardized ileal digestible (SID) lysine ( $\left.\mathrm{g} / E W_{2015}\right)$ on ADG and FCR from the start till day 35 of growing-finishing pigs using a broken-line model. The plateau, breakpoint (SID lysine in $\mathrm{g} / \mathrm{EW}_{2015}$ ) and slope below the breakpoint are presented for boars and gilts (Farm B). For ADG, only the breakpoint differed significantly between boars and gilts. For FCR, the plateau and breakpoint (model 4) differed between boars and gilts.
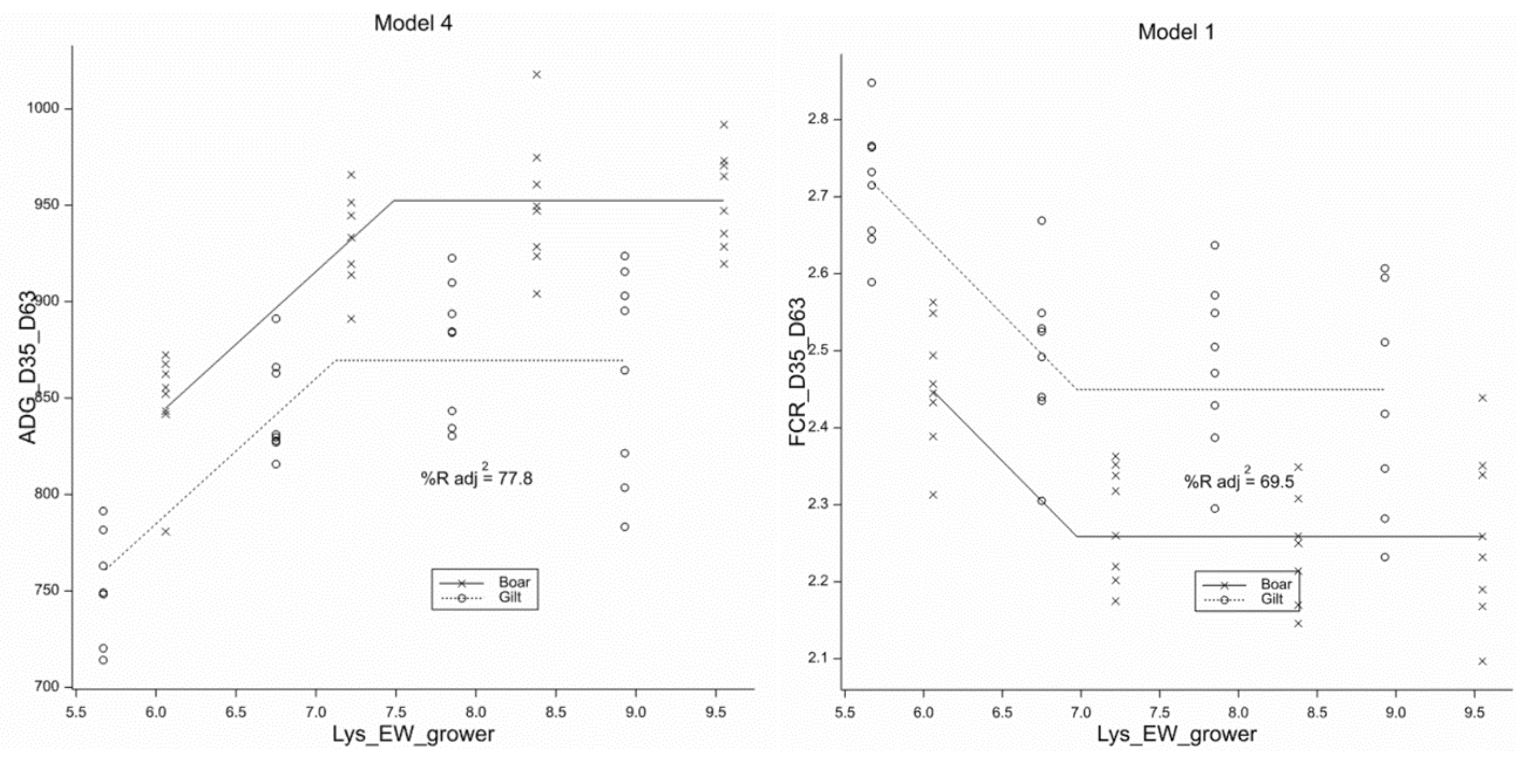

Figure 22 The effect of increasing standardized ileal digestible (SID) lysine ( $\left.\mathrm{g} / E W_{2015}\right)$ on ADG and FCR from day 35 till day 63 of growing-finishing pigs using a broken-line model. The plateau, breakpoint (SID lysine in $\mathrm{g} / \mathrm{EW}_{2015}$ ) and slope below the breakpoint are presented for boars and gilts (Farm B). For ADG, the plateau and breakpoint (model 4) differed between boars and gilts. For FCR, only the plateau (model 1) differed between boars and gilts. 

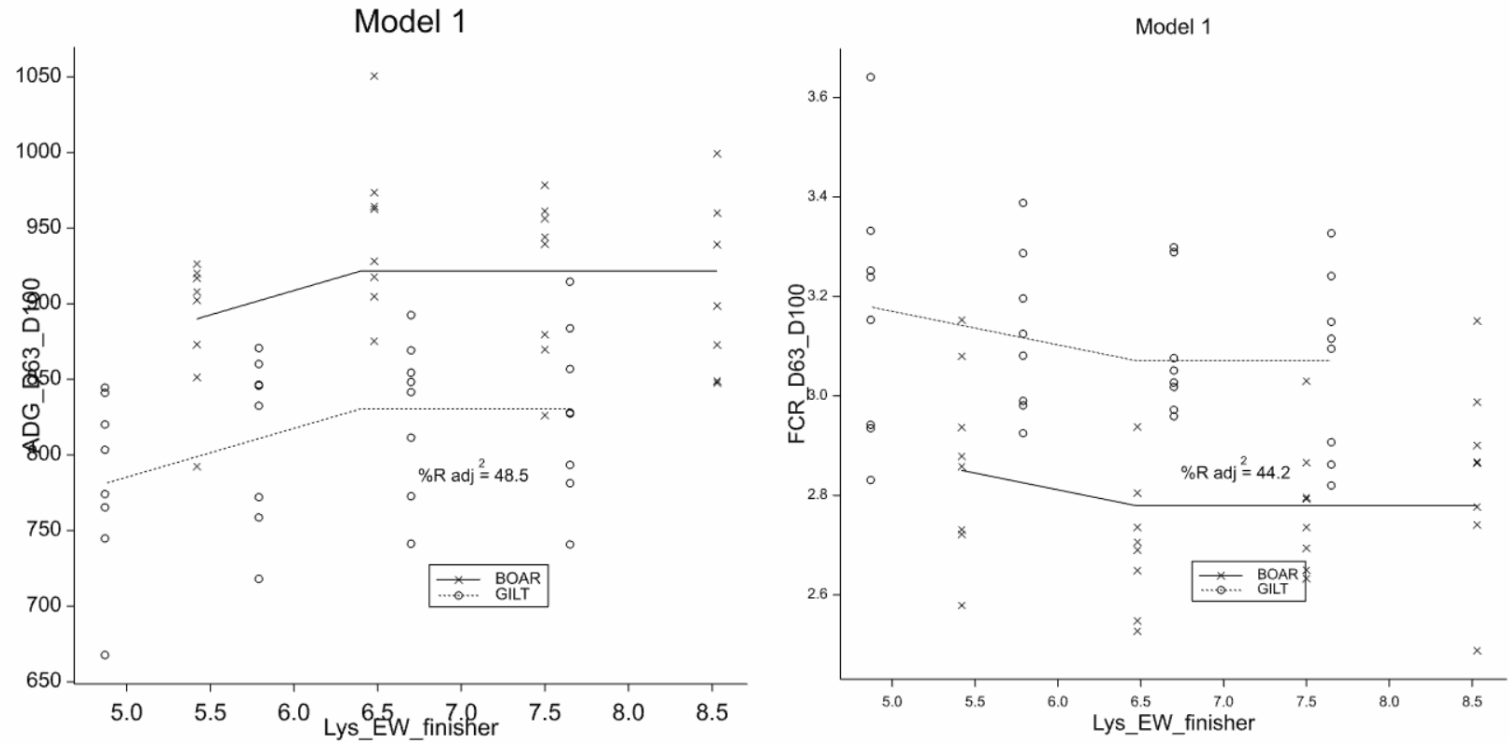

Figure 23 The effect of increasing standardized ileal digestible (SID) lysine ( $g / E W_{2015}$ ) on ADG and FCR from day 63 till first delivery of growing-finishing pigs using a broken-line model. The plateau, breakpoint (SID lysine in $\mathrm{g} / \mathrm{EW}_{2015}$ ) and slope below the breakpoint are presented for boars and gilts (Farm B). The plateau (model 1) for ADG and FCR differed between boars and gilts.
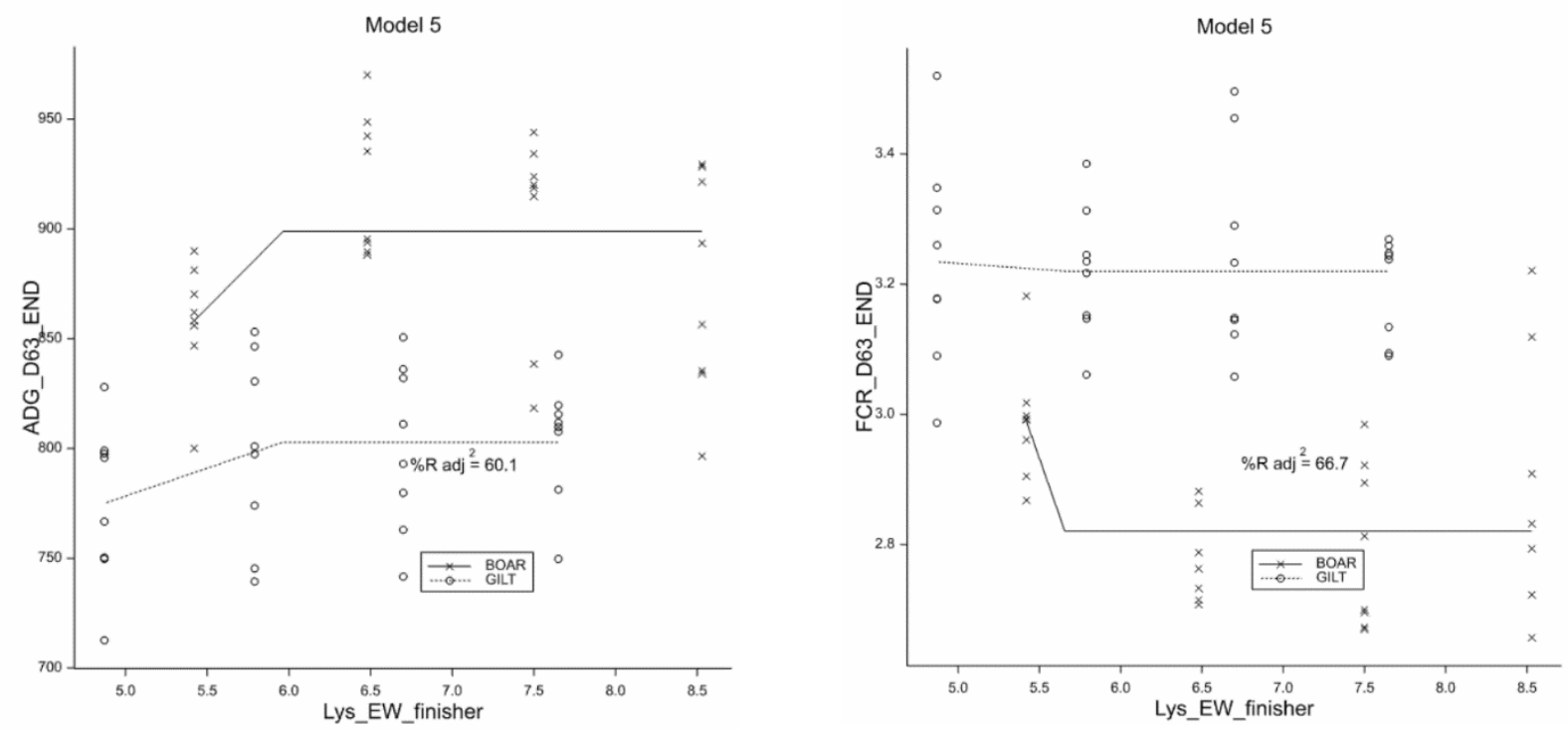

Figure 24 The effect of increasing standardized ileal digestible (SID) lysine ( $\left.\mathrm{g} / E W_{2015}\right)$ on ADG and FCR from day 63 until slaughter of growing-finishing pigs using a broken-line model. The plateau, breakpoint (SID lysine in $g / E W_{2015}$ ) and slope below the breakpoint are presented for boars and gilts (Farm B). The plateau and slope (model 5) for ADG and FCR differed between boars and gilts. 


\section{Discussion}

The goal of this experiment was to validate the updated SID lysine recommendations for current GF pigs (Van der Peet-Schwering and Bikker, 2018) on two farms with GF gilts and boars. In Table 15, the performance and SID lysine requirement of current and future GF (Van der Peet-Schwering and Bikker, 2018) as predicted with InraPorc (Van Milgen et al., 2008) is presented. Besides, the optimal dietary SID lysine level and corresponding ADG and FCR of the GF boars and gilts on Farm A and Farm $\mathrm{B}$ as estimated with broken-line analysis are presented in Table 15.

Table 15 ADG, FCR and standardized ileal digestible (SID) lysine requirement (in g/EW2015 and as a percentage of the recommended level for current growing and finishing (GF) male and female pigs) for the average current and future ${ }^{1}$ GF pig (Van der Peet-Schwering and Bikker, 2018) and the required dietary SID lysine level (breakpoint) and corresponding $A D G$ and FCR (plateau) of the GF pigs on Farm A and Farm B as estimated with brokenline analysis

\begin{tabular}{|c|c|c|c|c|c|c|c|c|}
\hline & \multicolumn{2}{|c|}{ Current GF pigs } & \multicolumn{2}{|c|}{$\begin{array}{c}\text { Future GF pigs: } 10 \% \\
\text { improved FCR }\end{array}$} & \multicolumn{2}{|c|}{ Farm A } & \multicolumn{2}{|c|}{ Farm B } \\
\hline & Boar & Gilt & Boar & Gilt & Boar & Gilt & Boar & Gilt \\
\hline ADG $(g / d)$ & 763 & 746 & 829 & 820 & 963 & 922 & 881 & 881 \\
\hline FCR & 1.90 & 2.03 & 1.75 & 1.85 & 1.67 & 1.81 & 1.70 & 1.85 \\
\hline $\begin{array}{l}\text { SID lysine (g/ } \\
\left.\mathrm{EW}_{2015}\right)\end{array}$ & 8.7 & 8.3 & 9.6 & 8.7 & $10.5-10.6^{2}$ & $9.0-9.5$ & $9.1-9.8$ & $8.7-8.9$ \\
\hline SID lysine (\%) & 100 & 100 & 110 & 105 & $121-122^{2}$ & $108-114$ & $105-113$ & $105-107$ \\
\hline \multicolumn{9}{|l|}{$50-80 \mathrm{~kg}:$} \\
\hline ADG $(g / d)$ & 924 & 893 & 1014 & 990 & 1126 & 1060 & 952 & 870 \\
\hline FCR & 2.18 & 2.37 & 1.99 & 2.10 & 2.11 & 2.29 & 2.26 & 2.45 \\
\hline \multicolumn{9}{|l|}{ 80-120 kg: } \\
\hline ADG $(\mathrm{g} / \mathrm{d})$ & 911 & 874 & 1012 & 960 & 1139 & 975 & 899 & 803 \\
\hline FCR & 2.62 & 2.87 & 2.37 & 2.56 & 2.41 & 2.79 & 2.82 & 3.22 \\
\hline $\begin{array}{l}\text { SID lysine (g/ } \\
\left.\mathrm{EW}_{2015}\right)\end{array}$ & 6.8 & 6.1 & 7.6 & 7.2 & $6.7-8.0$ & $5.6-6.5$ & $6.0-5.7$ & $6.0-5.7$ \\
\hline SID lysine (\%) & 100 & 100 & 112 & 117 & $99-118$ & $92-107$ & $88-84$ & $98-93$ \\
\hline
\end{tabular}

${ }^{1}$ The daily gain of the future growing and finishing pigs is $10 \%$ higher than the daily gain of the current growing and finishing pigs and is realized by a $10 \%$ improved feed conversion ratio; ${ }^{2}$ The optimal dietary SID lysine level ( $\mathrm{g} / \mathrm{EW} 2015$ and $\%$ ) is presented for ADG (first number) and FCR (second number).

\section{Starter phase}

During the starter phase $(20-50 \mathrm{~kg})$, the optimum dietary SID lysine level for ADG and FCR in boars on Farm A was 10.5 and $10.6 \mathrm{~g} / \mathrm{EW}_{2015}$ (121 and $122 \%$ of the recommended level for current GF boars), respectively. ADG and FCR in boars reached a plateau at $963 \mathrm{~g} / \mathrm{d}$ and 1.67 , respectively. In gilts on Farm A, the optimum SID lysine level for ADG and FCR was 9.0 and $9.5 \mathrm{~g} / \mathrm{EW}_{2015}$ (108 and $114 \%$ of the recommended level for current GF gilts), respectively. ADG and FCR in gilts reached a plateau at $922 \mathrm{~g} / \mathrm{d}$ and 1.81, respectively. ADG and FCR of the GF pigs on Farm A were better than ADG and FCR of the current and future GF pigs resulting in a higher SID lysine requirement than recommended for the current and future GF pigs during the starter phase.

On Farm B, the optimum dietary SID lysine level for ADG and FCR in boars during the starter phase was 9.1 and $9.8 \mathrm{~g} / \mathrm{EW}_{2015}$ (105 and $113 \%$ of the recommended level for current GF boars), respectively. ADG and FCR in boars reached a plateau at $881 \mathrm{~g} / \mathrm{d}$ and 1.70 , respectively. In gilts on Farm B, the optimum SID lysine level for ADG and FCR was 8.7 and 8.9 g/EW2015 (105 and 107\% of the recommended level for current GF gilts), respectively. ADG and FCR in gilts reached a plateau at $881 \mathrm{~g} / \mathrm{d}$ and 1.85, respectively. ADG of the GF pigs on Farm B was better than ADG of the current and 
future GF pigs whereas FCR of the GF pigs on Farm B corresponds to the FCR of the future GF pigs resulting in a higher SID lysine requirement than recommended for the current GF pigs.

Overall, the FCR of the pigs on both farms in the starter phase was slightly below (better) that of "future" pigs and in line with that, the estimated SID lysine requirements were somewhat above the values calculated for the future pigs (Table 15). The estimated requirements of the boars on farm $A$ were well above those of Farm $B$ and above the recommendation for future boars.

It can be concluded that the recommended SID levels in starter diets of 8.7 and $8.3 \mathrm{~g} / \mathrm{EW}_{2015}$ for current boars and gilts, respectively, are too low on both farms. For maximizing ADG and minimizing FCR, the recommended SID level in starter diets for boars and gilts was 10.6 and $9.5 \mathrm{~g} / \mathrm{EW}_{2015}$, respectively, on Farm A and 9.8 and $8.9 \mathrm{~g} / \mathrm{EW}_{2015}$, respectively, on Farm B.

\section{Grower phase}

During the grower phase $(50-80 \mathrm{~kg})$, the optimum dietary SID lysine level for ADG and FCR was not significantly affected by sex of the pigs, hence one estimate for the two sexes was made. For boars on Farm A this was 7.1 and $7.4 \mathrm{~g} / \mathrm{EW}_{2015}$ (93 and 97\% of the recommended level for current GF boars), respectively. ADG and FCR in boars reached a plateau at $1126 \mathrm{~g} / \mathrm{d}$ and 2.11 , respectively. In gilts on Farm A, the optimum SID lysine level for ADG and FCR was also 7.1 and $7.4 \mathrm{~g} / \mathrm{EW}_{2015}$ (100 and $104 \%$ of the recommended level for current GF gilts), respectively. ADG and FCR in gilts reached a plateau at $1060 \mathrm{~g} / \mathrm{d}$ and 2.29, respectively. ADG of the GF pigs on Farm A was higher than ADG of the current and future GF pigs whereas the FCR was slightly better than the FCR of the current GF pigs. This resulted in a slightly lower SID lysine requirement for boars and a slightly higher SID lysine requirement for gilts than recommended for the current GF pigs.

On Farm B, the optimum dietary SID lysine level for ADG and FCR in boars during the grower phase was 7.5 and $7.0 \mathrm{~g} / \mathrm{EW}_{2015}$ (99 and $92 \%$ of the recommended level for current GF boars), respectively. $A D G$ and FCR in boars reached a plateau at $952 \mathrm{~g} / \mathrm{d}$ and 2.26, respectively. In gilts on Farm $B$, the optimum SID lysine level for ADG and FCR is 7.1 and $7.0 \mathrm{~g} / \mathrm{EW}_{2015}$ (100 and 99\% of the recommended level for current GF gilts), respectively. ADG and FCR in gilts reached a plateau at $870 \mathrm{~g} / \mathrm{d}$ and 2.45, respectively. ADG of the GF pigs on Farm $B$ corresponds with the ADG of the current GF pigs, whereas FCR of the GF pigs on Farm B was slightly worse than in the current pigs. This results for both boars and gilts in a SID lysine requirement as recommended for current GF pigs.

It can be concluded that the recommended SID levels in grower diets of 7.6 and $7.1 \mathrm{~g} / \mathrm{EW}_{2015}$ for current boars and gilts, respectively, are in accordance with the SID lysine requirement of boars and gilts during the grower phase on Farm A and Farm B.

\section{Finisher phase}

During the finisher phase $(80-120 \mathrm{~kg})$, the optimum dietary SID lysine level for ADG and FCR in boars on Farm A was 6.7 and $8.0 \mathrm{~g} / \mathrm{EW}_{2015}$ (99 and $118 \%$ of the recommended level for current GF boars), respectively. ADG and FCR from day 63 till slaughter in boars reached a plateau at $1139 \mathrm{~g} / \mathrm{d}$ and 2.41 , respectively. In gilts on Farm A, the optimum SID lysine level for ADG and FCR was 5.6 and $6.5 \mathrm{~g} / \mathrm{EW}$ 2015 (92 and $107 \%$ of the recommended level for current GF gilts), respectively. ADG and FCR from day 63 till slaughter in gilts reached a plateau at $975 \mathrm{~g} / \mathrm{d}$ and 2.79, respectively. ADG of the boars on Farm A was better than ADG of the current and future boars whereas FCR corresponds with the FCR of the future boars resulting in a higher SID lysine requirement than recommended for the current boars during the finisher phase. ADG of the gilts on Farm A corresponds to ADG of the future gilts, whereas the FCR corresponds with the FCR of the current gilts resulting in a SID lysine requirement as recommended for current gilts.

On Farm B, the optimum dietary SID lysine level for ADG and FCR in boars during the finisher phase was 6.0 and $5.7 \mathrm{~g} / \mathrm{EW}_{2015}$ (88 and $84 \%$ of the recommended level for current GF boars), respectively. ADG and FCR from day 63 till slaughter in boars reached a plateau at $899 \mathrm{~g} / \mathrm{d}$ and 2.82, respectively. In gilts on Farm B, the optimum SID lysine level for ADG and FCR was also 6.4 and $5.7 \mathrm{~g} / \mathrm{EW}_{2015}(98 \%$ and $93 \%$ of the recommended level for current GF gilts). ADG and FCR from day 63 till slaughter in gilts reached a plateau at $803 \mathrm{~g} / \mathrm{d}$ and 3.22, respectively. ADG of the boars on Farm B corresponds with the ADG of the current boars whereas FCR was worse than in the current pigs resulting in a lower SID lysine requirement than recommended for the current boars. ADG and FCR of the gilts on Farm B 
are worse than of the current gilts resulting in a slightly lower SID lysine requirement than recommended for the current gilts.

It can be concluded that the recommended SID level in finisher diets of $6.8 \mathrm{~g} / \mathrm{EW}_{2015}$ for current boars, respectively, might be too low for boars on Farm A (not for maximizing ADG but for minimizing FCR) but is too high for boars on Farm B. The recommended SID level in finisher diets of $6.1 \mathrm{~g} / \mathrm{EW}_{2015}$ for current gilts might be too low for gilts on Farm A (not for maximizing ADG but for minimizing FCR) but is in accordance with the SID lysine requirement of gilts during the finisher phase on Farm B. For maximizing ADG and minimizing FCR, the recommended SID level in finisher diets for boars and gilts is 8.0 and $6.5 \mathrm{~g} / \mathrm{EW}_{2015}$, respectively, on Farm $A$ and 6.0 and $6.0 \mathrm{~g} / \mathrm{EW}_{2015}$, respectively, on Farm B.

Overall, some interesting observations based on the expected and determined growth performance and estimated requirements can be made:

- In general, the approach adopted by Van der Peet-Schwering and Bikker (2018) to define the growth performance based on ADG and FCR and derive the SID lysine requirements using InraPorc was confirmed by the present study. The difference in estimated requirements compared to recommendations for current pigs was largely explained by the lower or higher FCR realised in each phase on the two farms. The higher estimate of lysine requirements in the starter phase was in line with the lower (better) realised FCR compared to current pigs on both farms. The lower estimate of lysine requirements in the finisher phase was in line with the higher (worse) realised FCR compared to current pigs, especially on Farm B. Overall, the estimated lysine requirements were within $5 \%$ of expected values when the influence of FCR was taken into account. This result may give confidence to the approach based on InraPorc, using FCR as major criterion. The deviation in ADG between the two farms and the current pigs exceeded the differences in FCR. This was caused by differences in daily feed intake between the two farms and relative to the assumptions for current pigs. However, as demonstrated by Van der Peet-Schwering and Bikker (2018) differences in ADG mediated by feed intake have little effect on the optimal dietary SID lysine/EW 2015.

- The growth curve or description of the growth performance through different phases (Van der Peet and Bikker, 2018) using InraPorc did not adequately reflect the observed growth performance of the pigs on the two farms. Overall, the realised performance, especially FCR, was well above that of current pigs in the starter phase, relatively close to current pigs in the grower phase and, mainly on Farm B, below that of current pigs in the finisher phase. These results suggest that the growth curve of the pigs in VIC Sterksel, used to define the current pigs, deviates somewhat from the growth curve of the pigs on the two farms in the present study. For adequate application of lysine recommendations based on InraPorc, it would be recommended to (re)define the pigs on these two farms in InraPorc and to determine the growth and feed intake pattern on a representative group of farms. In Appendix 4, the boars and gilts on Farm A and Farm B are characterized with InraPorc and the SID lysine requirement estimated with broken-line analysis and based on InraPorc are presented.

- From the present study, it cannot be concluded that the recommendations for current pigs are inadequate. This depends on the mean performance level of present pig farms. The results, however, demonstrate that the pigs on the two farms in this study can already realise the performance level of future pigs, at least in the starter phase. It emphasises that for adequate application of the lysine recommendations of Van der Peet-Schwering and Bikker (2018) on individual farm level, it is necessary to obtain an adequate description of the growth performance of the pigs on the target farm in the starter, grower and finisher phase. This information can be used for a farm specific application of the general recommendations.

- InraPorc can be a good tool for nutritionist to predict the SID lysine requirement for growing and finishing boars and gilt on farms in practice. Information on both overall performance (ADG, ADFI and FCR) and performance during the starter, grower and finisher phase, however, is necessary for an accurate prediction of SID lysine requirement during all phases. 


\section{Conclusions}

Based on the results of this study, the following conclusions were drawn:

- In general, the approach adopted by Van der Peet-Schwering and Bikker (2018) to define the growth performance based on ADG and FCR and derive the SID lysine requirements using InraPorc was confirmed by the present study. Adequate farm specific typing of growth performance of the pigs is crucial. The growth curve on a farm may deviate from that used for the current GF pigs in Van der Peet-Schwering and Bikker (2018).

- $\quad$ The recommended SID levels in starter diets of 8.7 and $8.3 \mathrm{~g} / \mathrm{EW}_{2015}$ for current boars and gilts, respectively, were too low for the farms in this study. For maximizing ADG and minimizing FCR, the recommended SID levels in starter diets for boars and gilts were 10.6 and $9.5 \mathrm{~g} / \mathrm{EW}_{2015}$, respectively, on Farm $A$ and 9.8 and 9.0 g/EW2015, respectively, on Farm B.

- The recommended SID levels in grower diets of 7.6 and $7.1 \mathrm{~g} / \mathrm{EW}_{2015}$ for current boars and gilts, respectively, are in accordance with the SID lysine requirement of boars and gilts during the grower phase on Farm A and Farm B.

- $\quad$ The recommended SID level in finisher diets of $6.8 \mathrm{~g} / \mathrm{EW}_{2015}$ for current boars might be too low for boars on Farm A (for minimizing FCR, not for maximizing ADG) but too high for boars on Farm $B$. The recommended SID level in finisher diets of $6.1 \mathrm{~g} / \mathrm{EW}_{2015}$ for current gilts might be too low for gilts on Farm A (for minimizing FCR, not for maximizing ADG) but is in accordance with the SID lysine requirement of gilts during the finisher phase on Farm B. For maximizing ADG and minimizing FCR, the recommended SID levels in finisher diets for boars and gilts were 8.0 and 6.5 g/EW2015, respectively, on Farm A and 6.0 and 6.0 g/EW2015, respectively, on Farm B.

- The difference in estimated requirements on Farm A and Farm B compared to recommendations for current pigs was largely explained by FCR realised in each phase on the two farms, relative to the FCR of current pigs. 


\section{References}

AgroVision. 2017. Kengetallenspiegel 2016. Bedrijfsvergelijking AgroVision B.V.

GenStat. 2018. GenStat for Windows 18th Edition. VSN International Ltd. Hemel Hempstead, UK.

Uniformeringsafspraken Varkenshouderij. 2012. www.agroconnect.nl.

Van Milgen, J.M., A. Valancogne, S. Dubois, J.Y. Dourmad, B. Sève and J. Noblet. 2008. InraPorc: A model and decision support tool for the nutrion of growing pigs. Animal Feed Science and Technology, 143, 387-405.

Van der Peet-Schwering, C.M.C. and P. Bikker. 2018. Amino acid requirement of growing and finishing pigs. Report 1101, Wageningen Livestock Research, Wageningen.

Van der Peet-Schwering, C.M.C., S.B. Straathof, G.P. Binnendijk and J.Th.M. van Diepen. 2012. Influence of diet composition and level of AA on performance of boars, barrows and gilts. Rapport 563 [in Dutch], Wageningen Livestock Research, Wageningen. 


\section{Appendix 1 Composition of the diets (\%)}

\begin{tabular}{|c|c|c|c|c|c|c|c|}
\hline & & $\begin{array}{c}\text { Starter } \\
\text { diet } \\
125 \% \\
\end{array}$ & $\begin{array}{c}\begin{array}{c}\text { Starter } \\
\text { diet }\end{array} \\
\mathbf{8 0 \%} \\
\end{array}$ & $\begin{array}{c}\text { Grower } \\
\text { diet } \\
125 \% \\
\end{array}$ & $\begin{array}{c}\text { Grower } \\
\text { diet } \\
\mathbf{8 0} \% \\
\end{array}$ & $\begin{array}{c}\text { Finisher } \\
\text { diet } \\
125 \% \\
\end{array}$ & $\begin{array}{c}\text { Finisher } \\
\text { diet } \\
\mathbf{8 0 \%} \\
\end{array}$ \\
\hline Barley & & 20.0 & 20.0 & 23.0 & 23.0 & 23.0 & 23.0 \\
\hline Wheat & & 22.0 & 25.0 & 18.0 & 20.0 & 18.0 & 18.0 \\
\hline Maize & & 19.4 & 20.0 & 24.9 & 25.0 & 26.1 & 26.4 \\
\hline Soybean meal & & 20.0 & 16.4 & 12.2 & 10.0 & 5.0 & 4.0 \\
\hline Sunflower seed meal & & 7 & 7.0 & 10.0 & 9.3 & 11.0 & 10.2 \\
\hline Rapeseed meal & & 5.5 & 6.0 & 6.1 & 7.0 & 9.5 & 9.5 \\
\hline Wheat middlings & & - & - & - & - & 3.4 & 5.0 \\
\hline Palm oil & & 0.20 & 0.35 & - & - & - & - \\
\hline Molasses & & 1.5 & 2.0 & 2.0 & 3.0 & 1.5 & 2.3 \\
\hline Monocalcium phosphate & & 0.21 & 0.36 & - & - & - & - \\
\hline Salt & & 0.54 & 0.55 & 0.55 & 0.53 & 0.35 & 0.39 \\
\hline Limestone & & 1.1 & 1.0 & 1.1 & 1.1 & 1.0 & 1.0 \\
\hline Premix & & 0.23 & 0.23 & 0.20 & 0.20 & 0.20 & 0.20 \\
\hline Phytase & & 0.01 & 0.01 & 0.02 & 0.02 & 0.01 & 0.01 \\
\hline Syn lysine L liquid 50\% & & 0.75 & - & 0.75 & - & 0.74 & - \\
\hline Syn methionine DL98 & & 0.17 & - & 0.12 & - & 0.07 & - \\
\hline Syn threonine L98 & & 0.22 & - & 0.20 & - & 0.18 & - \\
\hline Syn tryptophan 98 & & 0.04 & - & 0.03 & - & 0.03 & - \\
\hline Syn valine 97 & & 0.04 & - & 0.02 & - & 0.00 & - \\
\hline Acid & & 1.1 & 1.1 & 0.9 & 0.9 & - & - \\
\hline \multicolumn{8}{|l|}{ Calculated nutrients } \\
\hline $\mathrm{EW}_{2015}$ & & 1.10 & 1.10 & 1.10 & 1.10 & 1.10 & 1.10 \\
\hline Crude ash & $\mathrm{g} / \mathrm{kg}$ & 52 & 52 & 50 & 49 & 47 & 48 \\
\hline Calcium & $\mathrm{g} / \mathrm{kg}$ & 6.2 & 6.2 & 6.1 & 6.1 & 5.9 & 5.9 \\
\hline Phosphorus & $\mathrm{g} / \mathrm{kg}$ & 4.7 & 4.9 & 4.3 & 4.2 & 4.7 & 4.6 \\
\hline Digestible P & $\mathrm{g} / \mathrm{kg}$ & 2.9 & 2.9 & 2.5 & 2.5 & 2.4 & 2.4 \\
\hline $\mathrm{Na}$ & $\mathrm{g} / \mathrm{kg}$ & 2.4 & 2.4 & 2.4 & 2.4 & 1.6 & 1.8 \\
\hline Crude protein & $\mathrm{g} / \mathrm{kg}$ & 205 & 189 & 187 & 174 & 174 & 163 \\
\hline Crude fibre & $\mathrm{g} / \mathrm{kg}$ & 48 & 47 & 51 & 51 & 57 & 57 \\
\hline Starch & $\mathrm{g} / \mathrm{kg}$ & 388 & 405 & 410 & 422 & 423 & 428 \\
\hline Crude fat & $\mathrm{g} / \mathrm{kg}$ & 30 & 32 & 29 & 29 & 31 & 31 \\
\hline $\mathrm{dEB}$ & meq & 228 & 219 & 206 & 209 & 184 & 190 \\
\hline IK & $\mathrm{g} / \mathrm{kg}$ & 68 & 69 & 75 & 76 & 89 & 91 \\
\hline FK & $\mathrm{g} / \mathrm{kg}$ & 116 & 112 & 107 & 105 & 107 & 107 \\
\hline SID lysine ${ }^{1}$ & $\mathrm{~g} / \mathrm{kg}$ & 12.0 & 7.3 & 10.5 & 6.24 & 9.38 & 5.36 \\
\hline SID met+cys/SID lysine & & 0.63 & 0.77 & 0.64 & 0.87 & 0.65 & 0.99 \\
\hline SID threonine/SID lysine & & 0.69 & 0.78 & 0.70 & 0.82 & 0.71 & 0.88 \\
\hline SID tryptophan/SID lysine & & 0.21 & 0.27 & 0.21 & 0.29 & 0.21 & 0.31 \\
\hline SID isoleucine/SID lysine & & 0.58 & 0.89 & 0.58 & 0.92 & 0.57 & 0.96 \\
\hline SID leucine/SID lysine & & 1.06 & 1.63 & 1.08 & 1.74 & 1.10 & 1.86 \\
\hline SID valine/SID lysine & & 0.70 & 1.03 & 0.70 & 1.10 & 0.70 & 1.19 \\
\hline
\end{tabular}




\begin{tabular}{|c|c|c|c|c|c|c|c|}
\hline SID histidine/SID lysine & & 0.36 & 0.56 & 0.36 & 0.59 & 0.37 & 0.63 \\
\hline Vitamin D3 (3a671) & IE & 2000 & 2000 & 1000 & 1000 & 1000 & 1000 \\
\hline Vitamin A (3a672a) & IE & 6500 & 6500 & 5000 & 5000 & 5000 & 5000 \\
\hline Vitamin E (3a700) & IE & 47 & 47 & 40 & 40 & 40 & 40 \\
\hline Total phytase added ${ }^{1}$ & FTU & 550 & 550 & 700 & 700 & 500 & 500 \\
\hline Lysine & $\mathrm{g} / \mathrm{kg}$ & 13.3 & 8.7 & 11.7 & 7.4 & 10.6 & 6.6 \\
\hline Methionine & $\mathrm{g} / \mathrm{kg}$ & 4.9 & 3.1 & 4.2 & 3 & 3.7 & 3 \\
\hline Threonine & $\mathrm{g} / \mathrm{kg}$ & 9.5 & 6.8 & 8.5 & 6.3 & 7.8 & 5.9 \\
\hline Tryptophan & $\mathrm{g} / \mathrm{kg}$ & 2.9 & 2.4 & 2.6 & 2.2 & 2.4 & 2.1 \\
\hline Isoleucine & $\mathrm{g} / \mathrm{kg}$ & 8.0 & 7.5 & 7.0 & 6.7 & 6.3 & 6.1 \\
\hline Leucine & $\mathrm{g} / \mathrm{kg}$ & 14.7 & 13.8 & 13.1 & 12.7 & 12.1 & 11.7 \\
\hline Valine & $\mathrm{g} / \mathrm{kg}$ & 9.9 & 8.9 & 8.7 & 8.2 & 8.0 & 7.7 \\
\hline Histidine & $\mathrm{g} / \mathrm{kg}$ & 4.9 & 4.6 & 4.4 & 4.2 & 4.0 & 3.9 \\
\hline Cysteine & $\mathrm{g} / \mathrm{kg}$ & 3.6 & 3.5 & 3.4 & 3.4 & 3.4 & 3.4 \\
\hline Phenylalanine & $\mathrm{g} / \mathrm{kg}$ & 9.6 & 9.0 & 8.5 & 8.2 & 7.8 & 7.5 \\
\hline Tyrosine & $\mathrm{g} / \mathrm{kg}$ & 6.2 & 5.7 & 5.4 & 5.1 & 4.8 & 4.7 \\
\hline Arginine & $\mathrm{g} / \mathrm{kg}$ & 13.1 & 12.1 & 11.6 & 11.0 & 10.7 & 10.2 \\
\hline Glycine & $\mathrm{g} / \mathrm{kg}$ & 8.8 & 8.4 & 8.2 & 7.9 & 7.8 & 7.6 \\
\hline Alanine & $\mathrm{g} / \mathrm{kg}$ & 8.7 & 8.2 & 8.0 & 7.7 & 7.5 & 7.3 \\
\hline Asparagine & $\mathrm{g} / \mathrm{kg}$ & 17.8 & 16.2 & 15.0 & 14.1 & 12.9 & 12.3 \\
\hline Glutamic acid & $\mathrm{g} / \mathrm{kg}$ & 40.0 & 38.3 & 36.3 & 35.6 & 34.0 & 33.3 \\
\hline Proline & $\mathrm{g} / \mathrm{kg}$ & 12.8 & 12.5 & 11.8 & 11.7 & 11.4 & 11.3 \\
\hline Serine & $\mathrm{g} / \mathrm{kg}$ & 9.3 & 8.7 & 8.1 & 7.8 & 7.4 & 7.2 \\
\hline
\end{tabular}

${ }^{1}$ in the diets $0.13 \mathrm{~g}$ of SID lysine is attributed to phytase 


\section{Appendix 2 Analysed nutrients with NIR ( $\mathrm{g} / \mathrm{kg})$}

\begin{tabular}{|c|c|c|c|c|c|c|}
\hline & 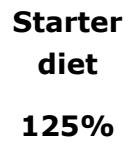 & $\begin{array}{c}\text { Starter } \\
\text { diet } \\
\mathbf{8 0} \%\end{array}$ & $\begin{array}{c}\text { Grower } \\
\text { diet } \\
125 \%\end{array}$ & $\begin{array}{c}\text { Grower } \\
\text { diet } \\
80 \%\end{array}$ & $\begin{array}{c}\text { Finisher } \\
\text { diet } \\
125 \%\end{array}$ & $\begin{array}{c}\text { Finisher } \\
\text { diet } \\
\mathbf{8 0 \%}\end{array}$ \\
\hline \multicolumn{7}{|l|}{ Farm A } \\
\hline No of feed deliveries & 6 & 6 & 6 & 6 & 4 & 5 \\
\hline Crude protein & 202 & 186 & 184 & 173 & 173 & 165 \\
\hline Moisture & 124 & 121 & 122 & 120 & 113 & 114 \\
\hline Crude ash & 55 & 48 & 52 & 45 & 51 & 45 \\
\hline Crude fibre & 48 & 49 & 53 & 52 & 57 & 57 \\
\hline Crude fat & 30 & 32 & 29 & 30 & 35 & 36 \\
\hline Starch & 376 & 400 & 401 & 422 & 418 & 434 \\
\hline Sugar & 53 & 47 & 48 & 47 & 47 & 45 \\
\hline \multicolumn{7}{|l|}{ Farm B } \\
\hline No of feed deliveries & 4 & 4 & 5 & 5 & 11 & 11 \\
\hline Crude protein & 202 & 187 & 184 & 173 & 175 & 166 \\
\hline Moisture & 124 & 122 & 121 & 121 & 117 & 117 \\
\hline Crude ash & 54 & 46 & 52 & 45 & 50 & 43 \\
\hline Crude fibre & 47 & 47 & 52 & 51 & 56 & 56 \\
\hline Crude fat & 30 & 32 & 29 & 30 & 34 & 35 \\
\hline Starch & 378 & 404 & 407 & 425 & 416 & 433 \\
\hline Sugar & 55 & 51 & 47 & 46 & 47 & 44 \\
\hline
\end{tabular}




\section{Appendix 3 Analysed nutrient composition ( $\mathrm{g} / \mathrm{kg})$}

\begin{tabular}{|c|c|c|c|c|c|c|}
\hline & $\begin{array}{c}\text { Starter } \\
\text { diet } \\
125 \%\end{array}$ & $\begin{array}{c}\text { Starter } \\
\text { diet } \\
\mathbf{8 0} \%\end{array}$ & $\begin{array}{c}\text { Grower } \\
\text { diet } \\
125 \%\end{array}$ & $\begin{array}{c}\text { Grower } \\
\text { diet } \\
\mathbf{8 0} \%\end{array}$ & $\begin{array}{c}\text { Finisher } \\
\text { diet } \\
125 \%\end{array}$ & $\begin{array}{c}\text { Finisher } \\
\text { diet } \\
\mathbf{8 0 \%}\end{array}$ \\
\hline \multicolumn{7}{|l|}{ Farm A } \\
\hline Dry matter & 876 & 879 & 878 & 881 & 885 & 885 \\
\hline Crude protein & 210 & 189 & 189 & 173 & 176 & 164 \\
\hline Crude ash & 51 & 50 & 46 & 46 & 44 & 44 \\
\hline Crude fat & 26 & 28 & 25 & 26 & 28 & 29 \\
\hline Starch & 356 & 377 & 391 & 402 & 399 & 403 \\
\hline Sugar & 58 & 58 & 55 & 58 & 51 & 54 \\
\hline Crude fibre & 49 & 51 & 55 & 55 & 59 & 57 \\
\hline ASP & 17.32 & 15.52 & 14.76 & 13.65 & 12.43 & 11.71 \\
\hline THR & 9.24 & 6.72 & 8.32 & 6.30 & 7.61 & 5.79 \\
\hline SER & 8.08 & 7.16 & 7.32 & 6.65 & 6.22 & 6.02 \\
\hline GLU & 38.64 & 36.52 & 35.80 & 34.03 & 32.74 & 31.75 \\
\hline GLY & 8.84 & 8.33 & 8.28 & 7.83 & 7.83 & 7.56 \\
\hline ALA & 8.79 & 8.25 & 8.10 & 7.72 & 7.55 & 7.27 \\
\hline VAL & 9.97 & 8.99 & 8.91 & 8.37 & 8.15 & 7.85 \\
\hline ILE & 8.20 & 7.63 & 7.35 & 6.89 & 6.53 & 6.17 \\
\hline LEU & 14.43 & 13.48 & 13.22 & 12.43 & 11.85 & 11.36 \\
\hline TYR & 6.96 & 6.53 & 6.28 & 5.87 & 5.39 & 5.35 \\
\hline PHE & 9.36 & 8.65 & 8.55 & 8.01 & 7.53 & 7.24 \\
\hline HIS & 5.69 & 5.30 & 5.08 & 4.87 & 4.83 & 4.56 \\
\hline LYS & 13.54 & 9.02 & 11.89 & 7.71 & 10.78 & 6.84 \\
\hline ARG & 13.24 & 12.02 & 11.90 & 10.95 & 10.73 & 10.15 \\
\hline PRO & 13.23 & 12.30 & 12.21 & 11.77 & 11.62 & 11.54 \\
\hline TRYP & 2.89 & 2.45 & 2.66 & 2.28 & 2.44 & 2.20 \\
\hline CYS.ox & 3.54 & 3.46 & 3.37 & 3.36 & 3.28 & 3.33 \\
\hline MET.ox & 4.71 & 3.04 & 4.08 & 2.93 & 3.67 & 2.94 \\
\hline \multicolumn{7}{|l|}{ Free AA: } \\
\hline ASP & 0.33 & 0.33 & 0.34 & 0.36 & 0.35 & 0.36 \\
\hline THR & 2.33 & 0.34 & 2.27 & 0.42 & 2.09 & 0.40 \\
\hline SER & 0.07 & 0.05 & 0.07 & 0.07 & 0.06 & 0.06 \\
\hline GLU & 0.50 & 0.49 & 0.48 & 0.45 & 0.45 & 0.43 \\
\hline GLY & 0.05 & 0.05 & 0.05 & 0.05 & 0.05 & 0.05 \\
\hline ALA & 0.17 & 0.16 & 0.18 & 0.18 & 0.16 & 0.18 \\
\hline VAL & 0.47 & 0.08 & 0.28 & 0.07 & 0.07 & 0.07 \\
\hline ILE & 0.06 & 0.06 & 0.06 & 0.06 & 0.06 & 0.06 \\
\hline LEU & 0.05 & 0.04 & 0.04 & 0.04 & 0.04 & 0.04 \\
\hline TYR & 0.00 & 0.00 & 0.00 & 0.00 & 0.00 & 0.00 \\
\hline PHE & 0.00 & 0.00 & 0.00 & 0.00 & 0.00 & 0.00 \\
\hline HIS & 0.22 & 0.14 & 0.20 & 0.15 & 0.17 & 0.13 \\
\hline
\end{tabular}




$\begin{array}{lllllll}\text { LYS } & 3.69 & 0.19 & 3.74 & 0.18 & 3.65 & 0.14 \\ \text { ARG } & 0.33 & 0.30 & 0.26 & 0.22 & 0.20 & 0.18 \\ \text { PRO } & 0.15 & 0.16 & 0.18 & 0.14 & 0.20 & 0.17 \\ \text { MET } & 1.42 & 0.00 & 1.00 & 0.00 & 0.65 & 0.00\end{array}$

\section{Farm B}

Dry matter

Crude protein

Crude ash

Crude fat

Starch

Sugar

Crude fibre

$\begin{array}{cccccc}878 & 881 & 878 & 880 & 888 & 887 \\ 209 & 191 & 191 & 176 & 173 & 165 \\ 50 & 50 & 47 & 47 & 44 & 44 \\ 27 & 28 & 26 & 26 & 28 & 30 \\ 361 & 375 & 378 & 401 & 399 & 396 \\ 57 & 57 & 55 & 58 & 52 & 54 \\ 49 & 48 & 55 & 54 & 62 & 60\end{array}$

ASP

THR

SER

GLU

GLY

ALA

VAL

ILE

LEU

TYR

PHE

HIS

LYS

ARG

PRO

TRYP

CYS.OX

MET.ox

$\begin{array}{cccccc}16.94 & 15.21 & 14.54 & 13.99 & 12.75 & 12.07 \\ 8.89 & 6.65 & 8.25 & 6.53 & 7.81 & 6.05 \\ 7.75 & 7.42 & 6.91 & 6.98 & 6.57 & 6.44 \\ 37.99 & 36.54 & 34.69 & 34.76 & 33.22 & 32.48 \\ 8.65 & 8.22 & 8.09 & 8.05 & 7.95 & 7.71 \\ 8.68 & 8.12 & 7.97 & 7.89 & 7.68 & 7.48 \\ 9.82 & 8.90 & 8.77 & 8.44 & 8.30 & 8.06 \\ 8.12 & 7.49 & 7.12 & 7.00 & 6.55 & 6.29 \\ 14.33 & 13.27 & 12.83 & 12.63 & 11.98 & 11.59 \\ 6.92 & 6.48 & 6.03 & 5.97 & 5.60 & 5.35 \\ 9.35 & 8.57 & 8.33 & 8.07 & 7.75 & 7.42 \\ 5.70 & 5.36 & 5.07 & 4.80 & 4.78 & 4.63 \\ 13.18 & 8.78 & 11.60 & 7.77 & 10.74 & 6.92 \\ 12.86 & 12.01 & 11.40 & 11.28 & 10.79 & 10.25 \\ 13.11 & 12.49 & 11.77 & 12.24 & 12.08 & 11.87 \\ 3.00 & 2.56 & 2.67 & 2.31 & 2.49 & 2.21 \\ 3.51 & 3.65 & 3.41 & 3.32 & 3.36 & 3.36 \\ 4.73 & 3.05 & 4.03 & 2.91 & 3.68 & 2.99\end{array}$

Free AA:

\begin{tabular}{|c|c|c|c|c|c|c|}
\hline ASP & 0.33 & 0.32 & 0.32 & 0.39 & 0.34 & 0.36 \\
\hline THR & 2.36 & 0.38 & 2.25 & 0.45 & 2.12 & 0.39 \\
\hline SER & 0.07 & 0.06 & 0.07 & 0.08 & 0.07 & 0.07 \\
\hline GLU & 0.53 & 0.48 & 0.47 & 0.47 & 0.43 & 0.44 \\
\hline GLY & 0.06 & 0.05 & 0.05 & 0.05 & 0.05 & 0.05 \\
\hline ALA & 0.17 & 0.17 & 0.18 & 0.18 & 0.16 & 0.17 \\
\hline VAL & 0.48 & 0.08 & 0.26 & 0.08 & 0.07 & 0.07 \\
\hline ILE & 0.07 & 0.06 & 0.06 & 0.07 & 0.06 & 0.06 \\
\hline LEU & 0.05 & 0.05 & 0.04 & 0.05 & 0.04 & 0.04 \\
\hline TYR & 0.00 & 0.00 & 0.00 & 0.00 & 0.00 & 0.00 \\
\hline PHE & 0.00 & 0.00 & 0.00 & 0.00 & 0.00 & 0.00 \\
\hline HIS & 0.17 & 0.23 & 0.16 & 0.14 & 0.20 & 0.19 \\
\hline LYS & 3.79 & 0.23 & 3.70 & 0.20 & 3.63 & 0.12 \\
\hline ARG & 0.35 & 0.28 & 0.26 & 0.24 & 0.23 & 0.19 \\
\hline PRO & 0.17 & 0.17 & 0.14 & 0.18 & 0.16 & 0.20 \\
\hline MET & 1.45 & 0.00 & 0.96 & 0.00 & 0.62 & 0.00 \\
\hline
\end{tabular}




\section{Appendix 4 SID lysine requirements on Farm A and B predicted with InraPorc}

In Table 1, the characterization of the boars and gilts on Farm A and Farm B and the performance and SID lysine requirements based on InraPorc (Van Milgen et al., 2008) are presented. Characterization of the boars and gilts on Farm A, based on overall performance and on performance during the starter, grower and finisher phase, was successful. On Farm B, it was more difficult to characterize the pigs properly. Because all the GF pigs were weighed at $1^{\text {st }}$ delivery (the remaining pigs at second or third delivery were not weighed when they were delivered to the slaughterhouse), we decided to characterize the pigs on Farm B based on the performance from start till $1^{\text {st }}$ delivery and based on the performance during the starter, grower and finisher (till $1^{\text {st }}$ delivery) phase. In this way, the characterization of the boars on Farm B was quite successful. The characterization of the gilts on Farm $B$, however, was less successful, as the FRC during the starter, grower and finisher phase as predicted with InraPorc was somewhat higher than measured in this trial.

For all three phases $(25-50 \mathrm{~kg}, 50-80 \mathrm{~kg}$ and $80-120 \mathrm{~kg}$ ), the SID lysine requirement on Farm A and Farm B estimated with broken-line analysis (this trial) and based on InraPorc are presented. The daily SID lysine required for maintenance and protein deposition and the daily excess or deficiency of SID lysine during the growing-finishing period for the boars and gilts on Farm A and Farm B is presented in Figures 1-8. 
Table 1 Characterization of the boars and gilts on Farm A and Farm B and performance and SID lysine requirements based on InraPorc (Van Milgen et al., 2008)

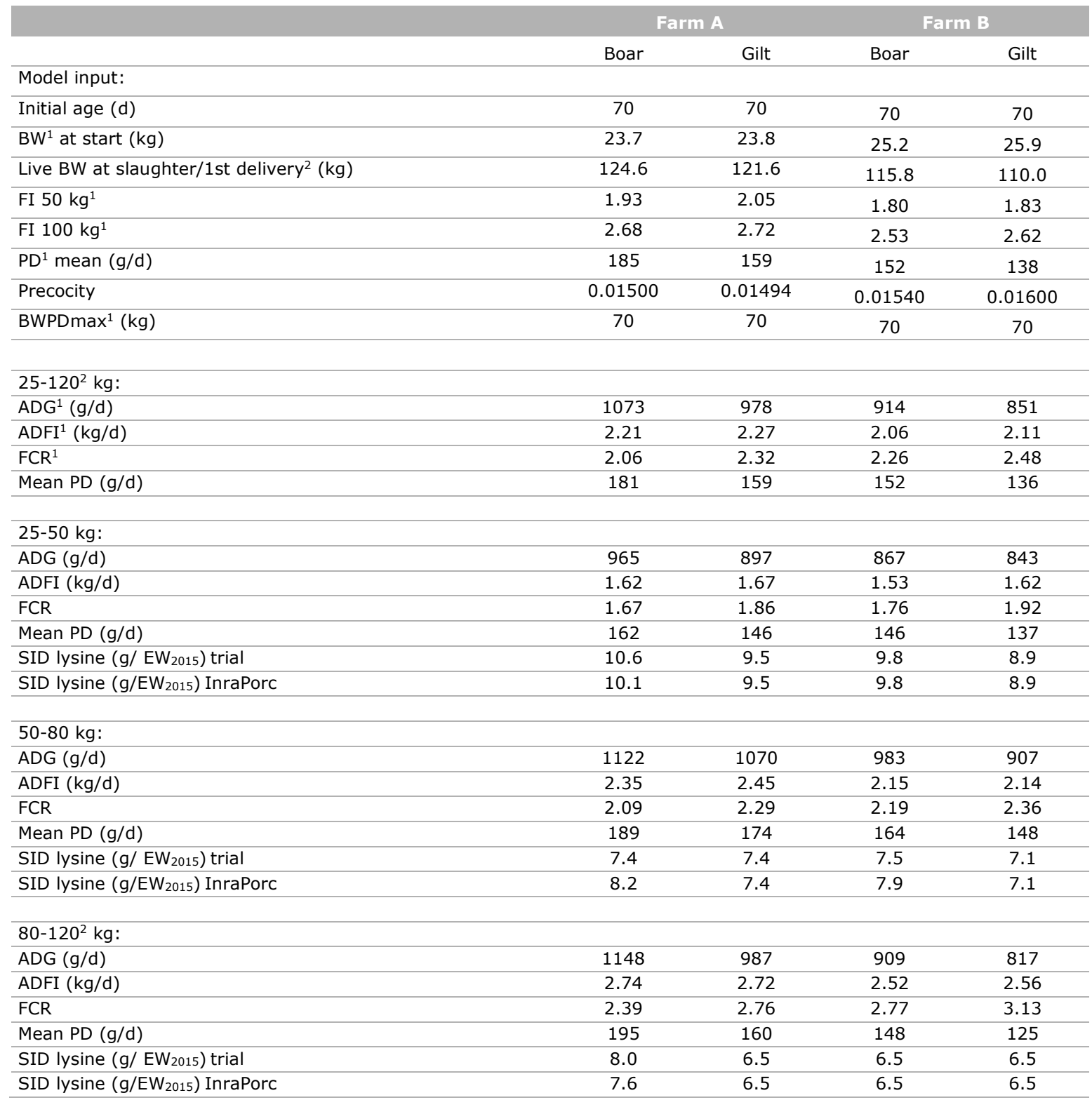

${ }^{1} \mathrm{BW}=$ body weight; FI $50 \mathrm{~kg}=$ feed intake at a BW of $50 \mathrm{~kg} ; \mathrm{FI} 100 \mathrm{~kg}=$ feed intake at a BW of $100 \mathrm{~kg} ; \mathrm{PD}=$ protein deposition; BWPDmax = $\mathrm{BW}$ at which the marginal PD becomes zero; $A D G=$ average daily gain; $A D F I=$ average daily feed intake; FCR = feed conversion ratio; $P D=$ protein deposition.

2 Live BW at slaughter: on Farm A (all pigs were weighed the day before slaughter); BW at $1^{\text {st }}$ delivery on Farm B: on Farm B, all pigs were weighed at $1^{\text {st }}$ delivery; the remaining pigs after $1^{\text {st }}$ delivery were not weighed when they were delivered to the slaughterhouse. Therefore $B W$ was calculated from slaughter weight. Because, in general, calculated BW is higher than live BW, the live BW at $1^{\text {st }}$ delivery was used in the calculations with InraPorc. 


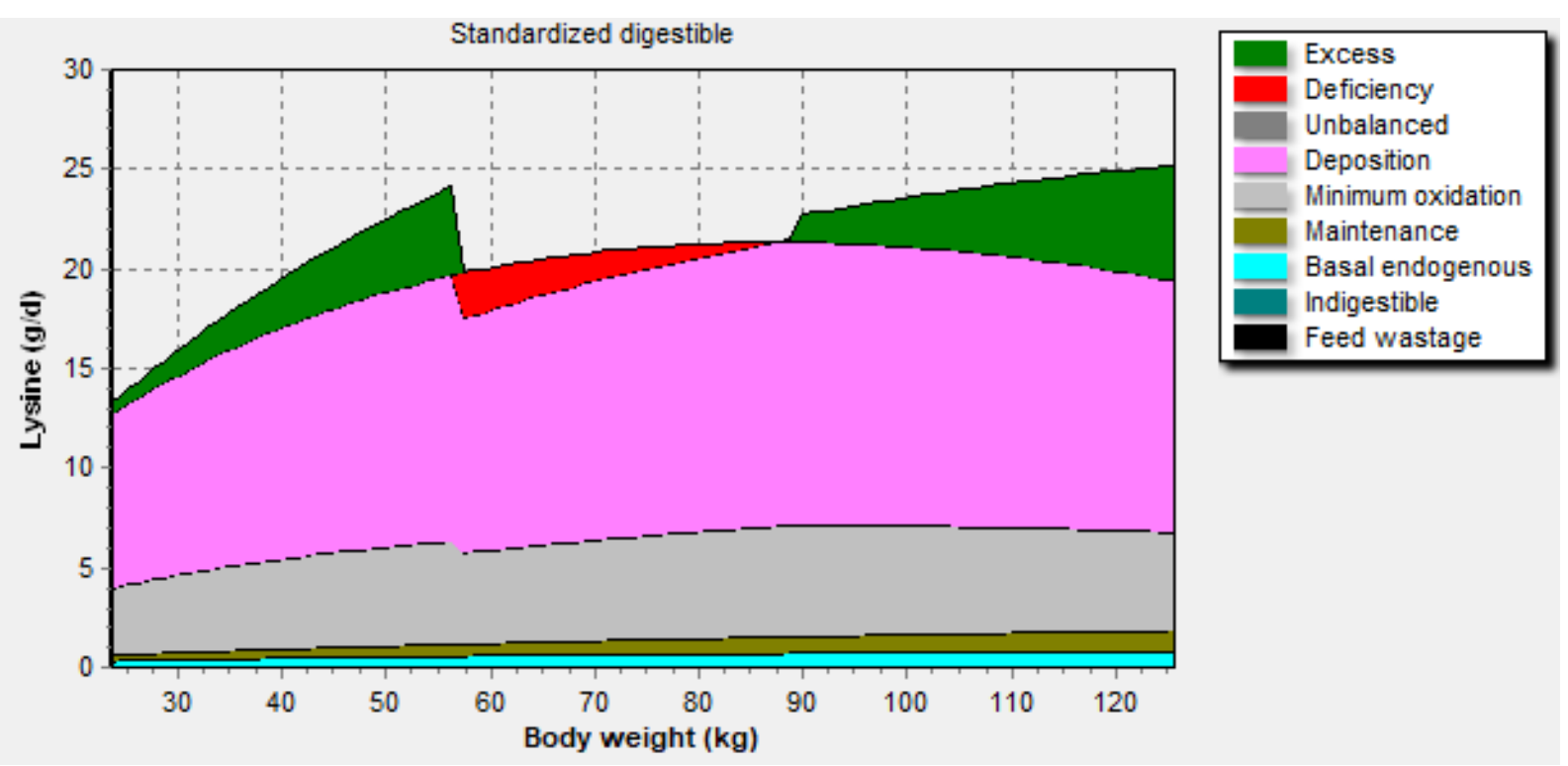

Figure 1 Daily SID lysine requirement for boars on Fam A as estimated with broken-line analysis (starter diet: $10.6 \mathrm{~g}$ SID lysine/EW 2015; grower diet $7.4 \mathrm{~g}$ SID lysine per EW 2015; finisher diet $8.0 \mathrm{~g}$ SID lysine per EW 2015) compared with the requirement calculated with InraPorc

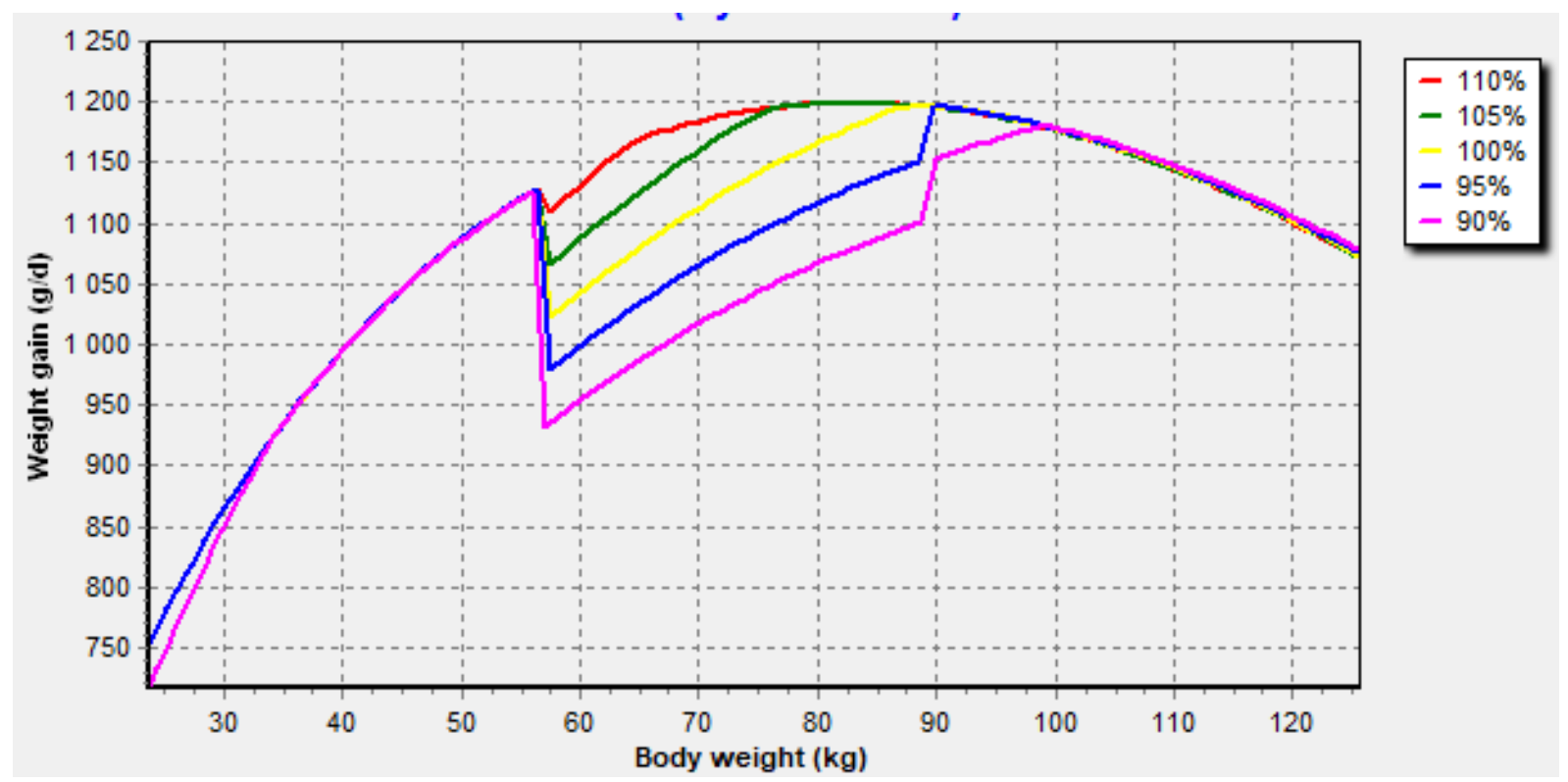

Figure 2 Effect of 90, 95, 100, 105 and 110\% supply of SID lysine as estimated with the brokenline model for boars on Farm A on daily gain predicted with InraPorc

The results in Figure 1 and 2 show that during the starter and finisher phase, the required SID lysine level as estimated with broken-line analysis is $5 \%$ higher than predicted by InraPorc, as a $95 \%$ supply of SID lysine results in a similar ADG as a supply of $100 \%$. Therefore, the recommended SID lysine level in starter and finisher diets for boars on Farm A might be 10.1 and $7.6 \mathrm{~g} / \mathrm{EW}_{2015}$, respectively, as predicted with InraPorc, instead of 10.6 and $8.0 \mathrm{~g} / \mathrm{EW}_{2015}$, respectively, as estimated with broken-line analysis (see Table 1). The recommended SID lysine level in the grower diet, however, might be $10 \%$ too low, as a $110 \%$ supply of SID lysine results in a higher ADG than a $100 \%$ supply. Therefore, the recommended SID lysine level in grower diet for boars on Farm A might be $8.2 \mathrm{~g} / \mathrm{EW}_{2015}$ as predicted with InraPorc, instead of $7.4 \mathrm{~g} / \mathrm{EW}_{2015}$, as estimated with broken-line analysis. 


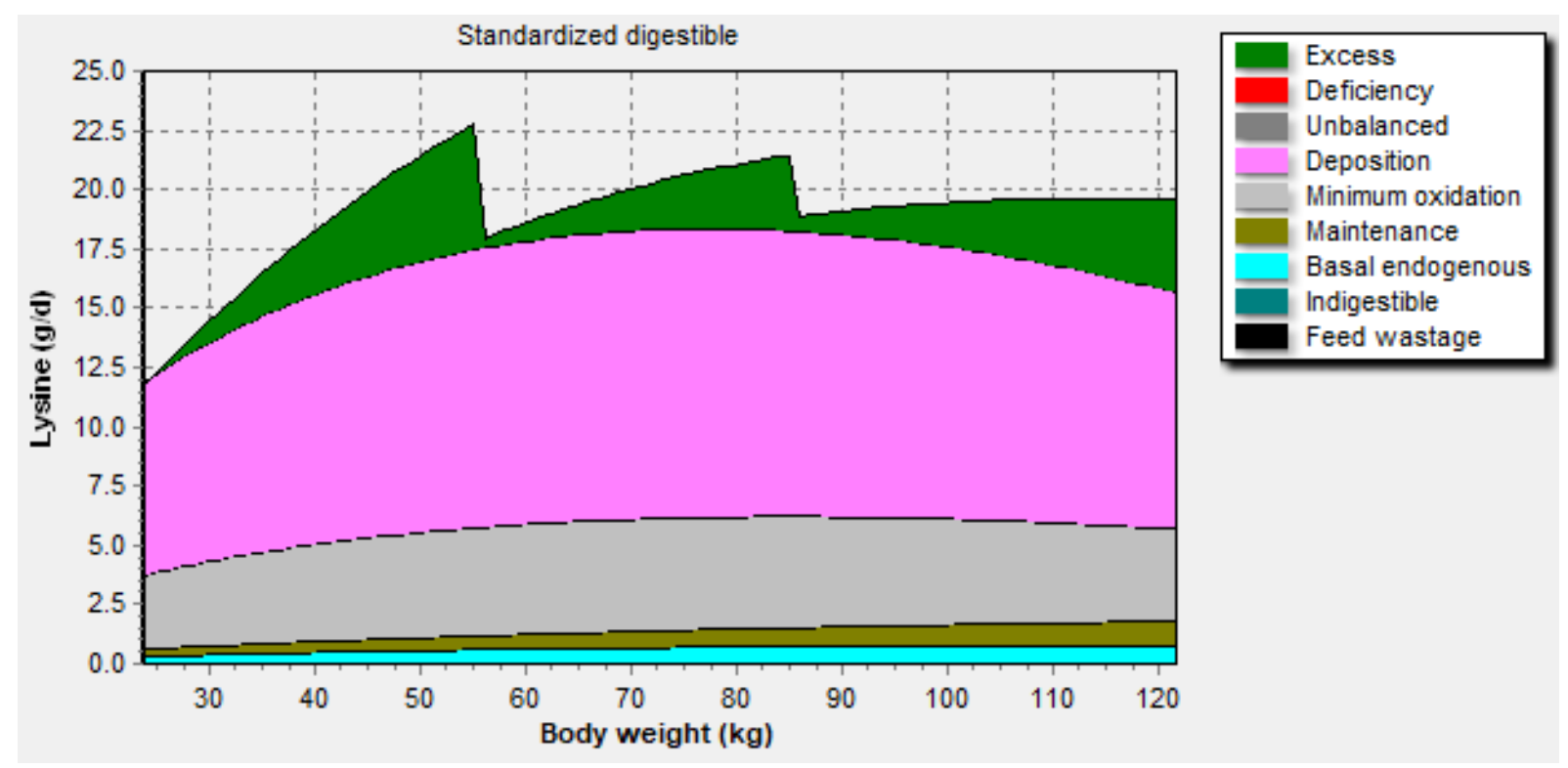

Figure 3 Daily SID lysine requirement for gilts on Fam A as estimated with broken-line analysis (starter diet: $9.5 \mathrm{~g}$ SID lysine/EW 2015; grower diet $7.4 \mathrm{~g}$ SID lysine per EW 2015; finisher diet $6.5 \mathrm{~g}$ SID lysine per EW 2015) compared with the requirement calculated with InraPorc

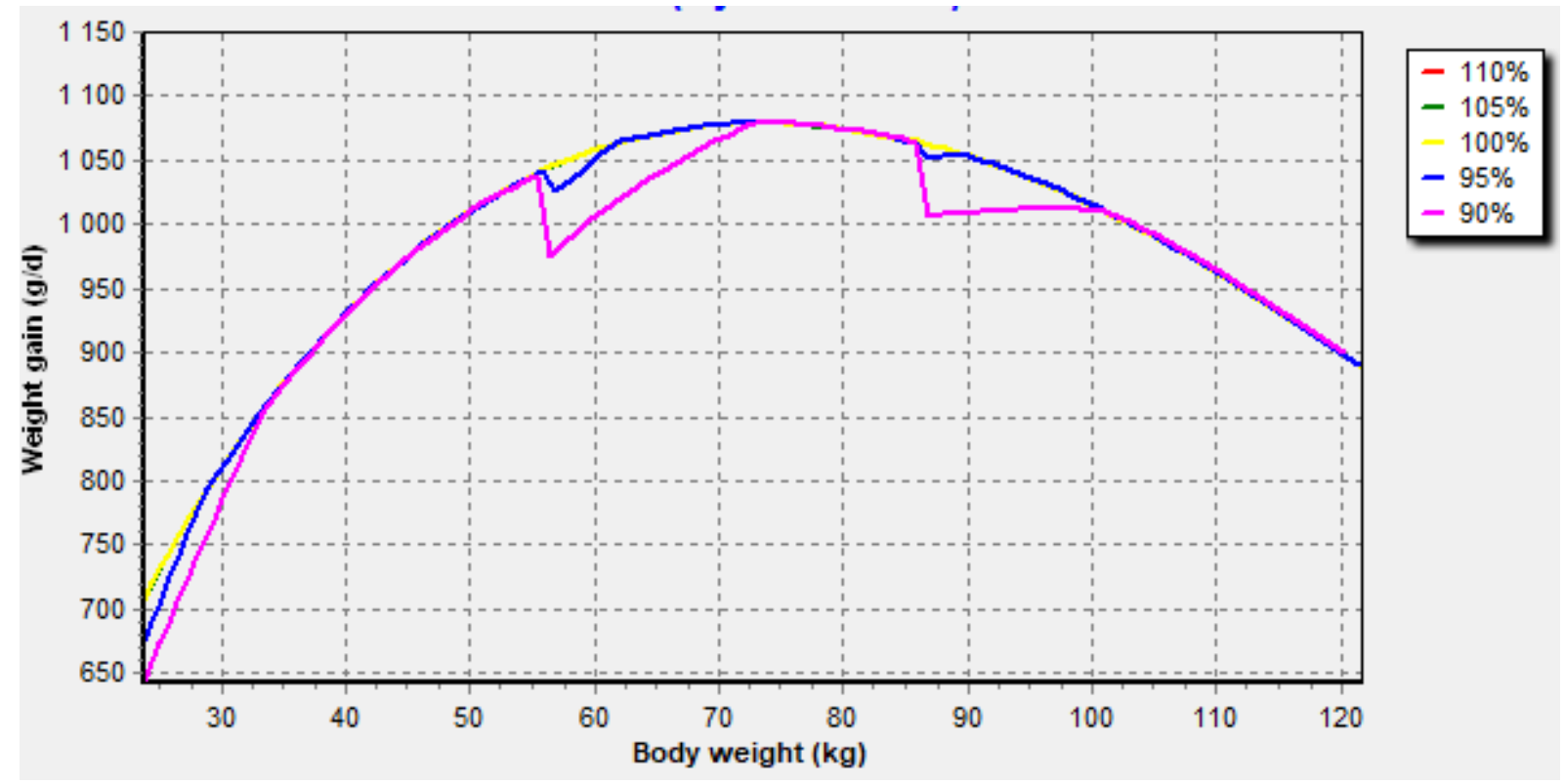

Figure 4 Effect of 90, 95, 100, 105 and 110\% supply of SID lysine as estimated with the brokenline model for gilts on Farm A on daily gain predicted with InraPorc

The results in Figure 3 and 4 show that the recommended SID levels for gilts on Farm A during the starter, grower and finisher phase as estimated with broken-line analysis and as estimated with InraPorc are similar as a supply of $100 \%$ results in the highest ADG. 


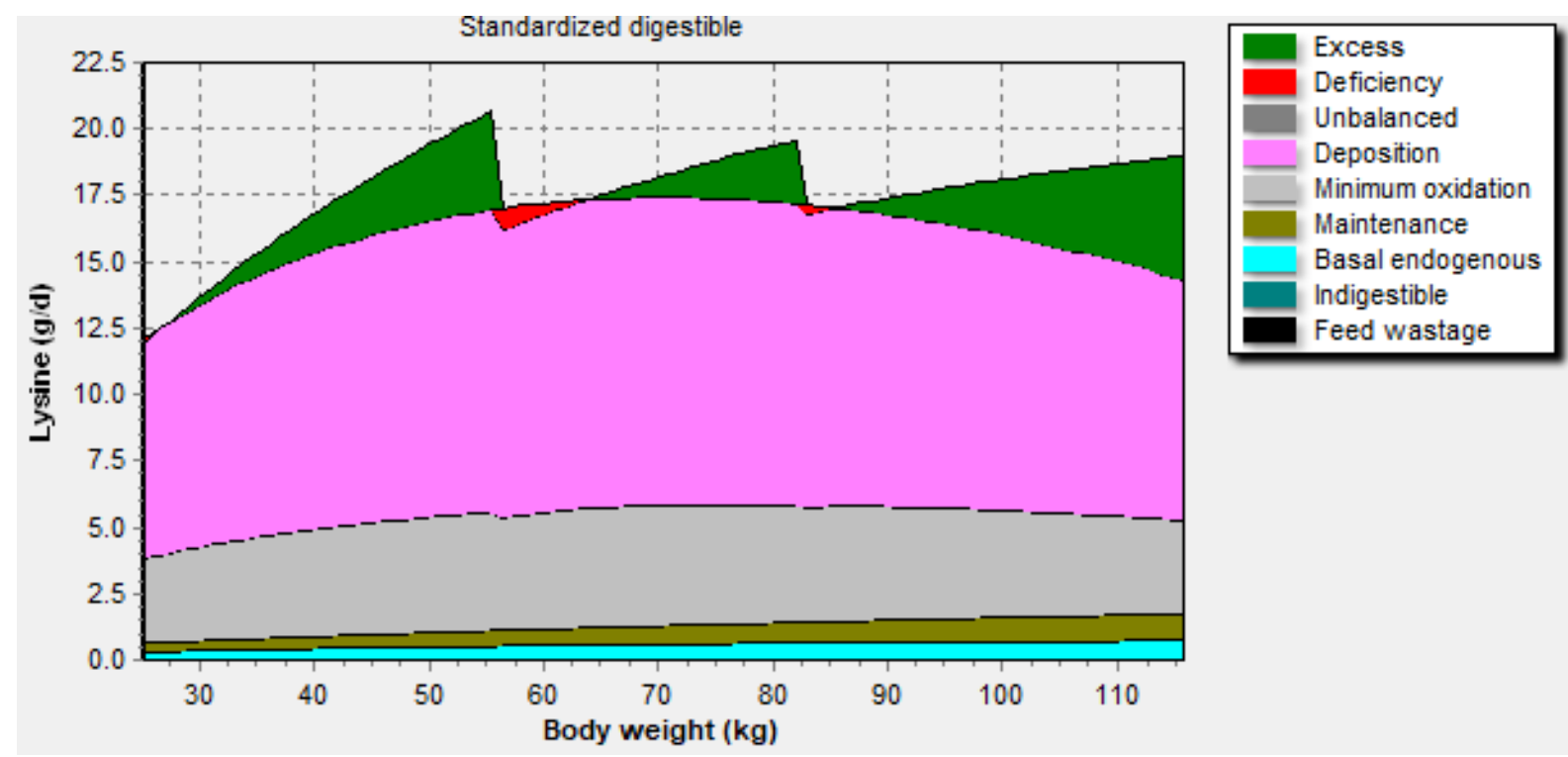

Figure 5 Daily SID lysine requirement for boars on Fam B as estimated with broken-line analysis (starter diet: $9.8 \mathrm{~g}$ SID lysine/EW 2015; grower diet $7.5 \mathrm{~g}$ SID lysine per EW 2015; finisher diet $6.5 \mathrm{~g}$ SID lysine per EW 2015) compared with the requirement calculated with InraPorc

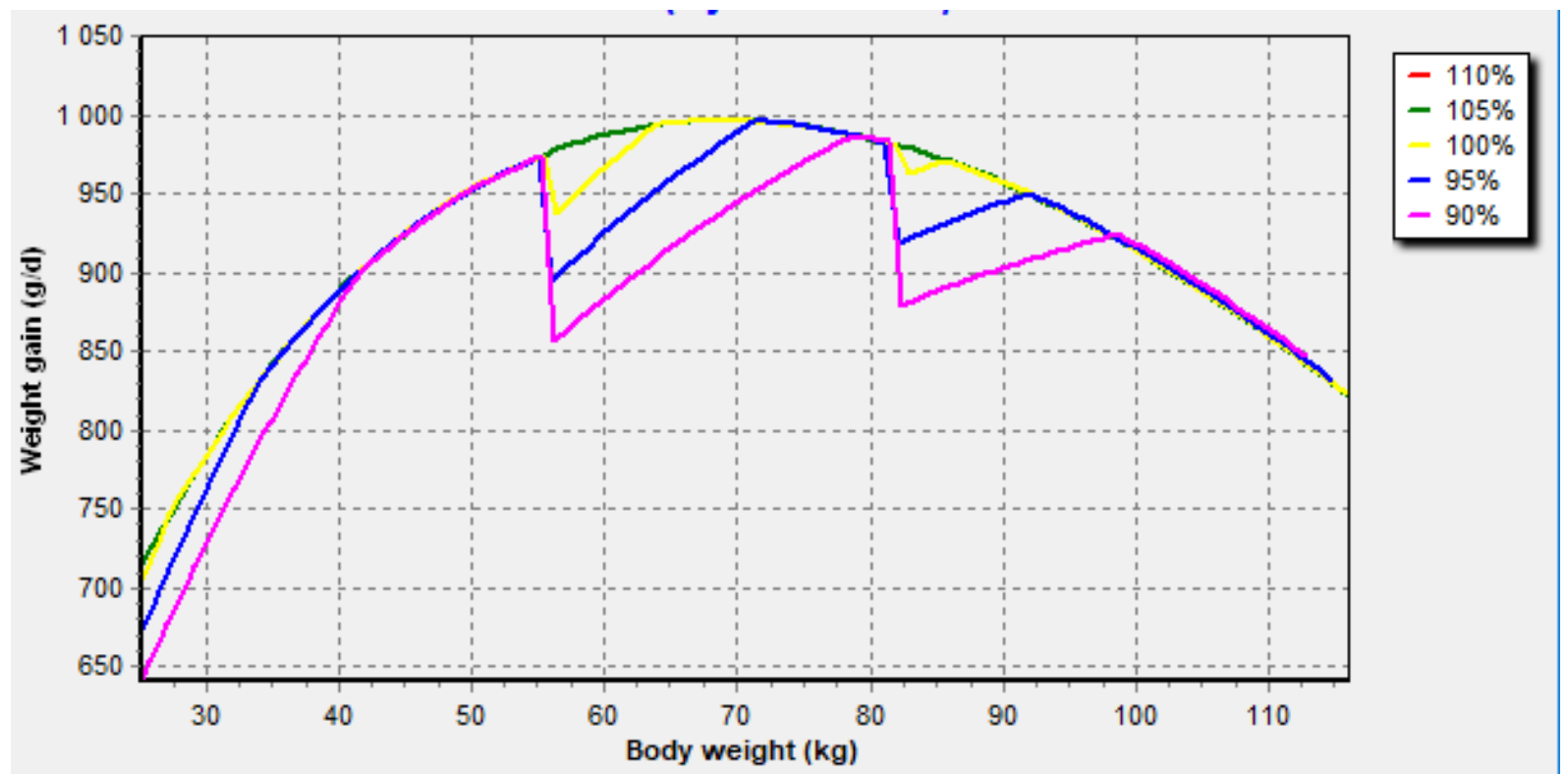

Figure 6 Effect of 90, 95, 100, 105 and 110\% supply of SID lysine as estimated with the brokenline model for boars on Farm $B$ on daily gain predicted with InraPorc

The results in Figure 5 and 6 show that the recommended SID levels for boars on Farm B during the starter and finisher phase as estimated with broken-line analysis and as estimated with InraPorc are similar as a supply of $100 \%$ results in the highest ADG. The recommended SID lysine level in the grower diet, however, might be $5 \%$ too low, as a $105 \%$ supply of SID lysine results in a higher ADG than a $100 \%$ supply. Therefore, the recommended SID lysine level in grower diet for boars on Farm B might be $7.9 \mathrm{~g} / \mathrm{EW}_{2015}$, as predicted with InraPorc, instead of $7.5 \mathrm{~g} / \mathrm{EW}_{2015}$, as estimated with brokenline analysis. 


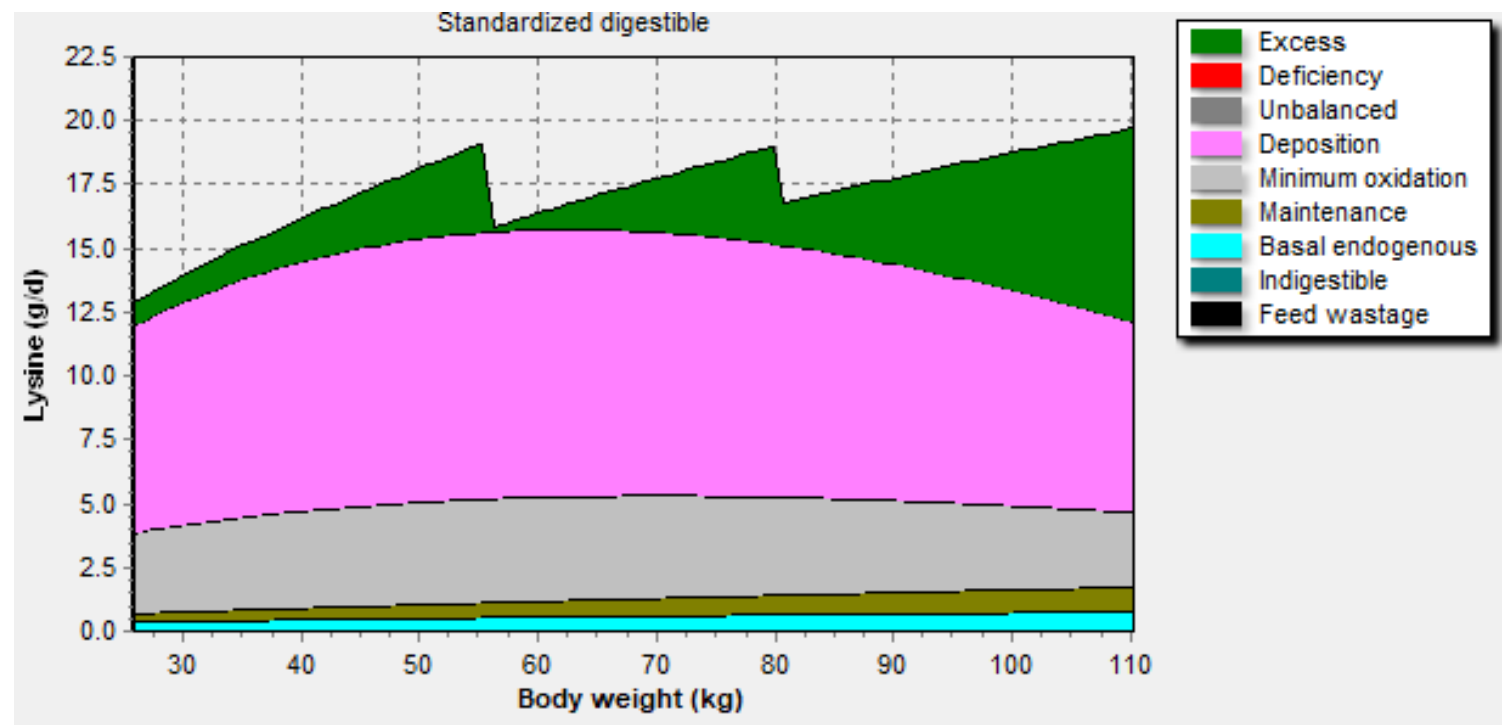

Figure 7 Daily SID lysine requirement for gilts on Fam B as estimated with broken-line analysis (starter diet: $8.9 \mathrm{~g}$ SID lysine/EW 2015; grower diet $7.1 \mathrm{~g}$ SID lysine per EW 2015; finisher diet $6.5 \mathrm{~g}$ SID lysine per EW 2015) compared with the requirement calculated with InraPorc

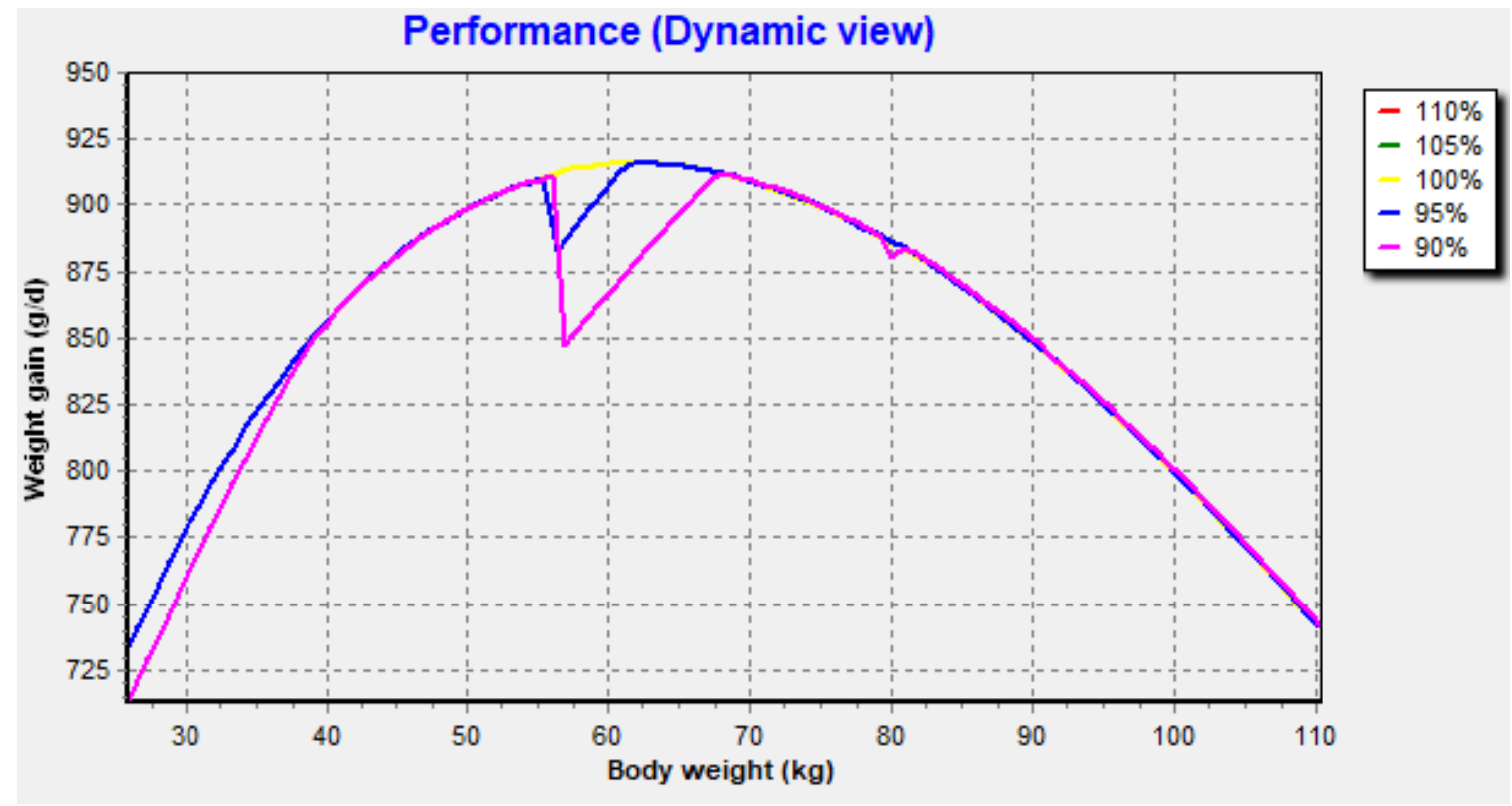

Figure 8 Effect of 90, 95, 100, 105 and 110\% supply of SID lysine as estimated with the brokenline model for gilts on Farm $B$ on daily gain predicted with InraPorc

The results in Figure 7 and 8 show that during the starter and finisher phase, the required SID lysine level as estimated with broken-line analysis is $5 \%$ higher than predicted by InraPorc, as a $95 \%$ supply of SID lysine results in a similar ADG as a supply of $100 \%$. However, the FCR during the starter and finisher phase for gilts on Farm B as predicted with InraPorc is somewhat higher (worse) than estimated with the broken-line analysis. As a higher FCR results in a lower SID lysine requirement, the SID lysine recommendations as estimated with the broken-line analysis seems reliable. The recommended SID levels for gilts on Farm B during the grower phase as estimated with broken-line analysis and as estimated with InraPorc are similar as a supply of $100 \%$ results in the highest ADG.

In conclusion: InraPorc can be a good tool for nutritionist to predict the SID lysine requirement for growing and finishing boars and gilt on farms in practice. Information on both overall performance (ADG, ADFI and FCR) and performance during the starter, grower and finisher phase, however, is necessary for an accurate prediction of SID lysine requirement during all phases. 


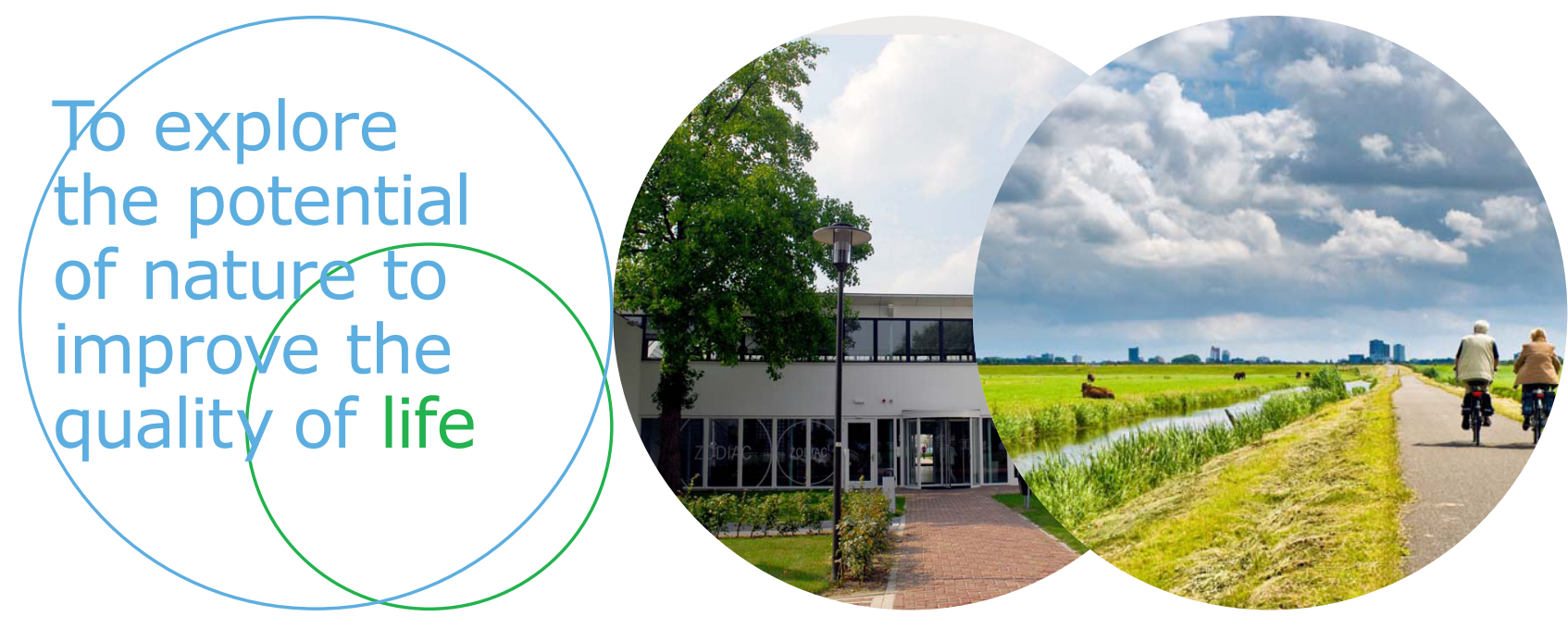

Wageningen Livestock Research P.O. Box 338

6700 AH Wageningen

The Netherlands

$\mathrm{T}+31(0) 317483953$

E info.livestockresearch@wur.nl

www.wur.nl/livestock-research

Wageningen Livestock Research creates science based solutions for a sustainable and profitable livestock sector. Together with our clients, we integrate scientific knowledge and practical experience to develop livestock concepts for future generations.

Wageningen Livestock Research is part of Wageningen University \& Research. Together we work on the mission: 'To explore the potential of nature to improve the quality of life'. A staff of 6,500 and 10,000 students from over 100 countries are working worldwide in the domain of healthy food and living environment for governments and the business community-at-large. The strength of Wageningen University \& Research lies in its ability to join the forces of specialised research institutes and the university. It also lies in the combined efforts of the various fields of natural and social sciences. This union of expertise leads to scientific breakthroughs that can quickly be put into practice and be incorporated into education. This is the Wageningen Approach. 